Law, Culture and Reprisals:

A Qualitative Case Study of Whistleblowing \& Health Canada's Drug Approval Process

by

\title{
Pamela Forward
}

A thesis submitted to the Faculty of Graduate and Postdoctoral Affairs in partial fulfillment of the requirements for the degree of

\author{
Master of Arts \\ in \\ Legal Studies
}

Carleton University

Ottawa, Ontario

(C) 2017

Pamela Forward 


\section{Abstract}

Countries around the world consider whistleblowing a reliable warning system for corruption and regulatory failure because whistleblowers are usually employees who have in-depth knowledge of complex systems and organizations often impenetrable and incomprehensible to outsiders. Why then do whistleblowers, these harbingers of wrongdoing, suffer censure and reprisals? The search for an answer to this question sparked this case study of a whistleblower's concerns regarding the effectiveness of Health Canada's drug approval process in 1996. It highlights the resulting impact on the whistleblower, the organization, and ultimately the implications for public safety and accountable government. The methods used were process-tracing, in-depth interviews and data and document review. The results suggested problems with culture in the main organization Health Canada, possibly exacerbated by deregulation. The conclusion is a multi-faceted approach to addressing culture is needed before whistleblower protection legislation can work and accountable organizations can flourish. 


\section{Acknowledgements}

First, and foremost, special thanks go to my thesis supervisor, Asst. Professor Paloma Raggo, School of Public Policy and Administration. Her expectations, knowledge, and guidance at once challenged, inspired and gave me courage when courage was failing. I also thank Assoc. Professor Vincent Kazmierski, Department of Law and Legal Studies, who was second reader. His astute comments and questions kept me focused, and at the same time stimulated me to think more broadly - not an easy feat. Thanks also to the other members of my Defence Committee, external member Assoc. Professor Ruth McKay, Sprott School of Business, and Chair- Professor Emeritus, R. Lynn Campbell, Department of Law and Legal Studies for a "never-to-be-forgotten" experience. The day of my defence was a high point of my life.

I owe a debt of gratitude to the former Royal Victoria Hospital, School of NursingAlumnae Association, Montreal, whose financial support at a critical time allowed me to continue my studies.

A very large thanks goes to the participant in the study, Michele Brill-Edwards, MD, FRCPC, without whose courage and patience in reliving her experiences this study would not have been possible. My gratitude also goes to a friend in the whistleblowing community, David Hutton, for several discussions and for critiquing a draft of this study.

Thank you to Heather Eaton, and Sue Britton for their support and encouragement and to my many friends and colleagues in the health care and public service communities who listened and discussed - often and patiently. Thanks also to Marilyn Baird and Dorothy Cohen. You know what you did.

My heartfelt thanks go to Andrew Squires without whose kindness and help this work would not have been finalized. Thanks also to Darren Paccione for jumping into the breach at the eleventh hour to provide essential help with formatting and copy editing.

And finally to my family - adult children, siblings, niece and family- thank you for believing in me and for caring. 


\section{Table of Contents}

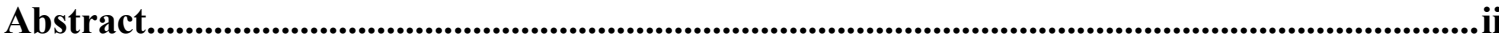

Acknowledgements ...........................................................................................................................ii

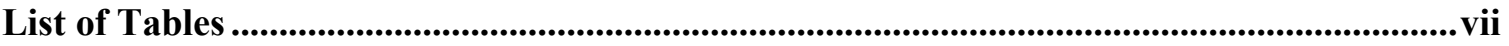

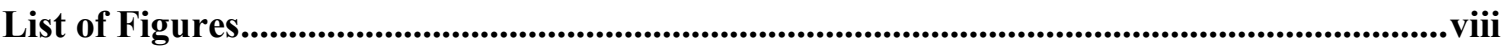

List of Appendices..............................................................................................................................

1 Chapter: Introduction ..........................................................................................................

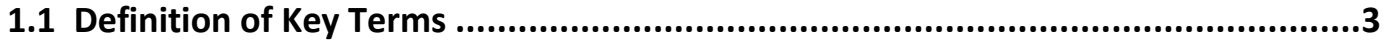

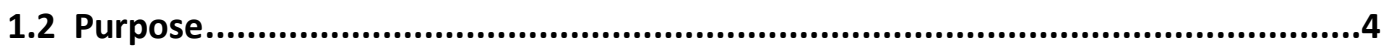

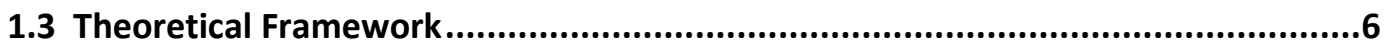

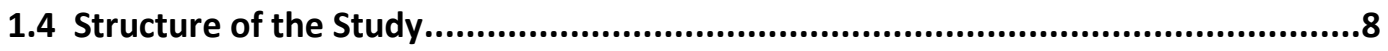

2 Chapter: Literature Review......................................................................................................10

2.1 The Field of Whistleblowing and Famous Whistleblowers..............................12

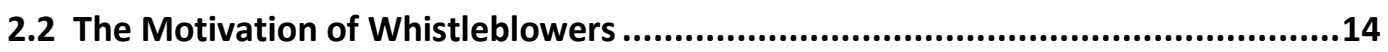

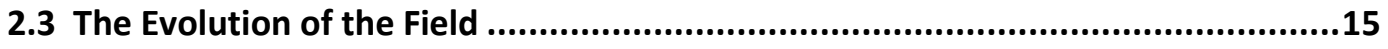

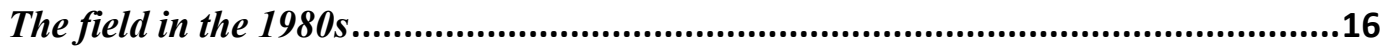

The field in the 1990 s.............................................................................................18

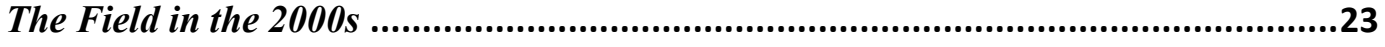

The Field in the Current Decade .............................................................................28

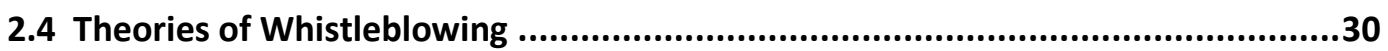

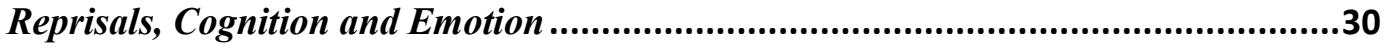

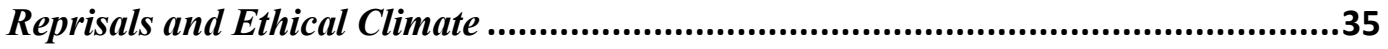

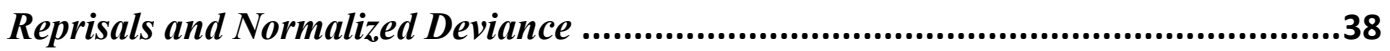


V

Reprisals and Organizational Learning .................................................................39

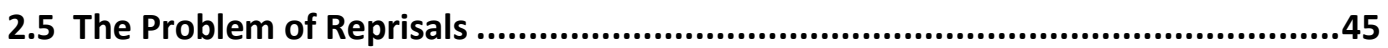

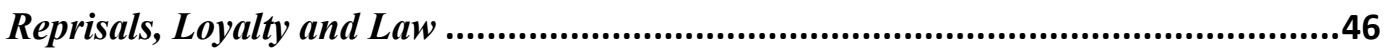

The Law and Protection for Whistleblowers...........................................................50

3 Chapter: Methodology and Methods ..........................................................................................55

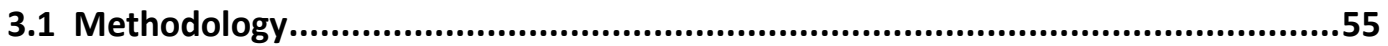

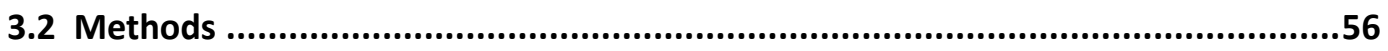

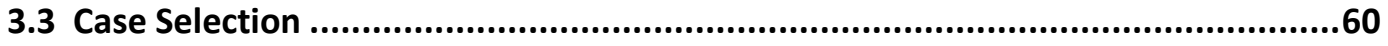

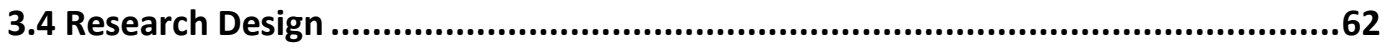

Research Questions ..........................................................................................62

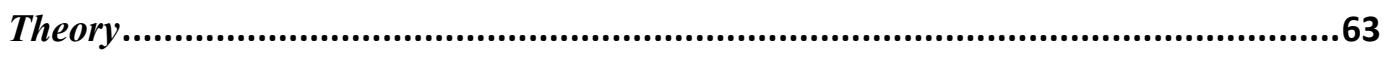

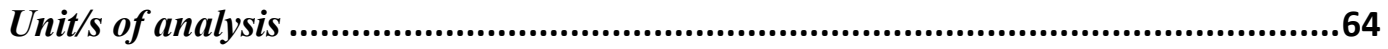

Data Analysis: linking the data to the theory........................................................66

Criteria for interpreting the findings..............................................................68

Judging the Quality of Research Design ...............................................................68

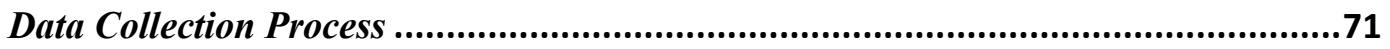

Researcher Reflexivity and Avoiding Bias...........................................................72

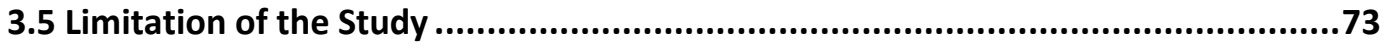

4 Chapter: Results of Case Study - Whistleblowing in Health Canada's............................75

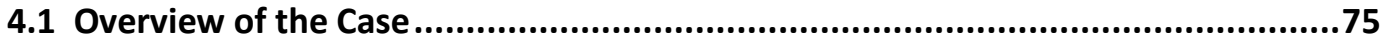

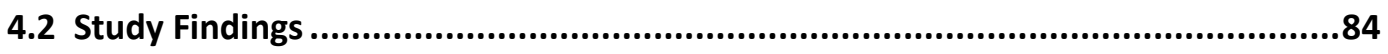

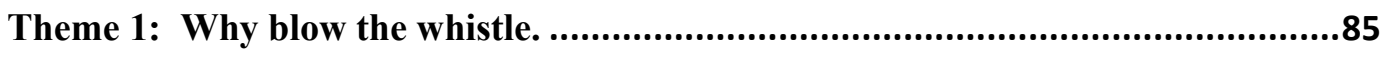

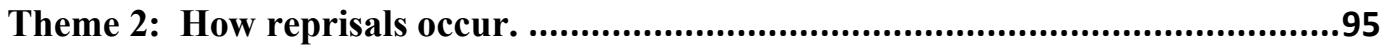




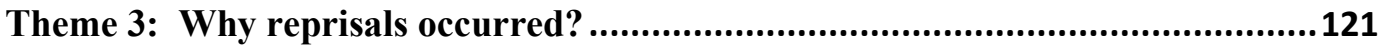

Theme 4: The Role of Law in Reprisals .......................................................130

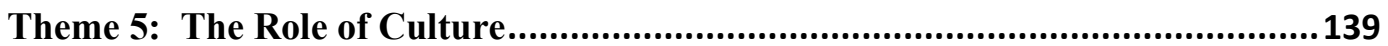

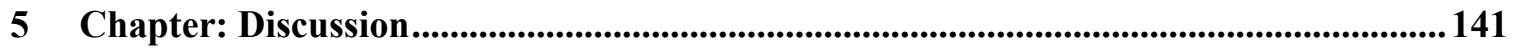

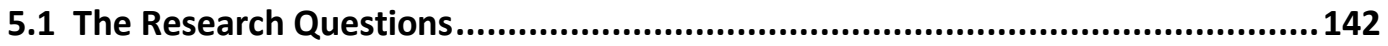

5.2 Understanding Reprisals - The Literature and Theory ...................................149

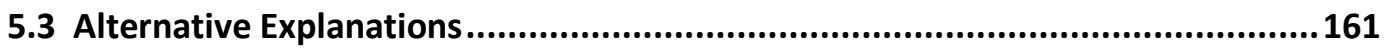

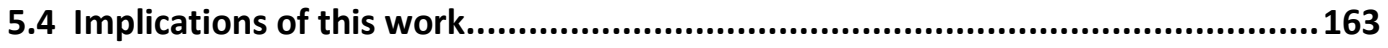

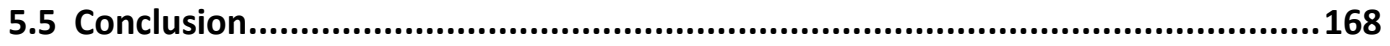

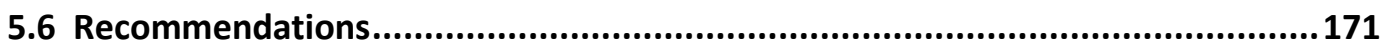

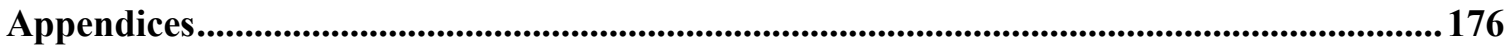

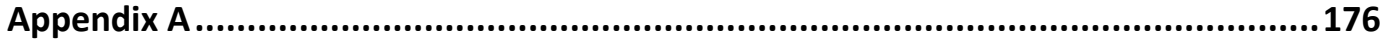

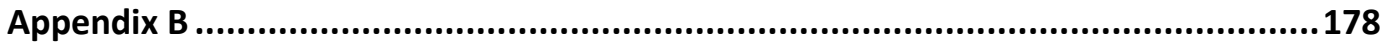

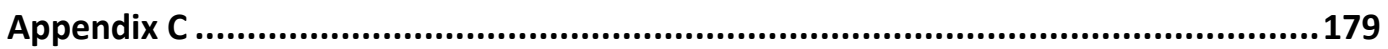

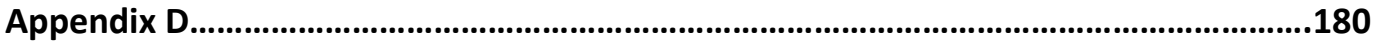

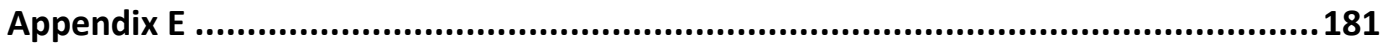

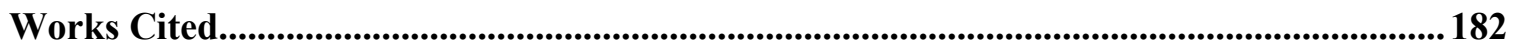




\section{List of Tables}

Table 2.1: Factors Influencing The Whistleblowing Process And Its Outcomes ............. 19

Table 2.2: Empirical Findings From MSBP Survey Data Sets: Predictors Of

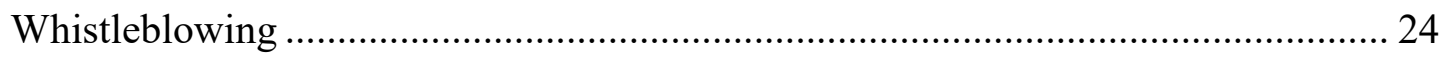

Table 2.3: Empirical Findings From MSBP Survey Data Sets................................... 25

Table 2.4: Empirical Findings Related To Whistleblowing Effectiveness..................... 26

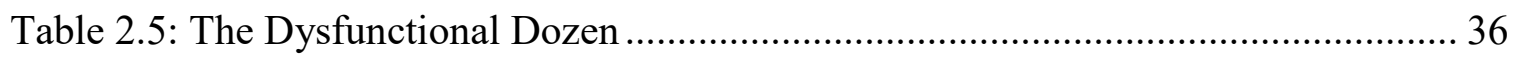

Table 2.6: Governing Characteristics And Values Of Model I And Model II - Theories In

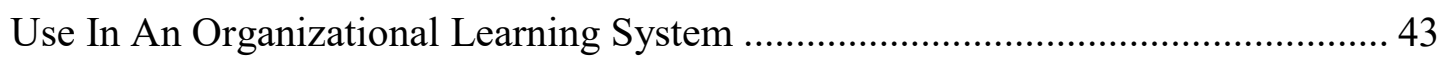




\section{List of Figures}

Figure 2.1: Law, Culture And Reprisal - Understanding The Whistleblowing Reprisal

Paradox In A Regulatory Agency In Canada ..................................................... 44

Figure 4.1: Timeline Of Key Events In Evolution Of Case Of Whistleblowing And

Health Canada's Drug Approval Process ............................................................. 78

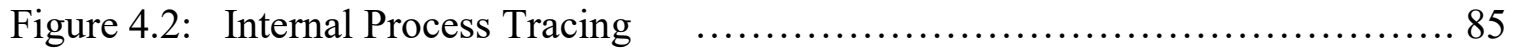

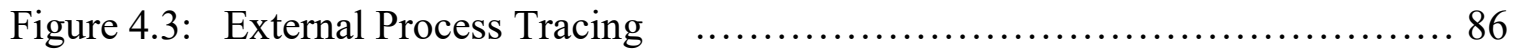




\section{List of Appendices}

Appendix A: List of Key Documentation and Sources ........................ 175

Appendix B: Interview Questions........................................ 177

Appendix C: Listing of Interventions Indicating Harm or Potential Harm Caused by CCB's at Sept. 18, 1995 Expert Advisory Committee Meeting, Health

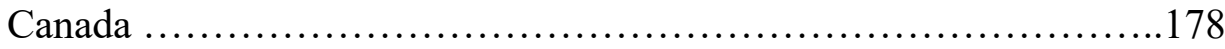

Appendix D: Studies Showing Clear Indication of Harm in CAD Using Certain CCB's ................................................................ 179

Appendix E: Presentations to Parliament and Senate Committees by Dr. Michele BrillEdwards, FRCPC 180 


\section{Chapter: Introduction}

The problem of reprisals against whistleblowers who expose organizational misconduct has been present for a long time in Canada and elsewhere. This is so, even though the value and importance of whistleblowers has been recognized by many countries in the struggle against corruption, including the G20. Whistleblowing is considered "a first and often best early warning system" (Wolfe et al. 8) for poor financial practice, corruption and regulatory failure because whistleblowers are usually organizational insiders with first-hand knowledge of complex systems and industries often impenetrable and unintelligible to outsiders (Wolfe et al. 8). ${ }^{1}$ Whistleblowing is now considered to be among the most effective, if not the most effective means to expose and remedy corruption, fraud and other types of wrongdoing (67).

However, paradoxically, whistleblowers often suffer censure and reprisals at the hands of organizational members when they decide to blow the whistle, whether internally or externally (Glazer and Glazer 133-66). Despite the acknowledged importance of whistleblowers and related efforts to make whistleblower protection legislation more effective and less "symbolic" (Latimer and Brown 766 -67), reprisals continue and are increasing (Miceli, Rehg, Near, Ryan 144-46).

Recently, issues such as the 2008 financial/sub-prime mortgage crisis in the U.S. and the on-going questionable activities of pharmaceutical companies such as the biasing of research, underscore just how important encouraging and facilitating whistleblowing is

\footnotetext{
1 The G20 countries, comprised of leaders from the world's largest economies, have included whistleblower protection as a priority element of cooperation between these countries since November 2010. The information cited above comes from, the report "Whistleblower Protection Laws in G20 Countries: Priorities for Action" which was written in advance of the G20 meeting of 2014 and is the first independent research assessment of whistleblower protection laws covering government and corporate employees across the G20 nations. The report is co-authored by a team of researchers from Blueprint for Free Speech, Griffith University, Transparency International-Australia and Melbourne University.
} 
to maintain transparent, ethical and accountable organizations and governments. These examples also demonstrate what happens when whistleblowing either does not take place or is ignored. The first example, the financial crisis of 2008 began in the United States with loosening/ignoring the rules for approving mortgages and insuring risk (subprime mortgage loans and mortgage backed securities). Looming trouble was trumpeted as early as 1997 in a report by at least one industry insider, U.S. financial analyst, Steve Eisen, in which he exposed the deceptions of at least a dozen subprime originator companies (M. Lewis 15). While his revelations caused a storm on Wall Street, and these early subprime companies failed shortly after, no major reforms took place and a second generation of subprime companies replaced them a few years later (M. Lewis 1523). Ignoring such warnings ultimately led to financial institution collapse, and a credit freeze that threatened to drag down the global economy (Havemann 1-3).

The second example involves some questionable activities of pharmaceutical companies. This has included allegations of biasing the conduct of research, inadequate communication of safety issues to regulators, and manipulating safety information to minimize safety concerns leaving the public at risk (Lexchin, Medicines 264). Dr. Joel Lexchin, an emergency room physician and health industry insider documented these activities and has in effect, been blowing the whistle on questionable practices involving regulation and the pharmaceutical industry since as early as 1990 (Drug makers 125763). A 2013 Symposium saw the documentation of how medical research, the production of medical knowledge, the practice of medicine, drug safety, and the Food and Drug Administration's oversight of the pharmaceutical market were corrupted (Rodwin 544- 
552). ${ }^{2}$ These examples also highlight the question of why more people from inside the financial and pharmaceutical companies involved in such misconduct were not blowing the whistle themselves. Many believe the answer is fear of reprisal.

In this research, I will consider how and why whistleblowers suffer reprisals in the Canadian context and the role of law and culture in perpetuating this situation, but first, I define key terms.

\subsection{Definition of Key Terms}

Key terms used in this study are reprisal, corruption, whistleblowing, and culture. The term reprisal is used in the sense of retaliation in the workplace. It encompasses any adverse action penalizing workers in retaliation for obeying the law, exercising their rights or otherwise annoying their employers by disclosing wrongdoing. Examples of such penalties are dismissal, demotion, suspension, passing over for projects or promotion or threats of such actions (Public Sector Integrity Commissioner, Reprisals 1).

Corruption refers here to institutional corruption. According to Lessig, this kind of corruption is not only about misuse of public funds, but is present when "there is a systemic and strategic influence which is legal, or even currently ethical, that undermines the institution's effectiveness by diverting it from its purpose or weakening its ability to achieve its purpose, including, to the extent relevant to its purpose, weakening either the public's trust in that institution or the institution's inherent trustworthiness [. . .]" (553). For example, one form of institutional corruption could be ideology (a set of beliefs or ideas) within a judiciary without any money changing hands (Lessig 553). ${ }^{3}$

2 The Journal of Law, Medicine and Ethics in 2013 sponsored a Symposium in which Dr. Lexchin and others contributed sixteen (16) papers investigating the corruption of pharmaceutical policy. 
Whistleblowing means: "the disclosure by organization members (former or current) of illegal, immoral, or illegitimate practices under the control of their employers, to persons or organizations that may be able to effect action" (Near and Miceli, Dissidence 4). ${ }^{4}$

Culture in an organization, as described by Jurkiewicz and Giacalone, develops over time and is a function of leaders modeled behaviour, policies that are articulated, rewards for behaviours that are demonstrated, and "the collective activities of organizational members [that] cohere into a system of shared meaning" (3).

\subsection{Purpose}

The purpose of this research is to shed light on the paradoxical behaviour of censure and reprisals against whistleblowers who expose wrongdoing in public/government organizations. The dynamics of the conflict between the whistleblower and wrongdoer, and how this conflict is played out is examined in a specific case to better understand how and why this paradox continues in the Canadian

\footnotetext{
${ }^{3}$ An example of legal ideology is beliefs held by members of Canada's criminal justice system that can help explain the failure of criminal law in reigning in corporate crime. In the debate over corporate crime, Sargent contends that a juridical idea has developed, that being - there is a difference between "true crimes" and regulatory or public welfare offenses with the latter being less serious or important than the former (107). These less important offences relate to such everyday matters as traffic infractions, sales of impure food, violations of liquor laws and the like (Sargent 107). Sargent points out that these every day offences are the ones that cause more severe risks to "life, health, safety or the environment than many offenses found in the Criminal Code" (107). Further, the distinction between the two offenses creates a legal double standard where enforcement of regulatory offences is "continually subordinated to the enforcement of conventional Criminal Code offenses by the police, crown prosecutors and the judiciary" (108).

${ }^{4}$ It is believed that the term was first used by Ralph Nader in a series of conferences on Professional Responsibility in 1972. He did so to change the negative perception of people who report on wrongdoing from terms such as "rat", "squealer", etc. to a more positive connotation such as that of a referee in a game who blows the whistle to call attention to rule-breaking. Nader defined whistleblowing as "An Act of a man or woman who, believing that the public interest overrides the interest of the organization he serves, blows the whistle that the organization is involved in corrupt, illegal and fraudulent activity" (Rongine 281).
} 
context. I will answer the following questions informed by the perspective of the whistleblower:

(a) Why do whistleblowers decide to blow the whistle?

(b) How do reprisals against whistleblowers occur?

(c) Why do reprisals against whistleblowers occur?

(d) What is the role of law in reprisals against whistleblowers?

(e) What is the role of culture in reprisals against whistleblowers?

The hope is that such an understanding can contribute towards correcting the paradoxical behaviour so that whistleblowers are appreciated and the censure is more appropriately reserved for the wrongdoer. Such a correction could empower public servants to safely bring forward their observations and critical information so organizations can learn, self-correct, and improve (Burke 38).

A serious consequence of ignoring, discrediting, and subjecting whistleblowers to reprisals in public organizations is the negative impact on the government, the organization, its employees and society's welfare in general, including risks to health and safety. Another consequence of the continuation of reprisals against whistleblowers raises concerns about legitimizing organizational lawlessness and accepting corruption in government as a norm (Vaughan, Controlling 110; Burke, Tomlinson and Cooper eds. 67; Latimer and Brown 768). In addition, when institutional corruption occurs it can include loss of public trust (Conference Board 2, Jurkiewicz and Giacalone 1, Lessig $553)$. 


\subsection{Theoretical Framework}

Whistleblowing has been analyzed from the perspectives of several disciplines such as the law, philosophy and ethics, and social science such as the work of organizational behaviourists. The legal perspective sees whistleblowing as acceptable if the whistleblower believes that there is a danger to the public by the organization's actions (Near and Miceli, Myth 508-509). Philosophers and ethicists see whistleblowing as justified under certain conditions such as moral motives or an ethical act (Near and Miceli, Myth 508-9). Social scientists look at motivation and power relationships, the whistleblowing process and ways to predict the direction that the process will take in each organization (Near and Miceli, Dissidence 1-16). Recent work has looked at how and why retaliation occurs - examining underlying cognitive/emotional motives that trigger reprisals and the individual and contextual factors influencing the paradoxical behaviours (Sumanth, Mayer, Kay $165-84$ ). These approaches are drawn on as there is no single reason that explains whistleblowing. However, together, they can help to better understand how and why the paradox of censure and reprisal for many whistleblowers occurs and continues.

The more recent theories (2011) of organizational behaviour and ethics,

complement and expand on earlier theories such as those explaining how and why whistleblowers become "black sheep" and are ostracized (Marques, Yzerbyt, Leyens 1) and/or "scapegoated" (Girard 12-15). The cognitive-emotional model considers retaliation against whistleblowers, often at the hands of those who stand to benefit from the wrongdoing, highlighting certain individual and contextual factors. The presence or absence of these factors increase or decrease the likelihood of retaliatory behaviour and 
illuminates the extremes to which many in public organizations will go to protect themselves from public scrutiny (Sumanth, Mayer, Kay 165-184).

One of the contextual factors affecting retaliatory behaviour according to the cognitive-emotional model is ethical climate. Recent work allows for a consideration of the organizational determinants of ethical climate and ethical dysfunctionality at the structural, cultural and leadership level. It also provides a tool for measuring ethical dysfunctionality called the Dysfunctional Dozen (Jurkewicz and Giacalone 5-7). ${ }^{5}$ This is an important contribution as the tool can be used by leaders who choose to proactively assess their organizations' ethicality and make improvements as results indicate.

Several other theories/concepts help understand organizational misconduct and how ethical dysfunctionality such as reprisals occur in organizations as they carry out their mandates. One of these concepts is that of the "learning organization" (Argyris and Schon 3-29). The implications and repercussions for individual and organizational learning are considered when those in organizations respond to error and criticism with defensive reasoning rather than reflective or productive reasoning (73-78). This stance allows for ethical dysfunctionality to creep in and inhibits learning and/or change. Other relevant concepts/theories are normalized deviance (Vaughan, Challenger 119-125), obedience to authority (Milgram 1-12), and conformity in groups (Asch 31-35). They help explain how individuals in groups lose individuality/autonomy and shift focus to group norms which can separate people from their consciences to create a kind of "willful blindness" (Heffernan 1-4).

\footnotetext{
${ }^{5}$ The Dysfunctional Dozen are the manifestations of organizational ethical dysfunctionality. The list consists of the following organizational characteristics related to dysfunctionality: deception, dependency, distrust, egoism, immediacy, impiety, impunity, inequality, inhumanity, invariance, narcissism, and obduracy.
} 
This study focuses on the case of whistleblower Michele Brill Edwards, MD, Pediatrician, Clinical Pharmacologist, Fellow of the Royal College of Physicians and Surgeons of Canada. She was the most senior medical regulator in Health Canada for several years prior to the 1995 controversy over the safety of a heart drug that had been approved and on the market for some fifteen years. As senior medical regulator, she also had expertise in the application of the Food and Drugs Act (pers. comm. April 6, 2014). The study delves into the experience of the whistleblower as she attempts to have her concerns about perceived ethical lapses and/or wrongdoing concerning the safety of drug approvals addressed by the organization. It includes first, examining what occurred that led her to conclude she had no other option but to resign and go public. Second, it looks at the responses made by senior organization members and the dynamics involved when she raised concerns internally. Third, it examines the outcomes of these events. Lastly, it examines the role of law and the role of culture as the process unfolds. This is important as the law and culture are part of the context within which the events occurred.

\subsection{Structure of the Study}

This thesis is organized as follows: Chapter 2 contains a literature review which highlights the trends, debates and existing knowledge in the field of whistleblowing and helps identify gaps for exploration. In addition, I provide a more in-depth review of the theoretical framework used for analysis. This theory, along with the lived experience of the whistleblower and supported by official documents on the public record, helps shine light on how and why such paradoxical behaviour exists and continues, undermining accountability, public trust and safety. In Chapter 3, I describe the methodology and methods used to gather information and documentation regarding the decisions and 
events. Further, this study relies on process-tracing within a case study approach and draws from evidence based on interview of the whistleblower whose assertions are supported by official documents available from court and tribunal files. The fact that official government documents were available due to a court case provided an opportunity to support or otherwise the allegations of the whistleblower which is not always possible in whistleblowing cases and likely responsible for a dearth of in-depth whistleblowing case studies. In Chapter 4, I present what was found as the process tracing unfolded during the study. The findings suggest that the causal mechanisms for reprisals in this case were cultural dysfunction in the organization and at the time, little recourse for the whistleblower when concerns were not addressed and/or reprisals occurred. Further, while not the major focus of this study, the evidence suggested a possible area for further inquiry regarding why reprisals are perpetuated in government organizations, regardless of the existence of protective legislation. An inquiry into attitudes towards whistleblowing and whistleblowers in the mechanisms that usually provide checks and balances on abuses of power in organizations such as Courts and the Parliamentary Standing Committees could shed further light on the question. In Chapter 5 , I discuss the findings in the light of the theory and what these ideas mean, along with an interpretation and discussion of the implications of the findings. Lastly, I include conclusions and make recommendations to address the findings where appropriate. 


\section{Chapter: Literature Review}

The objectives of this literature review are to provide a survey of significant literature published on the topics of: first, whistleblowing and reprisals against whistleblowers; second, relevant theory that might account for reprisals; and third, whistleblowing and the role of law and culture in reprisals. At the outset, it is important to note that much of the literature in this area originates in the United States (US) as the US has had whistleblower protection legislation since 1978 - the Civil Service Reform Act (Near and Miceli, Wrongdoing 264). The follow-up 1989 Whistleblower Protection Act is one of the world's first comprehensive whistleblowing laws (Wolfe et al. 64). In fact, "whistleblowing" has been described by an Australian author as a U.S. import (Miceli, Rehg, Near, Ryan 132). In contrast, Canada implemented whistleblower protection legislation for its public servants - The Public Servant Disclosure Protection Act (PSDPA) - in 2007, almost thirty (30) years later. During the intervening time, the Professional Institute of the Public Service (PIPS) noted that attempts were made by parliamentarians from all parties including the Bloc Quebecois, through motions and private members' bills, to protect the rights of public sector employees who blew the whistle (8). This included a promise by the Liberal Party during the 1993 election to introduce whistleblower protection legislation in the first session of Parliament should they be elected. All attempts were unsuccessful and, while they were elected, the Liberal promise was not kept (PIPS 8). ${ }^{6}$ Consequently, the Canadian whistleblower literature over these intervening years has largely focused on debates regarding the need for

\footnotetext{
${ }^{6}$ The Auditor General Kenneth Dye's 1989 attempt to establish an anonymous telephone hotline for people to report on government mismanagement was also shut down by the government (PIPS 8).
} 
whistleblower protection legislation. The Canadian literature regardless of focus is sparse. This work represents a contribution towards filling this void.

Prior to the 1990's, most researchers focused largely on individual whistleblower cases, what motivated them to blow the whistle and the consequences (Miethe \& Rothschild 325). In the early 1990's there was recognition of the need for more of a focus on the implications of whistleblowing for organizations such as the opportunity it presented for organizational learning, improvement and renewal. More study of the whistleblowing process and organizational dissidence as an impetus for change and how it was likely to be effective was called for, along with explanatory theories (Graham 68384). This included consideration of legislation to protect whistleblowers from reprisals based on the assumption this would encourage whistleblowers to come forward (Miethe \& Rothschild 337-38). The field has evolved to the present concern with the fact that despite the presence of legislation to protect whistleblowers in jurisdictions such as the U.S., reprisals continue and are increasing in intensity (L. Lewis 1). Apart from strengthening legislation there is also a need to better understand how legislation is implemented and the role of culture in understanding reprisals (Near \& MiceliWrongdoing 274- 79; Wolfe et al 15; Latimer Brown769, 793).

This review begins with a brief introduction to the field of whistleblowing, examples of important whistleblowing cases in the U.S. and Canada and a consideration of what motivates whistleblowers. Following is a look at the evolution of the field and theories of whistleblowing over the decades. The subsequent section considers theories both general and specific to reprisals useful in understanding whistleblowing and finally, the problem of reprisals and the role of law and culture are considered. 


\subsection{The Field of Whistleblowing and Famous Whistleblowers}

The field of whistleblowing is broad and it occurs in just about every endeavor that human-beings engage in, whether individually or in groups - as in organizations. For example, anyone who notices the bruises and wounds inflicted on a child by a parent's physical punishment could be a whistleblower if s/he reports the situation to the authorities or media. However, as indicated at the outset, this research will focus on whistleblowing in organizations.

Regarding whistleblowing in organizations, whether public or private, the following examples demonstrate just how broad the field is. Some well-known public sector/government examples are: the revelations of Edward Snowden, the whistleblower behind the 2013 public exposure of America's National Security Agency's (NSA) secret surveillance of private citizens and others. Some believe Snowden "will go down in history as one of America's most consequential whistleblowers" (Greenwald, MacAskill and Poitras 1). Then there are the earlier revelations of Daniel Ellsberg, former government official and military strategist, who, in 1971 leaked the US governments' secret Pentagon Papers. These papers contained evidence that Americans had been misled by their own government about its involvement in the Vietnam war. These exposures shook up assumptions and beliefs about war and how governments work and stirred up skepticism and anti-war sentiment (A\&E TV 1). As Ellsberg commented in a recent interview, "They [the Pentagon Papers] made people understand that presidents lie all the time, not just occasionally, but all the time. Not everything they say is a lie, but anything they say could be a lie" (A\&E TV 3). Also notorious are the revelations of "deep throat", Mark Felt, second ranking officer of the Federal Bureau of Investigation 
(FBI). His anonymous disclosures over a period to the Washington Post uncovered the dirty tricks, secret surveillance, internal spies and cover-ups of Watergate fame. They also caused the resignation of an American President, Richard Nixon in 1974, and led to prison sentences for some of his aides (Von Drehle 1).

Many others have contributed their disclosures of wrongdoing towards helping expose and correct misconduct in various fields like public health, environment, law enforcement, etc. such as Jeffrey Wigand, chemist, activist, and scientist, who exposed the manipulations of tobacco companies who tried to hide the dangers of smoking (A\&E 1); Karen Silkwood, chemical technician at Kerr-McGee plutonium fuels production plant in Oklahoma who worked with her union to expose violations in safety practices at the plant, shook up the nuclear industry and was killed in a "suspicious" car accident one week before bringing evidence of this wrong doing to a journalist (A\&E 1); Lois Marie Gibbs a mother and resident of Love Canal, whose persistence helped move the New York State Department of Health and the State itself to take action on the danger of the toxic wastes dumped into the canal primarily by Hooker Chemical Corporation, a subsidiary of Occidental Petroleum ( Gibbs 1); and Frank Serpico, a New York City police detective, who worked internally to expose corruption in his department, and finally, when nothing happened, in 1970 went to the media, resulting in the Knapp Commission of Inquiry (Serpico 1-4).

Meanwhile, in Canada, whistleblowers have also been trying to have a positive impact on public affairs and public life. Canadians for Accountability (C4A), a whistleblowing organization, has identified some of them. They include: Dr. Nancy Olivieri, who fought for research integrity in new drug research at the University of 
Toronto and challenged the ethics of the University and a large pharmaceutical company in the process (C4A, Cases \& Other 1); Brian McAdam who disclosed corruption at the Canadian Consulate in Hong Kong and the infiltration of organized crime members into Canada. He was ostracized and pushed into a dead-end job(C4A, Cases \& Other 1); Ian Bron who reported lapses in public safety matters at Transport Canada (C4A, Cases \& Other 1); Dr. Shiv Chopra, Dr. Margaret Hayden and Dr. Gerard Lambert who resisted Health Canada's pressure to approve bovine growth hormone due to safety concerns and exposed problems with the drug approval process (C4A, Cases \& Other 1); Luc Pomerleau whose concern about changes to the federal government's food inspection regime led him to share an inappropriately classified document about the changes with his union, for which he was fired just a few weeks before twenty two (22) people died from the 2008 listeriosis outbreak (C4A, Cases \& Other 1); and Allan Cutler who raised concerns involving misuse of public funds in the province of Quebec long before it broke in the media - known as the Federal Sponsorship Scandal. He suffered reprisals which included having his responsibilities taken away and being forced to sit in a tiny room with no work for hours each day (C4A, Cases \& Other 1). This scandal led to the formation of the Gomery Commission of Inquiry. Some believe, the revelations in Judge Gomery's report were the catalyst for the Canadian Government to finally introduce long promised legislation to protect whistleblowers (Sulzner abs 171). These examples of Canadian whistleblowers and many more had no effective official policy to protect them.

\subsection{The Motivation of Whistleblowers}

Why does one blow the whistle? The 1989 work of Glazer and Glazer, one of the early studies on whistleblowing, disclosed the results of their work during the six years 
they travelled throughout the United States interviewing some sixty-four "employees of conscience" who had disclosed lawless acts in the workplace (xiii). They reported that whistleblowers had generally conformed to bureaucratic life until asked "to violate their own standards of appropriate workplace behaviour" (5-6). They were motivated by professional ethics, deeply held religious beliefs and community ties (97-132). According to this account, in many cases, professional ethics training had instilled an alternate belief system that allowed whistleblowers or "ethical resisters" to resist the powerful pressures in organizations to conform. This was sometimes strengthened by strong religious beliefs. Regarding community ties, workers were often motivated by concern for the well-being of their neighbors, friends and families (97-132). In some cases, their jobs required they report wrongdoing i.e. auditors or regulators. Generally, they believed that they were defending the true mission of their organizations and could not understand how their superiors could risk damaging these organizations by allowing wrongdoing to take place (6). Others suggest similar motivations such as Near and Miceli (Myth 1996), and Brewer and Seldon (1998). On the other hand, some assert that the whistleblower's motivations or ethics are irrelevant. What is relevant is "the whistleblowers perception or reason to believe that there has been wrongdoing" (Latimer and Brown 768).

\subsection{The Evolution of the Field}

Whistleblowing has been considered through many lenses and from many angles but, little of this discussion has taken place in Canada. However, this is changing as whistleblowing and whistleblowers have been the subject of increasing interest in recent years. This is likely due to the implementation of whistleblowing legislation first 
assented to by Parliament Nov. 25, 2005 and its coming into force by Order in Council on April 15, 2007 (PSDPA section 60). That is not to say that whistleblowing is a strictly modern phenomenon. One of the earliest recorded examples of whistleblowing took place in 1696 in England and involved corruption in the Royal Navy's sick and wounded service. ${ }^{7}$ Notably, Neufled argues, these "roots of whistleblowing" (397) were nurtured by institutional changes in England in the late 17th century. Relevant to the present context were the important steps Parliament took to become an "organ of inquiry into the workings of all government departments" along with the end of pre-publication censorship in 1695 (397).

\section{The field in the 1980s}

In more modern times, much of the research on whistleblowing began in the US following the implementation of the Civil Service Reform Act in 1978. It focused on individual stories of either "heroes or malcontents", the wrongdoing they had witnessed and the retaliation they had suffered. The characterization of "malcontents" was likely due to the social norm that prohibited "squealing" or "tattling". Glazer and Glazer reported that their work confirmed that these experiences are representative of hundreds of other employees who challenged illegal and unethical behaviour in their organizations (xiii). They discovered as had others, that whistleblowers are "conservative people devoted to their work and their organizations" (5).

\footnotetext{
${ }^{7}$ The hapless former clerk of the Commission for Sick and Wounded Seamen named Samuel Baston suffered the same fate that many modern-day whistleblowers do. He was punished for his whistleblowing on corruption in the Royal Navy's sick and wounded service during the nine years' war (Neufeld 397-98). Within days of writing and issuing a satirical pamphlet on the alleged corruption, Baston, the publisher and at least one "hawker" were arrested and charged with seditious libel. Baston was jailed for a while but released on bail. Within three months he had re-issued the pamphlet but this time it was ignored and he disappeared from the record (398).
} 
Beyond the individual stories, Near and Miceli's work began the process of trying to explain the whistleblowing phenomenon in 1985 by drawing on existing theories of motivation and power. They proposed an empirically testable model of the whistleblowing process and suggested variables that may affect the decisions of the whistleblower and the responses of the organization (Dissidence 1-14).

They asserted that whistleblowing is a process that has important implications for organizations which, at that time had rarely been considered (Dissidence 1). They noted the basic dilemma for any organization appeared to be a choice between accepting the benefits of whistleblowing (improving organizational effectiveness and cleaning up wrongdoing) or resisting the threats of whistleblowing to the organization's authority structures. The fear was that condoning the challenge to the organization's authority structure (and the manager's right to make decisions) even if the disclosure was internal, may push the organization into chaos and anarchy (Dissidence 1-2).

They proposed the steps in the whistleblowing process are first, the observer must decide if the activity is illegal, immoral or illegitimate, second, the observer must make the decision to report the activity, and third, the organization must respond in some way even if to do nothing and continue the allegedly wrongful action as the illegitimacy may be in dispute (dominant coalition sees it as perfectly legitimate); and last, ignore the whistleblower and take steps to silence her/him or discredit the charge (Dissidence 4-6 ). Some factors influencing the whistleblowing process and the response of the organization which were considered are: circumstances surrounding the questionable activity, individual characteristics of the whistleblower, power relations, dependence on the whistleblowing channel, organization's dependence on whistleblower, and organization's 
dependence on the questioned activity. Propositions related to these variables are summarized in Table 2.1.

Interestingly, some research findings indicate there is some mechanism operating to "depress the propensity to act" (Miceli and Near 132). Thus, it would likely be more important to change focus from trying to understand why whistleblowers act, to instead focus on what organizational, situational, and personal factors cause organization members to remain silent (Miceli and Near 132-33). This question is fundamental to understanding reprisals against whistleblowers and other wrongdoing.

\section{The field in the 1990s}

A 1992 review by Miceli and Near of the whistleblowing scholarship up to that time made important contributions to the field. One was the call to change research focus from individual "heroes or malcontents" to the process of constructive organizational renewal (Graham 683). Another was to link the study of the whistleblowing process to the elabouration of a general model of organizational dissidence as an impetus for change and how such change is likely to be effective (685). Graham noted that Miceli and Near, together and with certain other colleagues, had conducted the lion's share of the empirical research on whistleblowing up to the time of the review.

Another review in 1994 by Miethe and Rothschild also reviewed the literature on whistleblowing in a variety of types of organizations - public and private - and examined its role in detecting and controlling organizational misconduct. This research emphasized not only the importance of whistleblowing and whistleblowers as mechanisms of social control but asserted they are primary agents [emphasis added] of 
Table 2.1: Factors Influencing the Whistleblowing Process and its Outcomes

Circumstances Surrounding the Questionable Activity
The likelihood of whistleblowing is increased when:
Proposition 1: observers of wrongdoing can verify that questionable activity has occurred and view it as
clearly wrong, serious and recurring and there exist known complaint channels;
Proposition 2: such action is expected to result in the desired change by managers;
Proposition 3: they believe that the wrongdoing is of sufficient importance that they are prepared to
endure retaliation;
Proposition 4: the organizational climate is conducive to dissidence i.e. through policies and actions.
Individual characteristics
Whistleblowing is more likely to occur when:
Proposition 5a: observers of wrongdoing are male and have high self-esteem, an internal locus of control
(LOC) and a high level of moral reasoning than when they do not.
Proposition 5b: Internal LOC's will be more likely than external LOC's to attempt whistleblowing
through channels within the organization.

Power Relations

Proposition 6: Whistleblowers are likely to be less dependent on their employers, relative to other employees. This should be reflected in their lower age, aspiration, and experience level; their expressions of loyalty to persons or institutions other than their employer such as professional groups; their higher levels of support from family or friends; and the rates of employment in their relevant labour markets.

\section{Dependence on the whistleblowing channel}

Proposition 7: Whistleblowing is more likely to occur when observers of wrongdoing are highly dependent on the method of whistleblowing as a form of political action; that is, when they feel that alternative actions are not possible.

\section{The organization's dependence on the whistleblower}

Proposition 8a: Large organizations are more likely to engage in reprisals against the whistleblower when they are not highly dependent upon the whistleblower because the whistleblower is powerful; Proposition 8b: Large organizations that are less dependent upon the whistleblower will experience fewer internal whistleblowing attempts than will organizations that are highly dependent on the whistleblower.

\section{The organization's dependence on the questioned activity}

Proposition 9: Organizations are more likely to refuse to halt wrongdoing and to engage in reprisal against the whistleblower when they are highly dependent upon their wrongful behaviour.

Source: Adapted from Near \& Miceli,1985: "Organizational Dissidence: The Case of Whistleblowing". Journal of Business Ethics. 4, (1985): 1-16 
social control for organizational misconduct. This is so because there is such a low probability of getting caught for organizational wrongdoing due to "low public visibility and high technical complexity" (523) of illegal activity in organizations. As a result, only certain organizational insiders - potential whistleblowers - can observe wrongdoing.

This review also proposed certain theories of deviance which the authors asserted made up for short-comings in previous social psychological theories suggested by other researchers such as Near and Miceli to explain whistleblowing which, the authors pointed out, had not been empirically tested (Miethe and Rothschild 325). Further, Miethe and Rothschild propose that the basic limitation in these theories was that they did not explicitly encompass all the necessary conditions for understanding and increasing the likelihood of whistleblowing (325). These conditions are personal characteristics of the observer of wrongdoing (the whistleblower), the situational context, and the organizational structure. They suggest alternative theories of conformity and deviance include these factors such as rational choice, social learning and social bond theories and allow for a more comprehensive understanding (325-27) - particularly in situations where whistleblowing is considered "deviant" as opposed to normative. ${ }^{8}$ However, a significant theory explaining reprisals other than the failure of whistleblower legislation to protect them remained elusive.

In addition, Miethe and Rothschild examined and summarized evidence on the prevalence of whistleblowing and its correlates, i.e. individual and psychological factors,

\footnotetext{
${ }^{8}$ The authors describe these theories as follows: rational choice theory "assumes human behaviour is produced by the relative weighting of the probabilities and magnitudes of both rewards and punishments" (326); social learning theory proposes that learning takes place through interactions and associations with significant others who support and reinforce attitudes (326) and social bond theory proposes deviant behaviour results from the weakening of social bonds to society. The major bonds regulating human behaviour are attachments to others (family and peers), commitment, involvement, and belief (326). Augmenting such explanations is the work of Sumanth, Mayer and Kay which is discussed in depth later in this work.
} 
situational and cultural factors, the legal protection of whistleblowers against retaliation and considered the effectiveness of such legislation in encouraging whistleblowing (32243). The results in the case of the effectiveness of legislation were not definitive and doubt was cast on the outlook for the ability of legislation to protect whistleblowers and encourage whistleblowing in the future (339).

The multidisciplinary nature of the scholarly work was also highlighted in this decade - mainly ethical, legal and organizational. Along with this came a perception of the need for integration of these perspectives to separate myth from reality and to provide more accurate information to legislators and policy makers. Near \& Miceli reviewed then recent empirical work to answer two questions considered important at the time: first, are whistleblowers "crackpots"? And second, do most suffer serious retaliation following their actions? (Myth 510 - 16). They concluded first, that whistleblowers are not unusual people ("crackpots") but were in the wrong place at the wrong time and forced to play a role in the dynamic and complex whistleblowing process. Second, they concluded from surveys that most whistleblowers do not suffer retaliation and may not consider it important in deciding to blow the whistle or not. However, case studies indicated the opposite creating the need for more research and interdisciplinary cooperation (Myth 523).

The two primary theoretical perspectives used to explain retaliation in this work are the effects of organization structure and culture and the power relationships among the social actors involved (Myth 520). The main premise was that bureaucracies would be more likely to engage in retaliation than would less bureaucratic organizations. Whistleblowing could also be power struggles among social actors i.e. the whistleblower, 
the wrongdoer, the complaint recipient and the organization or top management team. The relative power of each of the actors and variables that might affect it was considered along with theories by which power shifts might occur among the actors (Myth 521- 22). The researchers point out however, that empirical research up to 1996 had not sufficiently demonstrated the superiority of any of these theories over one another in explaining whistleblowing and retaliation and more research was needed (Myth 521).

By the end of the 1990's some of the earlier propositions regarding the effect of protective legislation on wrongdoing and the incidence of whistleblowing and retaliation had been empirically tested, at least in the US Federal Public Service. This was accomplished through secondary analysis of data collected over three time periods 1980, 1983 and 1992- by the US federal government's Merit Systems Protection Board (MSPB), a creature of the CSRA. ${ }^{9}$ Regarding the effect of whistleblowing legislation created to encourage whistleblowing, the analysis of the surveys indicated two desired effects: - reduced incidence of perceived wrongdoing and an increase in the likelihood of whistleblowing. However, there were two undesired effects observed: perceived retaliation grew and whistleblowers increasingly sought anonymity (Miceli, Rehg, Near, Ryan 141-42).

Regarding the variables that predict retaliation over time, the results identified situational and personal predictors of retaliation as follows: comprehensive retaliation (i.e. total number of times retaliation was threatened or experienced) was associated with

\footnotetext{
${ }^{9}$ The Merit Systems Protection Board (MSPB) is an independent, quasi-judicial agency in the Executive branch that serves as the guardian of Federal merit systems. The Board was established by Reorganization Plan No. 2 of 1978, which was codified by the Civil Service Reform Act of 1978 (CSRA), Public Law No. 95-454. The CSRA, which became effective January 11, 1979, replaced the Civil Service Commission with three new independent agencies: Office of Personnel Management (OPM), which manages the Federal work force; Federal Labour Relations Authority (FLRA), which oversees Federal labour-management relations; and, the Board.
} 
seriousness of the wrongdoing, lack of management and/or supervisor support, lower pay, minority race and use of external channels. Comprehensive retaliation was not associated with lack of co-worker support, professional job status, job tenure and gender (Miceli, Rehg, Near, Ryan 142-44).

\section{The Field in the 2000s}

In 2008, Near and Miceli summarize the empirical findings referred to above regarding whistleblowing in the US Public Service based on secondary analysis of the data from surveys done of federal employees conducted in 1980, 1983 and 1992 (263). The 1980 survey was considered baseline as it was done shortly after the 1978 CSRA was implemented and the MSPB was created. The review reiterated earlier findings on predictors of whistleblowing, predictors of retaliation and expanded the conversation to include predictors of whistleblowing effectiveness. The empirical findings for predictors of whistleblowing and retaliation are summarized in Tables 2.2 and Table 2.3.

Regarding whistleblowing effectiveness, these authors raise an important question from a policy perspective: what are the conditions under which whistleblowing is effective in getting the wrongdoing stopped? They point out that whistleblowing is only beneficial to society if it causes organizations to stop the wrongdoing (Wrongdoing 274). Their concern was timely when one considers this was the decade of Enron and the US financial crisis the impact of which reverberated around the world.

They propose numerous reasons why organizations could resist termination of wrongdoing as follows: in some cases managers may not be aware that wrongdoing is occurring; however, in other cases top managers, may hesitate to stop wrongdoing because it first, benefits other valued employees they don't want to lose; second, does not 
seem very serious or seems even nonexistent; third, benefits the managers themselves;

fourth, in general has become normalized in the organization through processes of rationalization and socialization or fifth, managers do not like it when employees question their authority to make decisions (Wrongdoing 274-6).

Table 2.2: Empirical Findings Related to Predictors of Whistleblowing

\begin{tabular}{|c|c|c|}
\hline From MSPB Data 1980 & rom MSPB Data 1983 & $\begin{array}{c}\text { Overall MSPB } \\
\text { Data }\end{array}$ \\
\hline $\begin{array}{l}\text { Both internal and external whistleblowers } \\
\text { were compared with non-observers and } \\
\text { inactive observers of wrongdoing (Miceli } \\
\text { and Near 1984). } \\
\text { Five key findings: } \\
\text { 1. Whistleblowers believed that } \\
\text { whistleblowing was justified when } \\
\text { wrongdoing had been observed; } \\
\text { 2. Observers of wrongdoing (inactive } \\
\text { observers and whistleblowers) } \\
\text { perceived a more retaliatory climate in } \\
\text { their organization than non-observers; } \\
\text { 3. Observers of wrongdoing were more } \\
\text { likely than non-observers to support } \\
\text { cash incentives for whistleblowing } \\
\text { and to blow the whistle if they thought } \\
\text { managers would correct the } \\
\text { wrongdoing; } \\
\text { 4. External whistleblowers described } \\
\text { themselves as more knowledgeable } \\
\text { about channels for whistleblowing in } \\
\text { their organizations; } \\
\text { 5. Whistleblowers in general had higher } \\
\text { pay and education thus more power } \\
\text { and more likely to be viewed as } \\
\text { credible. }\end{array}$ & $\begin{array}{l}\text { Anonymous and identified } \\
\text { whistleblowers compared to one } \\
\text { another and to inactive observers } \\
\text { (Miceli \& Near 1988). } \\
\text { Whistleblowing and whistleblowers } \\
\text { were more positively associated with: } \\
\text { 1. Professional status; } \\
\text { 2. Working in a larger work group; } \\
\text { 3. More positive responses to the } \\
\text { job, } \\
\text { 4. Working in an organization } \\
\text { where others believed problems } \\
\text { could and would be corrected. } \\
\text { Also, different from inactive } \\
\text { observers, whistleblowers had: } \\
\text { 1. More years of service; } \\
\text { 2. More performance-related } \\
\text { awards; and } \\
\text { 3. Were male. } \\
\text { This suggested that they felt greater } \\
\text { power and freer to blow the whistle } \\
\text { as they were more likely to be viewed } \\
\text { as credible. }\end{array}$ & $\begin{array}{l}\text { Overall, including } \\
\text { 1993 data, the } \\
\text { MSPB results } \\
\text { showed } \\
\text { whistleblowers: } \\
\text { 1. Felt more } \\
\text { supported than } \\
\text { did inactive } \\
\text { observers; } \\
\text { 2. Acted when } \\
\text { wrongdoing } \\
\text { was serious or } \\
\text { repeated; } \\
\text { 3. Held positions } \\
\text { in larger } \\
\text { organizations } \\
\text { or units with } \\
\text { opportunity to } \\
\text { observe } \\
\text { wrongdoing; } \\
\text { Were } \\
\text { seasoned, high } \\
\text { performers } \\
\text { who believed } \\
\text { that } \\
\text { whistleblowing } \\
\text { was sometimes } \\
\text { warranted. }\end{array}$ \\
\hline
\end{tabular}

Source: Adapted from Near \& Miceli, 2008, "Wrongdoing, Whistleblowing, and Retaliation in the U.S Government." Review of Public Personnel Administration 28, 3, 2008: 263-281. 
Table 2.3: Empirical Findings Related to Predictors of Retaliation

Predictors of retaliation: Overall results -regression analyses of all three MSPB data sets

1. Employees who are relatively powerful and blow the whistle are less likely to suffer retaliation than those who are less powerful, when power is measured by demographic variables (pay, performance, and majority ethnic group) and perceived support from others. Levels of education did not fit this pattern. They were more likely to be retaliated against if they were external whistleblowers (Miceli et al 1999, Miceli \& Near 1992).

2. Preliminary evidence suggested that a large majority of whistleblowers use internal channels first. They go external when they are ineffective and have suffered reprisals (Rehg et al, 2008).

3. The preliminary findings in No. 2 above, if confirmed in later research, suggest the reason for retaliation with external whistleblowing is not so much the greater threat to the organization from public exposure. It may also be because the organization/managers were more resistant to problem correction when reported inside, perhaps as it was a very serious problem. Thus, the organization and managers themselves force the whistleblower to pursue the complaint outside.

Source: Adapted from Near \& Miceli, 2008, "Wrongdoing, Whistleblowing, and Retaliation in the U.S Government." Review of Public Personnel Administration 28, 3, 2008: 263-281.

Further, they quote an anonymous reviewer who suggests another hypothesis: managers may also believe that change is not in their best interest although it might be in the organization's best interests. They may believe that change would require acknowledging the wrongdoing and would thus lead to loss of status, loss of financial rewards or job, or civil or criminal charges (274- 75). They posit that the threat-rigidity hypothesis suggests managers often react with rigidity when threatened, even if change might be in the best interest of their organizations (276). The empirical findings regarding predictors of whistleblowing effectiveness from the three MSPB surveys are summarized in Table 2.4. Key questions emerging from this work are: what leads employees to effectively blow the whistle and why are some whistleblowers more likely than others to suffer reprisal? In answer, the authors underlined theoretical implications 
from initial findings which showed a pattern: first, employees are more likely to blow the whistle when wrongdoing is serious, frequent, long-lived or widespread and evidence is clear. However, because of this they are less likely to be effective in stopping the wrongdoing and are more likely to suffer reprisals.

Table 2.4: Empirical Findings related to Whistleblowing Effectiveness

Predictors of Whistleblowing Effectiveness: From MSPB Data 1980, 1983 and 1993

1. Data showed mixed support for theories of whistleblowing effectiveness (Miceli \& Near 2002). Variables indicating the wrongdoing was less rather than more serious and of short duration were associated with effectiveness in all three data sets examined. Variables associated with the whistleblower's status (i.e. role-prescribed whistleblowing) and power base (i.e. complaint recipient was in the Office of the Inspector General) were positively associated with effectiveness but retaliation against the whistleblower was negatively associated with effectiveness.

2. These results might support the threat-rigidity hypothesis in that whistleblowing that was less rather than more threatening to the organization resulted in less rigid response and greater willingness to terminate wrongdoing. They are also consistent with analysis of the whistleblower's power base relative to top management's as whistleblowers with more rather than less power was more effective in gaining top management's willingness to cease wrongdoing. More research is needed to see if this holds up in other types of samples.

Source: Adapted from Near and Miceli 2008, "Wrongdoing, Whistleblowing and Retaliation in the U.S. Government." Review of Public Personnel Administration 28, 3, 2008: 263-281.

Second, powerful whistleblowers are more likely to be effective and less likely to suffer retaliation. Third, organizations that are less rigid and more innovative (e.g. learning organizations) may be less threatened by whistleblowers and more willing to cease wrongdoing (277). But, bureaucracy is still the basis for most organizational structures built on the principle of managerial authority, and so may still resist tolerating or even encouraging dissent. This begs the question: how can organizations be encouraged to become learning organizations where dissent is considered acceptable? 
There is little empirical research on what happens to organization structure and performance if dissent is permitted (Near \& Miceli, Wrongdoing 277).

Policy implications of encouraging dissent were also identified. For example, top reasons people do not blow the whistle include not only fear of reprisal but maybe more importantly, a belief that nothing will get done. Near and Miceli propose several strategies to improve this situation. These include, first, that lawmakers could take policy actions with the aim of increasing penalties for wrongdoing and increasing sensitivity to wrongdoing. This they believe may have more impact on the incidence of whistleblowing than laws aimed at reducing retaliation against whistleblowers. If executives, presumably spurred by the consequence of penalties, acted to stop the wrongdoing, then whistleblowers would be more likely to blow the whistle (Wrongdoing 278), and second, managers and administrators faced with stiffer penalties could be proactive and encourage dissent i.e. valid whistleblowing, to prevent external whistleblowing and public censure. Possible strategies include transparency of organizational actions and clear channels for internal whistleblowing (ombudspersons, hotlines) that are recognized, understood and trusted by employees (278). While there is a need for more empirical research to validate and extend findings to know which actions are most likely to encourage whistleblowers to act, Near and Miceli conclude organizations can take early action by clearly defining wrongdoing, ensuring top managers understand what wrongdoing is and creating penalties for ignoring wrongdoing, so that managers will view whistleblowing as less threatening to the organization (279). 


\section{The Field in the Current Decade}

More recently, there appears to be an emphasis on understanding retaliation perhaps in response to the apparent failure of legislation on its own to improve the situation and the increase in occurrence and intensity. In addition to power and other perspectives on retaliation, scholars are beginning to consider more fully how individuals' cognitions and emotions, and perceptions of threat - to ego, group, or system - impact retaliation (Sumanth, Myer Kay 165). Near and Miceli’s suggestion that threat was associated with response rigidity - threat-rigidity theory - is in line with the above views. This was supported by the finding that when whistleblowing was less rather than more threatening to the organization i.e. wrongdoing was less serious and short lived, it resulted in less rigid response and greater willingness to terminate wrongdoing (Near and Miceli, Wrongdoing 275). Sumanth, Mayer and Kay suggest that retaliation may come from a multitude of sources and argue that anyone who stands to benefit from the unethical activity could retaliate, whether directly engaged in the wrongdoing or who knows of it but is not directly engaged in it. In both situations factors such as ethical climate and a norm of self-interest are at play (166 - 67).

There also appears to be more interest in the organizational context and culture as it impacts not only how the organization functions and whether it is "conducive or prohibitive to unethical acts" (Jurkiewicz and Giacalone 1) but also impacts the law and how it is enforced or implemented. As noted by Latimer and Brown "failures of implementation or enforcement may undermine good laws" and "the existence of scepticism about whistleblowing law effectiveness and enforcement, or about pursuing redress, remains an important issue" (Latimer and Brown 793). 
In summary, this section reviewed the evolution of the theory and knowledge around whistleblowing over the decades when countries first began legislating protection for whistleblowers. This evolution began largely in the 1980's and was mostly descriptive and not theoretical, focusing on individual whistleblower stories, their motivations and the retaliation they suffered (Miethe \& Rothschild 1994). In the 1990's there was a recognition of the need for more research focus on organizations and the potential of whistleblowing and organizational dissidence as an impetus for organizational change and renewal (Graham 1992). The potential for legislation to both encourage whistleblowing and protect whistleblowers was also considered and placed in doubt (Miethe \& Rothchild 1994). In addition, reprisals were explained through the lens of structure, culture and power relationships (Near \& Miceli Myth 520). By the end of the 1990's many of the earlier hypotheses regarding whistleblowing and reprisals had been empirically tested. This work was summarized by researchers by the end of the 2000's and there was more focus on what would make whistleblowing more effective (Near \& Miceli Wrongdoing 2008).

These theories attempt to explain whistleblowing, reprisals and the behaviours of both the observers of wrongdoing and the organizational members who receive reports of wrongdoing when an observer decides to blow the whistle. Some use theories of motivation, power and dependency to explain the phenomenon (see Near \& Miceli 1985), while others propose theories of conformity and deviance such as social bond theory, rational choice theory, and social learning theory which they believe allows for a more comprehensive understanding (Miethe \& Rothschild 1994). 
While much has been learned, at present there is still a lack of consensus on which theory is best suited in explaining reprisals. There is also a lack of in-depth case studies to help deepen that understanding likely due to the difficulty in verifying what the whistle blower alleges. I address these issues in the next section.

\subsection{Theories of Whistleblowing}

In this section, the issue of gaps in explanatory theory regarding reprisals is addressed by drawing on the insights of researchers such as Miceli \& Near and colleagues over the decades to propose rather than one theory - several theories that are helpful. I suggest the following: recent theory focusing specifically on reprisals by Sumanth, Mayer and Kay (2011); more general theories pertaining to individuals and organizations by Asch (1955, 1961), Milgram (2009), Jurkiewicz \& Giacalone (2014), Vaughan (1983, 1996), and Argyris \& Schon (1996). These additional theories are described in more detail below. I conclude this section by proposing a diagrammatic summary of these individual and organizational theories which seem most useful in explaining the paradox of reprisals against whistleblowers. The subsequent case study where the allegations of the whistleblower are corroborated through official government and other documents from court and tribunal files- will allow for discovering whether the whistleblower's experience was similar or different from that suggested by the theory.

\section{Reprisals, Cognition and Emotion}

To begin, in 2011, Sumanth, Mayer, and Kay proposed mechanisms of cognition and emotion as the primary forces sparking reprisals against whistleblowers, moving beyond and providing alternative explanations to earlier power-based explanations which they believe are insufficient (169). Drawing on management and social psychology 
literatures and system justification theory, they propose "whistleblowing represents a perceived threat to one's ego, group and/or system, and these threats, in turn, activate cognitive and emotional processes" (167) that cause individuals to react. These concepts and processes include justification motives, moral emotions such as anger, shame and fear, and moral disengagement thus justifying the wrongdoing and triggering reprisals (169 -74). They further propose that the extent to which certain individual forces or moderators and organizational/contextual moderators are present in an organization, influences whether reprisals will be more or less severe (167). Individual moderators are Machiavellianism, ${ }^{10}$ organizational commitment, and belief in a just world. Organizational/contextual moderators are ethical climate, group cohesion, and legitimated behaviour.

They place two constraints on their model: first, the theory is intended to apply to situations where the whistleblower genuinely is intending to help their organization do the morally right thing. Second, they see those likely to retaliate from a broad perspective. This could be anyone who stands to benefit from the unethical activity either those directly engaged or who indirectly benefit from maintaining the status quo. In both cases a norm of self-interest is involved (167).

\section{Reprisals, Conformity and Obedience to Authority}

The impulses to conform and obey are particularly relevant to this examination of

\footnotetext{
${ }^{10}$ Machiavellianism is a person's tendency to deceive and manipulate other people for their personal gain and is part of the "dark triad" of personality traits which include narcissism and psychopathy (175).
} 
whistleblowing and reprisals. Asch's work on conformity and Milgram's on obedience help to explain why, at times, human beings are blind to and silent about behaviours that are contrary to their own ethical values, and sometimes the law as well, often with disastrous results. If we can advance this understanding, perhaps we can then determine what can be done to counter such tendencies in organizations - encouraging more whistleblowing and more ethical and accountable organizations.

Asch's experiment on conformity was conducted in the 50's and consisted of a simple test with a group of college students and demonstrated how readily people will conform to the group. As described by Heffernan the participants were:

Shown a single vertical black line of a certain length, and they needed to identify which of three separate lines matched it in length. All but one of the students had been told beforehand to choose an obviously "wrong" line. The isolated student gave his opinion last. In nearly $40 \%$ of the cases, the isolated student chose the obviously wrong answer. Repeated trials of the experiment showed that only a small minority -8 percent - could be counted on always to conform and only about a third could be counted on never to conform but the vast majority of us -58 percent - will, under certain conditions, conform. (127)

Heffernan comments that "under social pressure, most of us would simply rather be wrong than alone" (127). Heffernan uses Asch's studies to bolster this view. While it is important to appreciate the role conformity plays in shaping human action and explaining wrongdoing and reprisals, Asch actually conducted his experiments to clarify and inquire into the state of the theoretical and empirical situation on the topic at the time (up to the 
1950's). As he noted, this view "almost exclusively stressed the slavish submission of individuals to group forces, has neglected to inquire into the possibilities for independence and for productive relations with the human environment, and has virtually denied the capacity of men, under certain conditions to rise above group passion and prejudice" (Effects 223).

While his work showed a strong tendency to conform, Asch points out that consolation can be drawn from the fact that, when questioned later, "those who participated in this challenging experiment agreed nearly without exception that independence was preferable to conformity" (Opinions 35). The conditions needed to foster the development of independence - despite group forces- is a question requiring more attention in whistleblowing situations.

Milgram, a student of Asch, distinguished between obedience and conformity. According to this view, obedience is about obeying the orders of a formal authority, while conformity is the behaviour of someone "who adopts the habits, routines and language of his peers, who have no special right to direct his behaviour" (114). Like many thinkers and researchers following the Second World War, Milgram was concerned with finding an explanation for how the atrocities conducted under Hitler's regime, and carried out by his obedient followers resulting in the deaths of millions of Jews, could have happened. There were two participants in the study ostensibly to demonstrate the effect of punishment on learning - a "teacher" and a "learner". The teacher doesn't know the learner is an actor who takes direction from the experimenter. The teacher, whose behaviour is the subject of the experiment, proceeds as instructed to administer shocks to the learner each time he makes a mistake in the word pairs he is to remember. Each 
supposed shock continues until it reaches up to lethal intensity. The learner (actor) began to protest and screamed in agony and the experimenter would not agree for the teacher to stop. Despite their discomfort "a substantial proportion of teachers would continue to the last [lethal] shock on the generator (5)".

Milgram points out that outside of the experiment situation most saw

disobedience as proper. However, being in the situation made it difficult to act consistent with one's value's or conscience for the following reasons: first are "binding factors" that lock the subject (teacher) into the situation such as politeness, wanting to keep his promise to help the experimenter, and awkwardness of withdrawing; second are adjustments to the subjects thinking that undermine his resolve to quit such as becoming so absorbed in the narrow technical aspects of what he is doing and performing competently, he fails to see the broader consequences and deficiencies; and finally, while many of the teachers/subjects did not agree with what they themselves were doing and protested, most did not have the courage to act on their beliefs (5-11).

A particularly relevant finding from a variation on the original experiment stands out in Milgram's work and it tells us that "The problem of obedience therefore is not wholly psychological. The form and shape of society and the ways it is developing have much to do with it" (11). He proposed that the division of labour has fragmented jobs so that an individual gets to see one part of the whole. This has taken away from the human quality of work and life and in yielding to authority the human is "alienated from his own actions (11)." This aligns with earlier findings of researchers such as Miethe and Rothschild that whistleblowing takes place when whistleblowers are in positions where 
they can observe wrongdoing, i.e. management, professional status, and could be part of the explanation for why there are so few whistleblowers.

\section{Reprisals and Ethical Climate}

Jurkiewicz and Giacalone conclude that organizational dysfunctionality contributes to ethical dysfunctionality which fosters wrongdoing. They have developed a list of organizational characteristics called the Dysfunctional Dozen which can be used as a starting point by organizations and others to determine the level of ethical dysfunctionality in an organization. The presence of many of these characteristics would establish "a base threshold for dysfunctionality" (5). They suggest organizations and others can further develop the scale as an aid for planning and assessment and identifying the need for intervention to prevent unethicality developing. The characteristics are listed and described in Table 2.5.

Jurkiewicz and Giacalone describe how an ethical climate is constructed and focus on how an organization functions rather than on the specific acts of those within it. They argue that "the structure of an organization predisposes in large part whether it is itself conducive or prohibitive to unethical acts" (1). These researchers consider three elements of ethical dysfunction- structural, cultural and leadership. As previously noted, strict vertical hierarchies foster dysfunctional cultures. This occurs as communication is difficult and there is little or no recourse when employees are faced with top-down unethicality (Jurkiewicz \& Grossman 3-13). 
Table 2.5: The Dysfunctional Dozen

\begin{tabular}{|c|c|}
\hline $\begin{array}{l}\text { Organizational } \\
\text { Characteristic }\end{array}$ & Description \\
\hline Deception & $\begin{array}{l}\text { Entails behaviour that is imposturous, expedient, artificial, shallow, and politically } \\
\text { manipulative. Also can include outright lying or more subtly "unbounded } \\
\text { impression management" internally and externally. Such behavior is likely } \\
\text { modeled by leaders and replicated by subordinates. }\end{array}$ \\
\hline Dependency & $\begin{array}{l}\text { Strong ties and identification with leader. Psychological and fiscal dependence on } \\
\text { leader leading to strong desire to please to gain approval. Leader requires } \\
\text { obedience and self-determination is punished. Groupthink reinforced and lack of } \\
\text { critical analysis. }\end{array}$ \\
\hline Distrust & $\begin{array}{l}\text { Employees assume hidden agendas, rumor mill runs rampant, and ulterior motives } \\
\text { suspected of each other. Dysfunctional reporting on each other, surreptitious } \\
\text { observation and almost paranoid questioning of motives and intentions. }\end{array}$ \\
\hline Egoism & $\begin{array}{l}\text { Focus on self, irrespective and disdainful of others' efforts. View others as means } \\
\text { to an end, and associations dictated by utility rather than personal regard. Focus } \\
\text { on short term personal gain rather than collective sense of accomplishment. }\end{array}$ \\
\hline Immediacy & $\begin{array}{l}\text { Focus on immediate reward without regard for long-term consequences and } \\
\text { accountability is way down the road. Rewards for expediency toward goal } \\
\text { attainment. Desired ends justify any means, and Machiavellianism prevails. } \\
\text { Manipulation of data and spin of interpretation to enhance performance and } \\
\text { discount consequences. }\end{array}$ \\
\hline Impiety & $\begin{array}{l}\text { Demonstrated disesteem and contempt for employees. Uncivil and discourteous } \\
\text { tone of interactions. Sense that organization is more important than its members. } \\
\text { Employees bullied and harassed. Competition for attention rather than direction } \\
\text { toward production. }\end{array}$ \\
\hline Impunity & $\begin{array}{l}\text { Lack of accountability and blaming others. Procedural issues cited to deflect } \\
\text { blame and protect from responsibility. Pathological form of favoritism and } \\
\text { existence of character, truth, keeping obligations and promises are malleable and } \\
\text { exercised at individual's discretion and by personal preference. Influence tactics } \\
\text { and rewards based on who in best position to return favors. }\end{array}$ \\
\hline Inequality & $\begin{array}{l}\text { Sense of injustice and loyalty not in best interest of individual. Disparity and } \\
\text { unfairness in treatment. Output minimized, discouragement abounds and diversity } \\
\text { not valued. }\end{array}$ \\
\hline Inhumanity & $\begin{array}{l}\text { Lack mercy or kindness. Employees and management cruel to each other and } \\
\text { often to stakeholders. Impersonal and cold environment and lack of concern with } \\
\text { needs of employees as human beings. }\end{array}$ \\
\hline Invariance & $\begin{array}{l}\text { Management enforces only one right way to do things. Questioning is } \\
\text { discouraged, innovation and critical thinking are suppressed; proactive thinking, } \\
\text { creativity, and effective problem-solving are dissuaded either overtly or tacitly. } \\
\text { Behaviour outside established norm punished. Can lead to pursuing aberrant goals } \\
\text { with great yet unwarranted zeal. }\end{array}$ \\
\hline Narcissism & $\begin{array}{l}\text { Tendency to selfishness and exploiting others, self-aggrandizement, brutish } \\
\text { disregard for those who distract attention from oneself. }\end{array}$ \\
\hline Obduracy & $\begin{array}{l}\text { Harsh, inflexible, unyielding mindsets. Information that counters held beliefs and } \\
\text { attitudes not allowed. Decisions made to maintain status quo. Unwillingness to } \\
\text { change creates a threshold for ethical dysfunctionality. }\end{array}$ \\
\hline
\end{tabular}

Source: Adapted from Jurkiewicz and Giacalone. "Organizational Determinants of Ethical Dysfunctionality,” Journal of Business Ethics, Sept. 10, 2014, 1-12. 
An organization's culture develops over time and is a function of leaders modeled behaviour, policies that are articulated, rewards for behaviours that are demonstrated, and "the collective activities of organizational members [that] cohere into a system of shared meaning" (Jurkiewicz and Giacalone 3).

Certain aspects of an organization's culture are more likely to contribute to ethical dysfunction than others such as: a reward system that rewards unethical behaviour, for example pressuring for goal attainment while communicating a lack of concern for how this is done; an orientation towards profit that advantages the few over the many, for example, preferential salary increases, quid pro quo consulting opportunities; undue personal influence in the execution of contracts, kickbacks, or using organizational powers to procure personal influence through proffering favors; accountability programs without consistent consequences for leaders who do not equitably reinforce ethical standards and a code of ethics that is not backed up by ongoing ethics education at all levels of the organization and clear negative consequences for violations that are consistently enforced (4).

Regarding leadership, leaders have a powerful influence on the culture of an organization (1-12). This is transmitted for example through their behaviours which demonstrate what is important and what is not, how they respond to crises, what they reward and punish and who they hire and fire (4). Some findings regarding leadership dysfunction are: individuals will go to extremes to present themselves as ethical despite acting in direct opposition to their ethical claims; most people given opportunity, will act unethically termed "pervasive dishonesty of ordinary people"; individuals do not usually think rationally about ethical issues and do not recognize their own biases; and 
individuals engage in moral disengagement to justify unethical behaviour to themselves and reframe it as morally acceptable (Jurkiewicz \& Giacalone 5). Those most likely to engage in moral disengagement have four personality characteristics: Lack of moral identity, low empathy, a chance/external locus of control orientation and trait cynicism (5). Further, a "leaders' lack of ethicality is enhanced when the quality of service provided for which they are responsible is not immediately discernible" (Jurkiewicz and Giacalone 5). When outcomes become evident in the longer-term, leaders are not so concerned with doing the right thing in the moment. This ability to detach themselves from the consequences of their behaviour is learned over time and is a learned tactic for survival and success in an organization. Behaviours that contribute to ethical dysfunctionality are those that see leaders deflect the responsibility for ethical violations onto the system and reject strict definitions of right and wrong (5). These factors would likely decrease the likelihood of positive outcomes for whistleblowing and whistleblowers.

\section{Reprisals and Normalized Deviance}

Vaughan's ideas are useful in examining cultural and structural factors that could motivate unlawful behaviour in a government context as well as in the private sector. They also help explain how ethical dysfunctionality can become embedded in a culture and why organizational members remain silent. Her theories were gleaned from two case studies - the Challenger disaster and her exhaustive study of a fraud against the Ohio Department of Public Welfare perpetrated by the Revco Drug Store chain. ${ }^{11}$ Vaughan proposes that her work presents the relationship between certain cultural and structural

\footnotetext{
11 Revco is a large, complex organization with 159 drug stores in Ohio alone and 825 drug stores throughout 21 states in the United States (Controlling 5).
} 
factors and unlawful behaviour as a general model and is applicable to public organizations as well (Controlling 63). She theorizes that organizational misconduct is systematically produced by the external environment or social structure - the stable characteristics in the society in which the organization exists and conducts business, and the internal environment - or the stable characteristics of the organizations themselves (Controlling 54). Factors facilitating this process are "competition, economic success as a culturally approved goal, and erosion of norms supporting legitimate procedures for achieving it" (Controlling 54-66).

Some of the external and internal environmental factors she proposes are associated with misconduct in organizations involve competitive pressures and resource scarcity, organizational characteristics, regulatory ineffectiveness, and culture. These environmental factors facilitate the development of an organizational culture that includes the normalization of deviance, as well as, a culture of production and structural secrecy (Challenger 17-34, 119- 95, 196-237, 238- 77). It is my contention that the interplay of some of these factors can be demonstrated in the case under consideration and bolsters the 'wrongdoers' belief that they are doing nothing wrong. They thus deserve no penalty, but rather the problem is due to the intransigence of the whistle blower whose exposures would ruin their careers and the reputation of the organization.

\section{Reprisals and Organizational Learning}

Near and Miceli proposed that learning organizations were less rigid and would likely be more conducive to whistleblowing, and less conducive to reprisals (Wrongdoing 277). This is a reference to the work of Argyris and Schon on organizational learning and helps elucidate what happens in organizations that are governed by defensive 
reasoning in the face of error and criticism which can lead to dysfunctional ethical climates and reprisals for whistleblowers

According to Argyris and Schon, learning in organizations is about the detection and correction of error. They describe the following concepts as important in understanding this process: (1) single-loop learning and double-loop learning, (2) espoused theories versus theories-in-use ("mental maps") and (3) organizational learning systems consisting of organizational structures/processes and the behavioural world of the organization.

These concepts are briefly described as follows: first, single loop learning is "instrumental learning that changes strategies of action or assumptions underlying strategies in ways that leave the values of a theory of action unchanged" (Argyris \& Schon 20). Double loop learning is "learning that results in a change in the values of theory-in-use, as well as in its strategies and assumptions" (Argyris \& Schon 21). Some cases require inquiry through which organizational values and norms themselves are modified to correct error. For individuals or organizations to address the desirability of the values and norms that govern their theories-in-use, they must engage in double-loop learning. Double-loop learning in organizational inquiry explores not only the objective facts surrounding an instance of inefficiency, error, or criticism but also the reasoning and motivations that gave rise to them (22-7). This is the kind of inquiry and learning that should allow for whistleblowing to take place effectively without fear of reprisal, as presumably their concerns would be honestly and openly dealt with.

Second, the factors they regard as most critical to the successful achievement and maintenance of higher-level (double-loop) learning are: "the behavioural world of the 
organizations and the theories-in use of individuals that reinforce and are reinforced by it" (xix $-\mathrm{xx})$ which is another way of describing a culture. Moreover, Argyris and Schon emphasize the importance of "recognizing, surfacing, criticizing, and restructuring organizational theories of action or closely related term "mental models" (xix). They postulate that people have "mental maps" which underlie how they act in situations and involve the way they plan, implement and review their actions and further, these maps are what guide actions rather than the theories they espouse (xix). This "action theory" consists of two contrasting theories - those that are implicit in what practitioners do or theories- in- use, and those which they say they use to speak of their actions to others, or espoused theory. This distinction allows one to consider whether behaviour fits espoused theory or is there congruence between theory-in-use and espoused theory and further, developing congruence between theory-in-use and espoused theory is necessary to effectiveness (13-14). When an organization's culture is open to only single-loop learning and defensive responses to error or criticism and there is no congruence between theories-in-use and espoused theories (termed Model I theories-in-use) it is unlikely that whistleblowers and whistleblowing will do well. Conversely, when an organization's culture is open to double-loop or reflective, ongoing learning and actively seeks to ensure there is congruence between what they say they do and what they do (termed Model II theories - in - use), whistleblowing and whistleblowers, in theory, should flourish.

And finally, an organization's learning system is another important concept relevant to whistleblowing. It is made up of both organizational structures/processes and the organization's behavioural world (or culture) that either inhibits (O I Learning System) or facilitates (O II Learning System) organizational inquiry and learning. These 
two elements create the conditions that will make it likely that "crucial issues will be addressed or avoided, that dilemmas will be publicly surfaced or held private, and that sensitive assumptions will be publicly tested or protected" (28).

A learning system that facilitates addressing crucial issues, dilemmas and sensitive assumptions would make it less likely that a whistleblower would need to disclose wrongdoing externally as internal disclosures would be acceptable thus eliminating the need to go outside the organization. As well, more whistleblowing would likely take place as there would be less likelihood of reprisals if discussing problems or wrongdoing is considered acceptable. The learning system and the theories-in-use that individuals bring to its behavioural world are interdependent

Argyris and Schon point out that productive learning systems will not tend to become fixed and rigid because double-loop learning continually questions the status quo. They acknowledge that change will be difficult since the values of Model I theoriesin-use and O-I learning systems (which inhibit reflective/productive inquiry) are socially and culturally approved (112).

Seddon and O'Donovan in 2010 proposed, the reason we are not all working for learning organizations is that command and control management thinking still prevails and prevents productive learning (1-16). The theories of Argyris and Schon argue strongly for the importance of organizational structure and culture when examining the whistleblowing phenomenon. Culture, values and learning matter and shape whistleblowers and other organizational members' behaviour and feedback. See Table 2.6 for a summary of the governing characteristics and values of Model I (inhibiting) and Model II (facilitating) theories-in-use in an organizational learning system. 
Table 2.6: Governing Characteristics and Values of Model I and Model II - Theories in Use in an Organizational Learning System

\begin{tabular}{|c|c|}
\hline $\begin{array}{c}\text { Theories-in-Use - Model I } \\
\text { Characteristics inhibiting change in O I Learning } \\
\text { System (Single loop learning only) }\end{array}$ & $\begin{array}{l}\text { Theories-In-Use - Model II } \\
\text { Characteristics facilitating shift to O II Learning } \\
\text { System (Single and double loop learning flourish) }\end{array}$ \\
\hline $\begin{array}{l}\text { linked to defensive reasoning especially when } \\
\text { issues are embarrassing or threatening }\end{array}$ & $\begin{array}{l}\text { - linked to valid information, free and informed } \\
\text { choice and internal commitment }\end{array}$ \\
\hline $\begin{array}{l}\text { this sets up anti-learning consequences for double } \\
\text { loop learning called primary inhibitory loops } \\
\text { (inhibits face to face interactions). }\end{array}$ & $\begin{array}{l}\text { behavioural world shares power, task definition } \\
\text { and control, face saving actions resisted (defensive } \\
\text { and anti-learning). }\end{array}$ \\
\hline $\begin{array}{l}\text { - leads to defensive, dysfunctional responses } \\
\text { triggered and reinforced by "conditions for error" } \\
\text { such as: vagueness, ambiguity, untestability, } \\
\text { scattered information, information withheld, } \\
\text { undiscussability, uncertainty, } \\
\text { inconsistency/incompatibility. }\end{array}$ & $\begin{array}{l}\text { leads to lessening of competition to make } \\
\text { decisions for others, to one-up others, or to } \\
\text { outshine others for purposes of self-gratification. } \\
\text { Contributions of each member of group } \\
\text { maximized. }\end{array}$ \\
\hline $\begin{array}{l}\text { - further leads to anxiety, mistrust, uneasiness, and } \\
\text { increased interpersonal conflict. }\end{array}$ & $\begin{array}{l}\text { - processes and decisions open to scrutiny by those } \\
\text { expected to use them. }\end{array}$ \\
\hline $\begin{array}{l}\text { governing values are: unilateral goal setting and } \\
\text { actions, maximize winning and minimize losing, } \\
\text { minimize expressing negative feelings. }\end{array}$ & $\begin{array}{l}\text { evaluations and attributions are minimized unless } \\
\text { accompanied by usable data and the reasoning } \\
\text { behind them. }\end{array}$ \\
\hline $\begin{array}{l}\text { the above leads to secondary inhibitory loops } \\
\text { (inhibits interactions between groups) and } \\
\text { organizational defensive routines- to protect from } \\
\text { embarrassment and prevent identifying causes. }\end{array}$ & $\begin{array}{l}\text { - the above should lead to reduction in defensive } \\
\text { responses in individuals, within groups and among } \\
\text { groups, and an emphasis on double-loop learning. }\end{array}$ \\
\hline $\begin{array}{l}\text { four rules of defensive routines: (1) Craft } \\
\text { messages that contain inconsistencies; (2) act as if } \\
\text { messages not inconsistent; (3) make the ambiguity } \\
\text { \& inconsistency undiscussable. }\end{array}$ & $\begin{array}{l}\text { authors reason a change in individual theories-in- } \\
\text { use to Model II can lead to a change in } \\
\text { organizational theories-in use and help create O-II } \\
\text { learning systems and behavioural worlds. }\end{array}$ \\
\hline
\end{tabular}

Source: Adapted from: Argyris and Schon - Organizational Learning II - Theory, Method and Practice, (Addison - Wesley Publishing Company 1996).

In conclusion, Figure 2. 1 summarizes theories that are useful in gaining a better understanding of why reprisals against whistleblowers occur. The upper part depicts the external environment in which organizations exist which impacts misconduct. The lower part depicts what happens in the internal environment in organizations once whistleblowing occurs. 


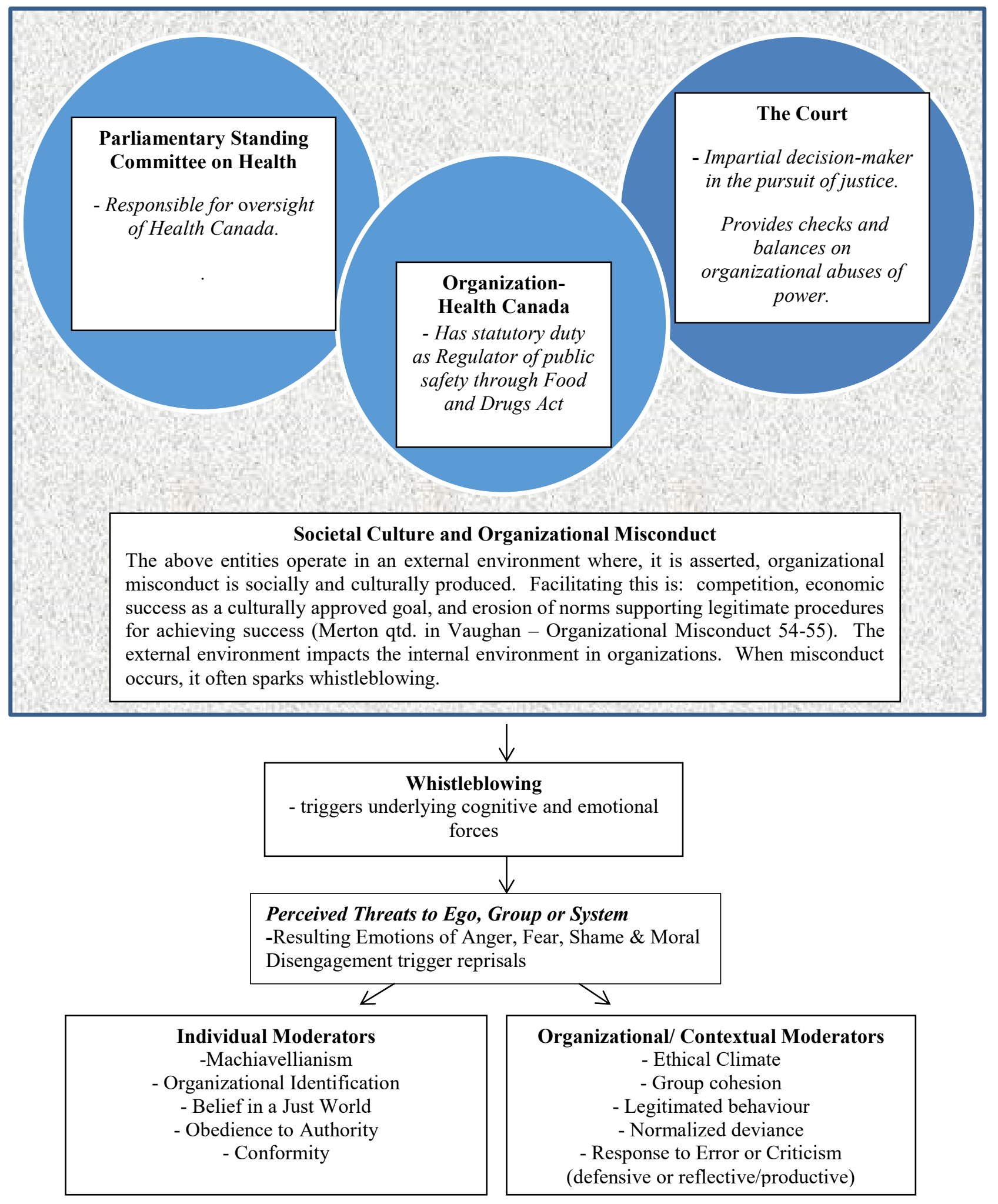

Figure 2.1 - Law, Culture and Reprisal - Understanding the Whistleblowing Reprisal Paradox in a Regulatory Agency in Canada

- Adapted from Sumanth, Mayer, Kay (2011), Milgram(2009), Asch (1955, 1961), Jurkiewicz \& Giacalone (2014), Vaughan (1983), Argyris \& Schon (1996). 


\subsection{The Problem of Reprisals}

Reprisals are problematic. As previously observed, reprisals are part of the reason why so many observers of wrongdoing remain silent thus enabling wrongdoing to continue at great costs to society. The solution to this problem was seen to be the institution of legislation to protect whistleblowers. It assumed that protecting them from reprisals would increase whistleblowing and presumably decrease reprisals (Miethe and Rothschild 337- 38). This strategy did not have the desired effect. The U.S. has a much longer history of whistleblower protection legislation than in Canada, dating as far back as the 1863 False Claims Act covering whistleblowers reporting fraud by contractors against the government. The modern legislation for federal employees began with the Civil Service Reform Act of 1978, and a large number of related laws. Some of these laws include the 1989 Whistleblower Protection Act, and the 1994 Whistleblower Protection Enhancement Act (Near and Miceli 264) covering federal public servants.

Numerous laws notwithstanding, recent testimony at a 2014 U.S. government committee hearing examining the Administration's treatment of whistleblowers, have described the situation as "alarming" (L. Lewis 1). ${ }^{12}$ It was reported there were record numbers of whistleblowers coming forward, and more whistleblowers received favorable findings attributed to the passage of the Whistleblower Protection Enhancement Act (WPEA) of 2012. However, government agencies were becoming more aggressive in their treatment of whistleblowers. Whereas before the WPEA, retaliation was in the form of suspensions, demotions, termination, etc., now the reprisals have gone up a notch to

12 The hearing was conducted by the U.S. Government Oversight and Reform Committee in Sept. 2014 and may be watched via video: https://oversight.house.gov/hearing/examining-administrations-treatmentwhistleblowers/ 
threats of criminal investigations and prosecutions if the Whistleblower doesn't

voluntarily resign (L. Lewis 1). The reason for the ongoing censure and reprisals despite legislation prohibiting this remains misunderstood.

To begin the process of clarifying the picture regarding reprisals in Canada, this section will first consider the question of loyalty, an aspect of both culture and the law that appears to affect whistleblowing situations in federal organizations in Canada. This is followed by a brief look at the Canadian whistleblower protection legislation with a view to identifying areas where the legislation might be improved to provide stronger protection.

\section{Reprisals, Loyalty and Law}

In line with this belief in the power of law to change cultures, many countries have enacted legislation to protect "public interest" whistleblowers from reprisals (Latimer and Brown 766). However, the power of culture to change laws has also been noted, as problems with the implementation of whistleblower protection legislation have been identified. It has been asserted that whistleblower laws must be seen in the context of culture. Latimer and Brown contend that these laws cannot work in a hostile environment. Further, "a precondition for whistleblower laws is the rule of law, including an independent legal system and an independent judiciary" (769). They propose that such legislation should "promote a culture where honest disclosures are respected, valued and even rewarded. A failure to support whistleblowers equates to the promotion of the protection of misconduct and wrongdoing" (768).

We know that reprisals continue and intensity is increasing, at least in the U.S. While there are no definitive explanations for this, several authors have made 
observations on the likelihood of and intensity with which reprisals are delivered and provide some insights into the power of structure and culture to influence behaviour in organizations. For example, organizations that employ thousands of workers are "organized hierarchically, and their leaders demand complete conformity and loyalty from their employees" (Glazer and Glazer 3).

The power of bureaucracies to shape people's consciousness in decisive ways is enormous as described by Jackall:

It regularizes people's experiences of time and indeed routinizes their lives by engaging them on a daily basis in rational, socially approved, purposive action; it brings them into daily proximity with and subordination to authority, creating in the process upward-looking stances that have decisive social and psychological consequences; it places a premium on a functionally rational, pragmatic habit of mind that seeks specific goals; and it creates subtle measures of prestige and an elaborate status hierarchy that in addition to fostering an intense competition for status also makes the rules, procedures, social contexts and protocol of an organization paramount psychological guides. (4)

Put more succinctly, a former Vice President of a large firm stated on the matter - "What is right in the corporation is what the guy above you wants from you. That's what morality is in the corporation" (Jackall 4). Whistleblowers, in effect, challenge this bureaucratic/corporate power, and in so doing face huge risks.

The issue of bureaucratic demands for complete conformity and loyalty raises important questions and points to the significant impact of culture in public organizations. Alford concludes from his work with whistleblowers and managers that 
"to run up against an organization is to risk obliteration" (4) and asks the rhetorical question "Could more terrible things in this world have been done under the banner of loyalty than any other?" (9). This raises the question - is loyalty necessarily a good thing? Or put another way, is it ethical to be loyal to an unethical organization?

The question of loyalty, a value and legal imperative in many organizations including Canada's Public Service, creates a tension in whistleblowing situations and is understood in different ways. For example, some believe that employees owe a duty of loyalty to their employers. However, they also believe this duty can be overridden by a greater duty to the public interest (Bowie 140- 43, Bok 3). Additionally, Duska argues that employees do not have an obligation to a company as companies are not properly objects of loyalty. Moreover, it would give them a moral status they do not deserve while at the same time lower the status of their employees. He notes a business exists to produce a good or service and to make a profit. Further, he proposes that loyalty depends on relationships that require self-sacrifice with no expectation of reward whereas business functions based on enlightened self-interest. Further, when it is profitable for either to do so, a company will release an employee, or an employee will leave the company (142-47).

Arguably, in contemporary society, Duska's thinking can be applied to government organizations as well. As has been observed, trends in public management have seen bureaucratic independence from the political executive gradually eroding and public managers becoming more like business - the entrepreneurs of a new, leaner, and increasingly privatized government that mirrors the values and practices of business (Sossin 33, Denhardt and Denhardt 549-59). 
The duty of loyalty is relevant for Canada's public servants as it is both a matter of contractual obligation and common law (Treasury Board 1). The problem and complexity with this duty is demonstrated by its paradoxical nature in that public servants must be impartial and non-partisan while at the same time remaining loyal to a legal entity (the Crown) whose powers are exercised by Ministers through the Cabinet, a political body (Public Service Commission (PSC) par. 5.18).

The Supreme Court of Canada's decision in Fraser v. Public Service Staff Relations Board (P.S.S.R.B), 1985, known as the Fraser case, is the leading case in Canada on the duty of loyalty. The decision qualifies the duty as follows:

As a general rule, federal public servants should be loyal to their employer, the Government of Canada. The loyalty owed is to the Government of Canada, not the political party in power at any one time. A public servant need not vote for the governing party. Nor need he or she publicly espouse its policies. And indeed, in some circumstances a public servant may actively and publicly express opposition to the policies of a government. This would be appropriate if, for example, the Government were engaged in illegal acts, or if its policies jeopardized the life, health or safety of the public servant or others, or if the public servant's criticism had no impact on his or her abilities to perform effectively the duties of a public servant or on the public perception of that ability. (Treasury Board 1) ${ }^{13}$

The judgement noted there may be other qualifications, thus inferring the above list was not meant to be exhaustive. The Courts have been inconsistent in interpreting and

\footnotetext{
${ }^{13}$ The Fraser case was sparked by the firing in 1982 of a Public Servant, Neil Fraser, for openly criticizing a decision of the Liberal government to change to the metric system of measurement in Canada (Treasury Board 1).
} 
applying this policy/precedent in whistleblower cases and the Treasury Board document characterizes the status of the duty of loyalty in Canadian courts as "a maturing concept" (1). In fact, others go further and state "Canadian courts have done little to protect whistleblowers" (Hoque 2). Further, Hoque believes with the Fraser decision "the Supreme Court of Canada endorsed a view that the interest in the actual and apparent impartiality of the public service justified an increased duty of loyalty on the part of public servants" (2). He asserts "[...] the actual quality of this protection as interpreted by the courts is questionable" (2). Prior to the 2007 PSDPA, this policy direction of the Court was the only protection for whistleblowers in Canada and the current legislation itself has received serious criticism.

The above discussion suggests it may be time to revisit the duty of loyalty in the workplace. Several authors have commented on this need and argued that whistle blowing is compatible with employee loyalty (Larmer 1992, Vandekerckhove 2004), and that the very existence of protective legislation reinforces the idea that whistleblowing should not be regarded as disloyal behaviour (Lewis, David 2011).

\section{The Law and Protection for Whistleblowers}

While it is clear from U.S. literature and existing Canadian literature that both law and culture play a role in the whistleblower's conflicted situation, what is not so well understood in the Canadian context is how and why censure and reprisal for the whistleblower occurs and is perpetuated.

The Canadian Federal government decided that whistleblowers should be protected, and introduced whistleblower protection legislation in 2005. It was implemented it in 2007. The history of this legislation, the Public Servants Disclosure 
Protection Act (PSDPA), along with its weaknesses, has been well documented in the literature (Saunders and Thibault 143-160, FAIR 1- 16, Gomery Commission of Inquiry 185-87, Fennessey 32-47, 48-70, Tweedie 57-88, Thomas 1-14). The Federal Accountability Initiative for Reform (FAIR) ${ }^{14}$ believes the legislation and this new quasi-judicial system was destined not to work: "It operates inside a bubble, shrouded in impenetrable secrecy, sealed off from our proper legal system, with layer upon layer of barriers and traps that ensnare whistleblowers, reject their cases and deny them due process" (17). They suggest that to be successful, the legislation must include five essentials they call "the gold standard" for judging any whistleblower legislation. These are

(a) full free speech rights;

(c) the Right to disclose all illegality and misconduct;

(d) no harassment of any kind;

(e) forum for adjudication, with realistic burden of proof and appropriate remedies; and

(f) mandatory corrective action.

Thomas identifies five broad factors that he sees as explaining the poor performance of Canada's disclosure regime: flawed legislation; structural complexity and implementation failure; uncommitted and ineffective leadership; political and administrative cultures which stressed control over information; and a lack of constructive scrutiny by Parliament (2). Further, he suggests that more important to the

\footnotetext{
${ }^{14}$ Federal Accountability Initiative for Reform (FAIR) is a non-profit Whistleblower organization supporting whistleblowers. http://fairwhistleblower.org/
} 
success or failure of the disclosure regime than detailed legislative provisions, structural arrangements and ongoing parliamentary scrutiny, are the impacts of leadership and the values and norms of behaviour in the overlapping political and administrative cultures of government. He points out that in the current context this culture has been "dominated by considerations of tight control over information and messaging about the performance of government" (2).

Several other researchers and observers have pointed out that in the eight years since its implementation, the PSDPA has fallen far short of its goal of protecting whistleblowers from reprisals and criticism abounds. In fact, the assertion that this legislation does not work has been empirically supported by Canadian researchers. For example, Fennessey's research, based on recent interviews with many Federal whistleblowers, supports her conclusion that legislation has not helped whistleblowers at all (87). She finds they are still seen and treated as troublemakers and some would argue the legislation has "only flamed the fire" (87- 8). She concludes that this has dire consequences for Federal accountability in Canada. In addition, Tweedie, using critical discourse analysis, argues that the PSDPA, the first bill in Canadian legislative history to offer federal government whistleblowers protection, is not about protection from retaliation or the elimination of wrongdoing. Rather it aims at controlling the context under which whistleblowing can occur. It is thus an instrument of oppression that suppresses rather than protects (iii, 81- 8). Notably, Judge Gomery of the Gomery Commission of Inquiry, recommended six amendments to improve the original PSDPA, only one of which made it into the final version of the Act. This change meant that 
private sector employees and the public have the right to make disclosures to the commissioner (Hurtubise-Loranger and Katz 4).

Christianne Ouimet was the first Federal Public Service Integrity Commissioner (PSIC). Her office was pivotal in the implementation of Canada's Public Servants Disclosure Protection Act (PSDPA), which came into force in 2007. Her early departure in October 2010 came just before the report of Canada's Auditor General was tabled in Parliament on December 9, 2010. The Auditor General reported in detail that the clear majority of over two hundred complaints received from public servants had not been investigated, the Commissioner engaged in inappropriate conduct towards her staff, the Commissioner engaged in retaliatory actions, and there was poor or lack of performance of mandated functions (pars 1-38).

Interestingly, the Federal Court of Canada decision by Mactavish, A. in El-Helou v. Courts Administration Service et al, 2011, ruled that under Mario Dion, the replacement PSIC, the Office of the Public-Sector Integrity Commissioner (OPSIC) failed in its duty, under the PSDPA, to ensure the right to procedural fairness and natural justice to the complainant. After three (3) years in office, Mario Dion resigned his post early. The Deputy Commissioner during his tenure, Joe Friday, replaced him in March 2015. There seems to be little hope in the whistleblower community that this appointment will bring about positive change (Cutler 2).

The above information indicates a pervasive negative influence of culture in the whistleblowing situation as it describes the behaviours of the powerful in the face of challenges questioning authorities regarding their actions, policies and decisions. In considering why legislation is not working and why reprisals are increasing, the law 
cannot be considered in a vacuum. As previously noted, a law's implementation can be negatively impacted if is introduced into a culture that is hostile as opposed to welcoming.

In summary, in this Chapter, the field of whistleblowing was discussed and examples of important whistleblowing cases in the U.S. and Canada were noted. The evolution of the research over the decades since whistleblowing became more prominent as a method for uncovering wrongdoing in the 1980's was reviewed. Theories of whistleblowing as they evolved over time were reviewed and a theoretical framework useful in explaining reprisals was identified. Finally, the problem of reprisals and the interconnectedness of law and culture in the whistleblowing situation was reviewed. Empirical findings in the Canadian context indicate culture plays an important role in how the implementation of the PSDPA to protect whistleblowers is implemented (Fennessey 32-47, 78-80, Hoque 2).

In the next Chapter, I discuss the methodology and methods I use to investigate the whistleblower reprisal paradox in a specific case study. 


\section{Chapter: Methodology and Methods}

\subsection{Methodology}

In this Chapter I describe my approach and the steps taken to gather, preserve and analyze the evidence regarding the case of whistleblowing and reprisal being investigated. As a researcher with a relativist orientation who believes there are multiple realities, I use a qualitative methodology and an interpretivist approach to better understand how and why the paradoxical behaviour of reprisals against many whistleblowers who expose wrong doing in organizations occurs and is perpetuated. A qualitative methodology is indicated and useful when the purpose of the research is to understand and interpret social interactions (Xavier 1) and to discover the meaning that people give to their experiences (Denzin \& Lincoln 17). The focus is as through a wideangle lens and examines the breadth and depth of phenomena in its natural/real-world context (Xavier 1). Denzin and Lincoln note that many qualitative researchers "stress the socially constructed nature of reality, the intimate relationship between the researcher and what is studied, and the situational constraints that shape inquiry. Such researchers emphasize the value-laden nature of inquiry. They seek answers to questions that stress how social experience is created and given meaning" (17). It is this kind of insight into the whistleblowing reprisal paradox that this research pursues. In qualitative research, subjectivity is expected whereas in quantitative research, objectivity is critical. Further, researcher and researcher's biases may be known to participants in the study, and participant characteristics may be known to the researcher (Xavier 1). 


\subsection{Methods}

In considering methodology the question of access posed challenges and restrictions on which methods could be used. A mixed-method approach such as a selfadministered survey of all employees at the main headquarters of Health Canada in Ottawa, along with a select number of interviews and document review would have allowed for useful data to be gathered. A survey would have been valuable to obtain numbers around such questions as how many employees had observed wrongdoing, how many had attempted to raise their concerns internally, was it considered acceptable to raise concerns openly, were there well-known channels for raising concerns, did the organization take the issues seriously, when concerns were raised were they investigated and acted upon, etc.? This would have provided some indication of the prevailing culture and whether raising critical issues was considered acceptable or not in the organization. However, the ability to conduct such a survey successfully would be contingent on the agreement of the Deputy Minister (DM), the number of employees who responded and fraught with practical difficulties. Even if the DM agreed, with one researcher working alone, dealing with the responses of many employees could be prohibitive. On the other hand, given the sensitive nature of the topic would a large enough number of employees respond to the survey to make it credible or even agree to be interviewed? Under these circumstances such access was deemed unlikely.

The US experience in the 1970's and 1980's relied almost entirely on case studies focused on what happened to the whistleblower. These were not in-depth as the "how" and "why" questions were not addressed. As observed by Near \& Miceli in 1985, there were two key problems in whistleblowing research at the time - "lack of a theoretical 
framework for interpreting the phenomenon, and lack of appropriate methods for observing the phenomenon" (Dissidence 13). The concern with case studies then was the problem of generalizability. Surveys also had inherent problems regarding respondents ability to recall past events, measures of their behaviour and its antecedents, and speculation as to their behaviours (Dissidence 13). In the intervening years, the thinking on case study research has evolved. There are many examples of important single case studies which have resulted in findings that were generalizable (Yin 42-44). ${ }^{15}$ Also, in addition to more acceptance for the possibility of generalizability from a single case study, some qualitative researchers have rejected the term generalizability as it is a term commonly accepted and more applicable to quantitative research. They propose a more appropriate term in qualitative research is transferability. From a qualitative perspective, transferability is primarily the responsibility of the one doing the generalizing. This person is also responsible for making the judgment of how sensible the transfer is. The likelihood of a positive judgement is enhanced when the researcher has done a thorough job in describing the context and the assumptions of the research (Trochim - Qualitative Validity).

Because of these considerations and others described below, I decided to use the methods of a single case study and process tracing to guide the search for an in-depth understanding of the whistleblowing paradox of reprisals. The methods I use are chosen as they are most useful in answering "how" and "why" questions particularly as there were no requirement for control of behavioural events as in an experiment. In addition,

\footnotetext{
${ }^{15}$ Examples of important single case studies that have resulted in generalizable findings are: Allison's case (1971) about the Cuban missile crisis; Whyte's study (1943/1993) which uncovered the relationship between individual performance and group structure; Vaughan's study (1996) on the loss of the Challenger and the sociology of a "mistake"; Warner \& Lunt's (1941) study on the origins of social class, and Jane Jacobs (1961) contribution to urban planning based on experiences from a single case - New York City elaborated in her famous book "The Death and Life of Great American Cities" (Yin 42-44).
} 
the focus is on relatively contemporary events i.e. where there are still participants that can be interviewed (Yin 9). The purpose is to describe, explain and explore to better understand how (description), and why (explanation) this paradox occurs and continues, and, to explore what might be the role of law and culture in the situation. Such information can provide insights into human and social processes that may inform pathways to correction of the paradox.

One rationale for choosing a single case design is that the phenomenon of reprisals against whistleblowers is a common one. The objective is to learn more about such common occurrences because of the lessons it might provide about social processes and the insights that might be gained about social relationships (Yin 52). A case study is an "empirical inquiry that investigates a contemporary phenomenon in depth and within its real-world context, especially when the boundaries between phenomenon and context may not be [clear]" (Yin 16). Whistleblowing and the reprisal paradox have existed for centuries and much has been written about it. However, not enough has been learned as the contradiction of reprisals continues unabated in contemporary society as has been noted by authors in both the US (Lewis, L. 1) and the UK (Wolfe, Worth and Dreyfus 3). Another reason for a single case is that the case can provide access to information that would not normally be easily available to a researcher i.e. official government documents and company documents. This was the circumstance in the selected case. The availability of information was due to the requirement to give evidence in court cases resulting from the whistleblowing as previously noted. The legal proceedings surrounding this case gave a rare opportunity for in-depth consider of the whistleblowing process. Access to the thinking and views of alleged wrongdoers logically would not 
normally be accessible to researchers because of the sensitivity involved. For example, it is highly unlikely a Deputy Minister would be open to answering a researchers' questions regarding why the information he/she provided to his/her Minister conflicted with official records in the Department, or why decisions were being made that appeared to favor the interests of companies over public safety, or why regulators in the Department did not appear to have followed-up on accumulating evidence - over more than a decade - of risks of harm to the public. In the selected case, the views of senior managers in the Department on many of the issues are on the public record and could be accessed by making a few trips to Toronto to search the Appeal Court records, as well as to the Federal Court and Superior Court offices to search records in Ottawa. Generally, lack of access to such information perhaps underlies why there is a scarcity of in-depth case studies in the whistleblowing field in Canada today.

Process tracing within the case study, is used in conducting an in-depth analysis of a single case. In process tracing, the case must include the effect/outcome under investigation - in this case the reprisals; the hypothesized cause - the whistleblowing; and the processes or events that link the hypothesized cause and the effect. The goal is to find out what happened in the "black box" (the causal mechanisms) between the effect (the reprisal) and the cause or intervention (the whistleblowing) or the how and why of the cause and the effect (Punton \& Wells 2). On a more practical level, since there is only one researcher involved, and because of the complexity of many whistleblower cases, it was determined that even though desirable, a multiple-case study design was not feasible at the time. 


\subsection{Case Selection}

Several possible cases were considered for inclusion in this research. I finally decided to conduct inquiries into one case - Health Canada and the drug approval process - for several reasons:

(a) This department has the social control capabilities of regulation and sanction of the drug manufacturing industry in Canada. The case involves the public resignation in 1996 of a senior human prescription drug regulator citing allegations of a flawed drug approval process. This involved conflict of interest and the privileging of the interests of pharmaceutical companies over those of the safety of the Canadian public. The seat of the Federal government is in Ottawa, and its actions and those of its departments, affect all Canadians in important ways.

(b) This case largely meets the criteria of ethicist Norman Bowie's ideal requirements of justifiable whistleblowing as follows:

i. that the act of whistleblowing stem from appropriate moral motives of preventing unnecessary harm to others;

ii. that the whistleblower use all available internal procedures for rectifying the problematic behaviour before public disclosure, although special circumstances may preclude this;

iii. that the whistleblower has some evidence that would convince a reasonable person;

iv. that the whistleblower perceives danger that can result from the violation;

v. that the whistleblower act in accordance with his or her responsibilities for "avoiding and/or exposing moral violations"; and 
vi. that the whistleblower's action has some reasonable chance of success.

(c) The details of the case and evidence needed to corroborate the information provided by interview of the key informant were all on the public record and might not otherwise have been available if a lawsuit had not been initiated by two of the protagonists. The documents were replete with real-life examples of how government actors, and the important sector of society they relate to, in this case pharmaceutical companies, interact rather than how they say they interact; what happens when an employee exposes actions, either internally or externally, that $\mathrm{s} /$ he believes are unethical or illegal and cause harm; what motivates the actors to behave the way they do, and what are possible explanations for their behaviours.

(d) The explanatory assertions of the theory/theoretical framework seemed reasonably applicable and indeed later did prove consistent with the experience and perceptions of the whistleblower substantiated in the official records.

I chose Health Canada and the drug approval process, as this was the case I was most familiar with. I had learned about the case in 1996. I was working in a Federal Department then and during my personal time, I was instrumental, along with others, in establishing a group to aid whistleblowers called "The Alliance for Public Accountability". Having worked in government - both in the bureaucracy and at the political level in a Ministers office as media, legislative and policy assistant respectively - and previously as a health care professional, I felt I could better comprehend the nuances in this case. 


\subsection{Research Design}

The data collection for this investigation took place in two phases. Phase I consisted of the document review. I did this first to determine if there was enough credible evidence available to substantiate or otherwise any information that might come from the main informant / whistleblower. The public record was rich in such evidence and so a decision was made to move ahead. Phase II consisted of the interview of the informant to gain insight into her real-life experiences and perceptions about the context, whistleblowing and its aftermath. Gathering information from multiple sources is an important part of research design as it allows for triangulating the evidence from these multiple sources to corroborate the findings (Yin 220). In other words, evidence from multiple sources that leads to or converges at the same point as the finding, supports it.

Other important components of research design are a case study's questions; theory and/or theoretical propositions; its unit/s of analysis; the logic linking the data to the theory; and the criteria for interpreting the findings (Yin 29).

\section{Research Questions}

The research questions are considered based on the whistleblower's experience:

(a) Why do whistleblowers decide to blow the whistle?

(b) How do reprisals against whistleblowers occur?

(c) Why do reprisals against whistleblowers occur?

(d) What is the role of law in reprisals?

(e) What is the role of culture in reprisals? 


\section{Theory}

The theory useful in understanding and explaining reprisals is based in organizational and social identity theory. This theory asserts first, that reprisals are triggered/will occur when threats are perceived to ego, group and system. The reprisals are moderated (more or less severe) by individual and organizational/contextual factors (Sumanth, Mayer \& Kay 165-84); and second, there are structural, cultural and leadership factors regarding how organizations function that predisposes an organization to either allow or prohibit unethical acts such as reprisals and other wrongdoing (Jurkiewicz \& Giacalone 1-3).

The theory useful in understanding how and why reprisals can occur with impunity is sociological, psychological and organizational theory. The key propositions are first, that organizational misconduct is socially and culturally produced and includes secrecy and the concept of normalized deviance (Vaughan, Challenger 119-125); second, members of groups generally obey authority whether right or wrong (Milgram 1-12) and conform to peer norms, again whether right or wrong (Asch, Opinions 31-35); and third, that an organization's learning system (structure and behavioural world/culture) is a powerful determinant of whether or not an error or criticism will be surfaced and/or corrected. A learning system governed by defensive reasoning rather than productive reasoning in response to error and criticism will make it more likely that crucial issues will be avoided rather than addressed, that dilemmas will be held private rather than publicly surfaced and that sensitive assumptions will be protected rather than publicly tested (Argyris and Schon 28-29). 


\section{Unit/s of analysis}

The organizations the whistleblower interacted with during the various events were Health Canada, the Parliamentary Standing Committee on Health and the Court in a subsequent defamation lawsuit. The main unit of analysis is Health Canada, the organization the whistleblower was employed in as the whistleblowing process unfolded. The Superior Court of Ontario and the Appeal Court of Ontario became involved because of the whistleblower's decision to resign and use the media as a channel to try to get the problem addressed. This resulted in defamation lawsuits against the $\mathrm{CBC}$. The Parliamentary Standing Committee on Health was involved because of the whistleblowers decision to resign because she could not get the problem addressed internally. The Standing Committee had oversight responsibility for Health Canada and extensive powers of investigation so Dr. Brill-Edwards raised the issue with the Standing Committee for its attention. The involvement of the Court and the Standing Committee were explored briefly as while these entities did not consider the reprisals per se, their involvement was a direct result of the act of whistleblowing in this case. Further, their involvement and the outcome seemed to suggest a clue as to why reprisals for whistleblowers in Federal organizations continue in general, despite legislation forbidding them.

The purpose of going to the Standing Committee was to get the wrongdoing that sparked the whistleblowing addressed. If the Standing Committee which is the mechanism that is supposed to ensure that the organization is functioning as it should, i.e. is not engaging in wrongdoing, dismisses a whistleblower with evidence of wrongdoing, then it would likely discourage whistleblowers from coming forward as they 
see that nothing will get done. This, in addition to reprisals, is one of the top reasons whistleblowers do not come forward (Near \& Miceli - Wrongdoing 278). Lack of oversight would likely encourage wrongdoers to keep on doing wrong- which includes reprisals against whistleblowers- as no one cares to even investigate them so there are no consequences. The same chilling effect would likely occur if Courts are perceived to deal harshly and/or unfairly with whistleblowers.

Identifying a unit of analysis is important as it helps define the case - what is it that is being studied - an individual, a group, an organization, a country, a program, a process, etc. Once this is done, consideration must be given to "bounding the case". For example, to define the estimated beginning and ending of the case, what time frame should the case include? This helps determine the scope of data collection and help in distinguishing between data about the subject of the study (the phenomenon) and data external to the case (the context). In the case, there were two phases to the whistleblowing: the first was internal whistleblowing and the second was external whistleblowing. The case encompasses the timeframe of 1981 to 2000 . The year 1981 is important as this is the date one of the drugs that led to the external whistleblowingnifedipine- was first approved and the facts in the approval documents are relevant to the case. The year 2000 is important, as this was the date of the decision of Cunningham, J.D. in Leenen v. $C B C$, a defamation lawsuit that took place as a result of a Fifth Estate documentary based on the disclosures of the whistleblower on Heath Canada's actions regarding drug safety issues. 


\section{Data Analysis: linking the data to the theory}

The way of linking data to the theory in this case is through a form of pattern matching called process-tracing. This involves a presumed set of "causal links" about the phenomenon or "how" and "why" something happened. There are three types of process tracing - theory- testing, theory- building, and explaining- outcome (or effect), each with a different approach (Punton \& Wells 2). According to Punton \& Wells who draw on Beach and Pedersen (2013):

1. theory- testing, is used when the cause or intervention (whistleblowing) and effect (reprisal) are known, we think the effect - at least in part - occurred because of the cause, and we think we know why the cause led to the effect/outcome, for example the theoretical propositions as described above.

2. theory- building, is used when either we know what the cause/intervention and the effect are and we think there is a causal link, or we know the effect but are not sure what caused it. We do not have a theory that explains why the cause/intervention (whistleblowing) led to the effect (reprisal).

3. explaining-outcome process tracing is used when we know there is an interesting outcome we want to investigate but do not know what caused it and want to fully explain why the outcome happened. (Punton \& Wells 2) Theory-testing and theory-building process tracing methods or analytic techniques are generally used when there is an interest in generalizability, (or as in this case, transferability) while explaining-outcome process tracing is often used to explain 
historical events such as the causes of a world war and explanations are applicable to the case under consideration only (2).

There are five steps in process tracing. They are: (1) developing a hypothesized causal mechanism; (2) operationalizing the causal mechanism; (3) collecting evidence; (4) assessing the inferential weight of evidence (four tests help here - "straw in the wind" tests, "hoop" tests, "smoking gun" and "doubly decisive" tests); and (5) conclusions of the process tracing exercise (Punton \& Wells 5-6). Under these definitions, this case study is largely one of theory-testing with a theory- building component. There are several theories that are relevant in the case of reprisals; however, the theory is insufficient as reprisals continue despite protective legislation in Canada and elsewhere. The theory-building component considers what might be perpetuating reprisals against whistleblowers in public organizations in Canada and there is no theory to explain this. This work raises the question of whether the mechanisms that exist to provide checks and balances on abuses of organizational power such as the courts and the Parliamentary Standing Committees are functioning as they should in whistleblower cases.

Further research should also be considered in the light of the current whistleblower legislation - the PSDPA. ${ }^{16}$ As it now stands, the Act ensures the continuation of the status quo as, in addition to its other weaknesses, under the Act whistleblowers are not permitted access to either the Courts or the Parliamentary Committees. Instead, they must submit to the decisions of the Public Service Integrity Commissioner, if s/he decides to handle the case, without further recourse (PSDPA).

\footnotetext{
${ }^{16}$ At the time of writing, Parliament is reviewing the PSDPA, five years after the time legislation required them to do so.
} 


\section{Criteria for interpreting the findings}

The findings in a case study not involving statistics can be considered more robust if rival explanations for the findings are identified and addressed (Yin 36). An example of such competing or opposing explanations in this case is the difference between Vaughan's theories regarding the loss of the Challenger and those of Sumanth, Mayer, and Kay and Jurkiewicz and Giacalone regarding ethical dysfunctionality. On the one hand Vaughan asserts that the organizational structures and forces that transformed deviance into acceptable behaviour were to blame for the disaster and not individuals. On the other hand, those of Sumanth, Mayer and Kay, and Jurkiewicz and Giacalone, allow for individual responsibility in the face of wrongdoing. The findings will be considered against this and other explanations such as a force larger than the whistleblowing accounts for the results (super rival), or social trends and not any force or intervention (social rival) account for the results (Yin 141).

\section{Judging the Quality of Research Design}

Commonly used tests to assess the quality of any empirical social research are construct validity, internal validity, external validity, and reliability (Yin 45). The tactics I use to ensure construct validity (identifying correct operational measures for the concepts being studied to offset possibility of "subjective" judgements) are: I use multiple sources of evidence (interview and document review to substantiate or otherwise the information uncovered), systematically compile evidence and have key informant and colleagues review draft case study report. To support internal validity (for explanatory or causal studies and not descriptive or exploratory): I do process-tracing and address rival explanations. To support external validity (defining the domain to which a study's 
findings can be generalized): I use theory. To support reliability (demonstrating that the operations of a study - such as the data collection procedures - can be repeated, with the same results): I develop a case study database, and develop a research instrument (subquestions to researcher as opposed to key informant) to guide data collection as described below.

To adequately address the overarching research questions regarding the whistleblowing paradox and facilitate the gathering of relevant data, the research instrument contains a series of sub-questions to myself to guide data collection and analysis. The first set of questions flow from the whistleblowing process:

(a) What did the whistleblower observe that she perceived as wrongdoing?

(b) What did she do because of these perceptions?

(c) What was the response of the organization to her concerns?

(d) Why did she decide to blow the whistle externally?

(e) What was the outcome?

The second set of questions is in line with Bowies criteria for justifiable whistleblowing as follows:

(a) Did the whistleblowers concerns' stem from moral motives of preventing harm to others and were her concerns about the safety of the drugs in question valid/validated?

(b) Did she take all possible efforts to correct the problem internally and/or were there special circumstances that precluded her from doing more?

(c) What was the evidence that would convince a reasonable person that there was wrongdoing? 
(d) What was the serious harm perceived by the whistleblower?

(e) What were the whistleblowers' professional responsibilities for avoiding and/or exposing moral violations?

(f) Did the whistleblowers' actions have any success?

Other relevant questions are, did the whistleblower suffer reprisals? And, finally, if apparent wrongdoing was demonstrated, did the wrongdoers experience consequences?

The third set of questions relates to the organizations the whistleblower interacted with i.e. Health Canada, and to a lesser extent the Court in the defamation lawsuit Leenen v. $C B C$, and the Standing Committee on Health. The questions I ask of each are: (a) Did the organization fulfill its role in accordance with its mandate? and (b) How would the answer impact whistleblowing and reprisals? While the focus is on Health Canada, the other two organizations are briefly considered. In the case of Health Canada, the questions relate to how it fulfilled its role as regulator of public safety by enforcing the Food and Drugs Act. In the case of the Court the question is regarding the role of the Judge and how that role was fulfilled with respect to his judgement of the whistleblower. I make no comment on his decision regarding defamation. ${ }^{17}$ In the case of the Standing Committee on Health the question is related to how it fulfilled its mandated role of oversight of Health Canada and its performance as regulator of public safety. If these oversight/accountability mechanisms are not functioning as they should, there are no checks and balances on abuses of organizational power in such cases and there is no incentive for organizations to correct wronging, including reprisals, as impunity reigns.

\footnotetext{
${ }^{17}$ The role of the Judge is to interpret the law, assess the evidence presented, and control how hearings and trials unfold. "Most important of all, judges are impartial decision-makers in the pursuit of justice" (Canadian Superior Court Judges Association).
} 


\section{Data Collection Process}

I began by gathering and analyzing evidence on the public record concerning a case of blowing the whistle on Health Canada's alleged flawed drug approval process. While some documentation was available on the internet, most of the information was garnered from official documents of the organizations involved largely obtained from court files i.e. the Federal Court of Canada, the Superior Court of Ontario and the Appeal Court of Ontario. The data was plentiful as there several court cases that flowed from the whistleblowing. One involved the Federal Court of Canada's review of the Public Service Labour Relations Tribunal decision ${ }^{18}$ and another involved the Superior Court of Ontario and the Ontario Court of Appeal because of defamation lawsuits regarding a documentary on the subject of the whistleblowing. ${ }^{19}$ This meant there was access to the views of senior members of Health Canada as presented to the court that would likely not otherwise have been available. See Appendix 1 for a listing of key documents and the source.

I subsequently interviewed the whistleblower/informant, Dr. Michele BrillEdwards, to provide context and obtain more information about her insights, opinions, explanations and meanings as she experienced the various events. The process consisted of observing/perceiving wrongdoing, deciding to raise it internally through official, internal channels, undergoing the response of her superiors in the organization and finally when she was unable to effect change, resigning so she could blow the whistle externally.

\footnotetext{
${ }^{18}$ Dr. Brill-Edwards along with a colleague - a Health Canada physician - had supported an application to the Public Service Labour Relations Tribunal by a Health Canada scientist regarding the improper appointment of a Director in the Bureau of Human Prescription Drugs where she herself worked.

${ }^{19}$ Two of the Doctors providing advice to Health Canada on the safety of a controversial drug were alleged to be in conflict of interest in a 1996 Fifth Estate documentary "The Heart of the Matter". They sued the Fifth Estate for defamation. The whistleblower was a witness for the Fifth Estate. She was not sued.
} 
This brought other reactions - such as a defamation lawsuit. The interview was unstructured, in-depth and consisted of two approximately two-hour interviews which were recorded and transcribed. The interviews were guided loosely by a set of questions attached at Appendix 2 and include dates and locations of interviews. Because of the document review and interview, I became aware that the Court case and the 1998 presentation to the Standing Committee on Health both occurred as a direct result of the whistleblowing and both played a role in how the whistleblowing process played out warranting some consideration. While it was necessary to limit this inquiry to the main organization, Health Canada (i.e. bound the case), a preliminary review indicated further inquiry is likely warranted about how whistleblowers fare in such forums as courts and standing committees. How they are dealt with could conceivably have an impact on whistleblowing and reprisals. For example, a perception that a whistleblower has been treated unfairly could likely discourage other whistleblowers from coming forward and encourage wrong doers to keep on doing wrong - including reprisals.

\section{Researcher Reflexivity and Avoiding Bias}

As previously mentioned, I chose Health Canada and the drug approval process, as this was the case I was most familiar with. I had learned about the case in 1996 while working in a Federal Department. During my personal time, I was instrumental, along with others, in establishing a group to provide assistance to whistleblowers called "The Alliance for Public Accountability". Having worked in government - both in the bureaucracy and at the political level in a Ministers office as media, legislative and policy assistant respectively - and previously as a health care professional for many years, I felt I could better comprehend the nuances in this case. 
This local knowledge could be both a blessing and a curse as it places a greater burden on myself as researcher, to be alert to possible bias and to be fair, honest, rigorous and scrupulous in conducting the research, gathering the evidence/data, and analyzing and interpreting the data collected (Yin 76- 7). With regard to bias, I believe it is fair to disclose at the outset that due to my background in health care (Registered Nurse), and government (BA Political Science), I do have two particular beliefs that I must keep in mind to guard against bias: first, I do believe in the primacy in health care decisionmaking of the precautionary principle ${ }^{20}$ as articulated in the health field by the medical maxim of "first do no harm", and second, as a former public servant and political advisor, I believe in open, accountable, democratic organizations and government and the rule of law. To check against bias, I must be open to considering alternative explanations for my findings and demonstrating this openness by discussing them in my work.

\subsection{Limitation of the Study}

A limitation of the study is that it analyzes only one case- limiting generalizability. However, the lessons learned could be important in and of themselves not only for the case under study, but in situations where the findings could be transferable, especially to a similar context such as another public regulatory agency (Trochim). Yin asserts the case study should be thought of as an opportunity "to shed empirical light about some theoretical concepts or principles" (40) and could lead to analytic generalizations that could extend beyond the setting for the specific case. He

\footnotetext{
${ }^{20}$ The European Union describes the precautionary principle as a principle that enables rapid response in the face of a possible danger to human, animal or plant health, or to protect the environment. In particular, where scientific data do not permit a complete evaluation of the risk, recourse to this principle may, for example, be used to stop distribution or order withdrawal from the market of products likely to be hazardous" (Eur-Lex 1).
} 
further notes that the theory underlying the initial design "as empirically enhanced by your case study's findings, will have formed the groundwork for an analytic generalization. Alternatively, a new generalization may emerge from the case study's findings alone" (41). 


\section{Chapter: Results of Case Study - Whistleblowing in Health Canada's Drug Approval Process}

The purpose of this research was to examine censure and reprisals against whistleblowers, to better understand the dynamics involved so this contradiction can be corrected, and to encourage the exposure of wrongdoing and strengthen accountability in organizations and government. As such, the following research questions framed the study:

(a) Why do whistleblowers decide to blow the whistle?

(b) How do reprisals against whistleblowers occur?

(c) Why do reprisals against whistleblowers occur?

(d) What is the role of law?

(e) What is the role of culture?

In depth interviews were conducted and the main informant participating in this study described her perceptions and experiences as a whistleblower mainly in the federal regulatory agency - Health Canada. Her experience in the 1998 Parliamentary Standing Committee on Health and the Leenen v. $C B C$ defamation Court case were considered briefly in that they were a direct result of the whistleblowing. This chapter reports on the research findings based on analysis of the data obtained from semi-structured interviews of the participant and official documents from government and other organizations involved. These documents were obtained from court records of related court and tribunal proceedings.

\subsection{Overview of the Case}

The participant in this study was Michele Brill-Edwards, MD, FRCPC. The period 
examined by this study was 1981 to 2000. Dr. Brill-Edwards had worked in different capacities in the Bureau of Human Prescription Drugs (BHPD) between 1980 and 1996. She had joined the Bureau in 1980 as an MD reviewer of submissions from pharmaceutical companies. ${ }^{21}$ She returned to University in 1983 to gain additional training and expertise in her field. She completed her training in Pediatrics and Clinical Pharmacology at the University of Toronto's Hospital for Sick Children and in 1986 obtained her fellowship ${ }^{22}$ from the Royal College of Physicians and Surgeons of Canada (FRCPC) in Pediatrics and Clinical Pharmacology. She returned to her position in the Department in 1986, was given increasing responsibilities and in 1988 became Acting /Assistant Director - Medical in BHPD (pers. comm. Apr. 6, 2014). Previously it had been a requirement that the Director of BHPD be a licensed physician, however, this had changed with the appointment of a Director who was not a physician but a pharmacologist in late 1988. The Assistant Director - Medical position was created to carry out the duties of the position of Director that required a medical licence (Canadian Human Rights Tribunal (CHRT) 13-4). At that time, this was the senior medical post for prescription drug approvals with vested responsibility and authority regarding new drug submissions and notices of compliance to ensure regulatory and medical consistency.

In September 1990, the Director of BHPD left his position. In October 1990, another non-physician Director filled the position on an acting basis without competition. Dr. Brill-Edwards remained in the post of Assistant Director - Medical until it was abolished in April 1992. She then went back to her original position as a medical

${ }^{21}$ Reviewers assess new drug submissions to ensure they comply with the regulations for efficacy and safety. Their recommendations are then sent to the Director for final scrutiny and approval before issuing a Notice of Compliance i.e. approval for marketing (Brill-Edwards, pers. comm. April 6, 2014).

${ }^{22}$ A fellowship is the national standard for specialist medical expertise (Royal College of Physicians and Surgeons of Canada website). 
reviewer, a position she remained in until her January 1996 resignation so she could speak freely about troubling events she had witnessed (pers. comm. Apr. 6, 2014). The dates when key events occurred are depicted in Figure 4.1 to allow for a clearer understanding of the evolution of this complex case. Dr. Brill-Edwards related that it took approximately ten years from the time she started at Health Canada in 1980 before she realized there were influences in the Department arising both internally and externally which were pushing in a direction she believed was a threat to public safety. She was in a position in 1988 - as Assistant Director - Medical to observe more directly what was happening and had final responsibility and authority regarding medical decision-making. She related there were influences that were of concern: "These influences were pushing in the direction of abusing our duty to safeguard the public and in the direction of serving private interests, particularly political and corporate interests. So, it was that realization that first prompted me to speak out within the organization" (pers. comm. Apr. 6, 2014). ${ }^{23}$

She further related the first incident arose in 1991. Her warnings regarding wording in the labelling that did not describe adequately for MD's the conditions of use of a new drug, sumatriptan/Imitrex, were ignored. The information in the product monograph/labelling is important as this is the information that helps doctors safeguard patients they are treating. Dr. Brill-Edwards contended that the labelling was inadequate and imprecise (pers. comm. Apr. 6, 2014; CBC Heart 8).

${ }^{23}$ Dr. Brill-Edwards was referring here to deregulation. A Canadian government report to the Ministerial Task Force on Program Review described deregulation as "reduced economic regulation" or "the reduced control by government or its agencies of such critical factors as prices, conditions of entry and exit and other competitive or market-related issues" (16). The Study Team commented "Regulatory reform is all about freedom" and "Regulation is the removal of freedom [...]" (11). 


\begin{tabular}{|l|}
\hline Short acting \\
nifedipine \\
approved in \\
Canada for Angina \\
despite concerns \\
for harm with long \\
term use. \\
\hline
\end{tabular}

Imitrex approved for
marketing by non-
physician Director
against medical direction
of Asst. Dir.-Medical -
Dr. Brill-Edwards.

Asst. Dir.-Medical position

abolished same day as

Director who lacked

qualifications re-

appointed. Dr. Brill-

Edwards demoted.

Returned to reviewer

position.

Dr. Brill-Edwards. $4^{\text {th }}$ nifedipine

study indicating

harm becomes

public \& causes

international

controversy.

Expert Advisory

Committee to

BHPD met with

Bureaucrats on

Sept. $18^{\text {th }}$ to help

decide what to do. removal of Director

on agreement of

parties to a new

indicating

harm.

hiring process. Edwards challenge re-
appointment of Director

to PSC and Federal Crt.

on public safety

grounds.
S. Chopra and Dr. Brill-

Dr. Brill-Edwards is invited to present

to Standing

Committee on

Health and exposes

wrongdoing. She

made a total of

eight presentations

to House \& Senate

committees

between 1997 \&

2008.

New hiring process resulted in

re-appointment of unqualified

Director. Dr. Brill-Edwards

had also competed for the

position as had others.

$1^{\text {st }}$ nifedipine

study

indicating

harm.

others and submitted affidavit
Dr. Brill-Edwards agreed to join

supporting Federal Crt.

application to remove Director

found unqualified by Public

Service Commission Appeal Bd.
Challenges to re-

appointment dismissed.

S. Chopra \& Dr. Brill-

Edwards appeal decision

to Federal Appeal Crt.
Brill-Edwards resigned. Appears in CBC's Fifth

Estate documentary

on nifedipine

controversy.

Leenen \& Myers sue $\mathrm{CBC}$ for

defamation. Brill-

Edwards is witness for $\mathrm{CBC}$.
Judge in Leenen $\checkmark$ CBC case finds for plaintiff making legal history. BrillEdwards is censured by Crt. as "disgruntled", "disloyal",

"biased", etc.

\section{Figure 4.1: Timeline of Key Events in Evolution of Case of Whistleblowing and Health Canada's Drug Approval Process}


On Jan. 13, 1992, the Director who was not a physician, approved the final Product Monograph without the corrections, initiating the final stage approval process for Imitrex by senior managers at National Health and Welfare as it was then known (Regush 6; memo to Franklin from Brill-Edwards, Jan. 15, 1992).

As a physician, Dr. Brill-Edwards, Asst. Director Medical, was concerned as this new drug could have serious adverse cardiac effects that could be lethal. The Asst. Director Medical's job description stipulated her position was vested with "[. . .] overall functional authority for final decisions with respect to submissions, ministerials, notices of compliance and pre-clinical new drug submissions, to question medical aspects of the outcome of any submission, and to monitor medical decisions of divisions to ensure medical appropriateness and regulatory consistency between divisions" (2).

While her job description, on paper, gave her responsibility and authority for the final word on medical and regulatory decision-making in the BHPD, the practice was different and this was not enacted (Affidavit Brill-Edwards, Fed. Crt. File No. T-302691). The request to correct the deficiencies in the labelling was overruled by a Director who did not have the required knowledge of marketed drugs available for human use as described by the Public Service Commission (PSC) decision and the Federal Court (Federal Crt. File no. T-3026-91). ${ }^{24}$

Dr. Brill-Edwards was aware that other members of the Department also had concerns and were challenging the 1990 appointment of the non-physician Director under the rules of PSC. She had been approached earlier to support an application to the

${ }^{24}$ The decision of H. Barkley in Shiv Chopra's appeal against the appointment without competition found the Director did not have the "required knowledge of marketed drugs available for human use or the actual knowledge of existing programs and activities relating to the scientific and medical appraisal of drugs" (Federal Crt. File T-3026-91). 
Federal Court for the Director's removal based on the PSC's decision. She was finally spurred to do so by the Director's signing-off on a hurried Notice of Compliance for inadequately labelled Imitrex on Jan. 13, 1992. That same day, Dr. Brilll-Edwards prepared an affidavit to the Federal Court testifying to the Director's over-ruling of medical authority in the drug approval process in this and other drug decisions, jeopardizing public safety. Notably, on Jan. 16, 1992, Glaxo Pharmaceuticals announced that it would construct a $\$ 70$ million manufacturing facility in Canada, promising more jobs and research spending (Regush 6; Financial Times of Canada, Jan. 27, 1992).

The Federal Court, in Joyal, J., Chopra and Deputy Minister of Health and Welfare, Public Service Commission and Emmanuel Somers, Feb. 1992, ordered the Director's removal and there was agreement a new hiring process would be held (Court File No. T-3026-91). The Director was reappointed after a competition in April 1992 and the same day, Dr. Brill-Edwards position of Acting/Assistant Director-Medical was abolished. She was returned to her previous role as a Reviewer of new drug submissions - in effect a demotion. While the same Director was reappointed, she still lacked the same qualifications regarding knowledge of marketed drugs for human use as before. 4). Subsequent challenges to the reappointment by Dr. Brill-Edwards and Shiv Chopra, DVM, PhD, were dismissed by the PSC Appeal Board (1992) and the Federal Court in Gibson, F.E., 1993, Dr. Shiv Chopra and Dr. Michele Brill-Edwards and The Department of National Health and Welfare (CHRT 14, Federal Court file no. T-214392). These decisions were based on the determination that it was a management prerogative to decide on qualifications for employees. 
Dr. Brill-Edwards was concerned that the Director would be reappointed as she still lacked the required knowledge of marketed drugs available for human use. As there was now a lack of the necessary medical expertise at that level, in a Director or an Assistant Director, Dr. Brill-Edwards had entered the competition regardless of the strained relationship with the Department. This was necessary as the only way to challenge an appointment was if one was a competitor for the post (pers. comm. Apr. 6, 2014). Shiv Chopra and Dr. Brill-Edwards jointly appealed to the Federal Court of Appeal the Nov. 1993 decision of the Federal Court dismissing their challenge. ${ }^{25}$ Following her demotion in 1992 Dr. Brill-Edwards perceived she suffered further career damage. According to her account, she was deprived of a World Health Organization (WHO) appointment, passed over for conferences and training and treated like a "leper" by some colleagues both inside the organization and outside (pers. comm. April 6, 2014). In 1995, another problem arose. An international controversy was sparked when the New York Times (March 12, 1995) printed a story about the findings of medical researchers questioning the safety of calcium channel blockers, a classification of heart drugs which included short-acting nifedipine - already on the market for almost fifteen years. Nifedipine was approved for treating angina or heart pain - a symptom of coronary artery disease (CAD) but was also used "off-label" (i.e. a not approved use) by doctors for hypertension as well (Dear Doctor letter No. 44, 1-4). It had been approved in Canada in December 1981 despite written concerns by the Reviewers of the potential for harm with long-term use over 6 months (Reviewers Report Sept. 23, 1981, 27-28;

\footnotetext{
${ }^{25}$ The appeal was abandoned in 1996 after Dr. Brill-Edwards resignation as she no longer had a legal interest and thus could not continue.
} 
Reviewers Report Dec. 30, 1981, 28). Evidence of harm had been accumulating for almost fifteen years ${ }^{26}$ but regulators had not acted until the story broke in the media.

An Ad Hoc Expert Advisory Committee (EAC) of four outside medical specialists had been convened by managers in BHPD. They met with Health Canada managers on September 18, 1995 to help determine what regulatory action the regulators should take. The EAC had discussed over thirty times during the day long meeting there was no reason to keep short-acting nifedipine on the market due to the risk of harm. Also, it was decided it should not be used for coronary artery disease (CAD) for which it had been originally approved, or "off label" for hypertension, for which it was not approved. See Appendix C for a listing of locations of these remarks in the Minutes of the Ad Hoc EAC meeting. Despite this advice from the medical specialists on the Ad Hoc EAC, the Department chose to keep the acknowledged problematic drug on the market. The senior bureaucrats removed the sentence in the draft Dear Doctor warning letter from the Advisory Committee to the effect that the drug should not be used for coronary artery disease. This was the precise indication for which it had been approved (E-mail from K. Gruchalla to V. Krupa, Nov. 22, 1995; letter from Vincent Krupa to Dr. F. Leenen, Jan. 24, 1996). Instead the senior bureaucrats sent out a Dear Doctor letter to Canada's doctors indicating not to use it as first line treatment and to use it "with great caution if at all", therefore leaving the public potentially at risk (Dear Doctor letter No. 44, Jan. 23, 1996). This acknowledgement that the drug should no longer be used for its approved use under the Regulations could/should have triggered suspending the Notice of Compliance until an examination of new evidence demonstrated satisfactory safety (Section C.08.013, Regulations, Food and Drugs Act). They kept the drug on the market

\footnotetext{
${ }^{26}$ See Appendix 4 for a list of relevant studies showing potential for harm from as early as 1986 .
} 
in deference to "the regulatory environment", not to leave the Department open to "legal liability" and to ensure the drug manufacturers were "neither favoured nor disadvantaged unfairly” (Letter from Vincent Krupa to Dr. F. Leenen, Jan. 24, 1996). Dr. BrillEdwards, knowing that many doctors would not see this warning before more harm was done and more lives were lost felt she could no longer remain silent (pers. comm. April 6, 2014). ${ }^{27}$ She resigned in January 1996, one month before the CBC's Fifth Estate documentary on the controversy called "The Heart of the Matter" in which she was one of several physicians interviewed.

Within a few short weeks, broadcasting of the TV documentary was stopped by a defamation lawsuit brought against the $\mathrm{CBC}$ by two of the members of the EAC appointed by Health Canada. The decision of Cunningham, J.D. in Leenen v. CBC, 2000, found for the plaintiff and made one of the largest awards against the media in Canadian legal history (Lexpert). Further, the whistleblower, Dr. Brill-Edwards was judged to be a “disgruntled” (51), “chagrined” (56), “biased” (19), employee.

Following her resignation Dr. Brill-Edwards made eight presentations to Standing Committees of both the House of Commons and the Senate regarding her concerns for public safety and the direction of the Department. See Appendix 5 for a listing of presentations. Her presentation to the Standing Committee on Health in 1998 stands out as the Committee had invited her and at their request, she provided them with information and documentation that they were being misled by senior bureaucrats from the Department. This Committee has oversight responsibilities for Health Canada, and

\footnotetext{
${ }^{27}$ That changes to prescribing practices as a result of adverse news about CCB's occurred gradually with accumulating small impacts from educational interventions and lay media attention was noted in a study by concerned medical researchers published in The Lancet in 1998 (Maclure et al 943- 48). Another study on the same theme was done in 2005, some ten years after the 1995 controversy, because there were still "widespread concerns against prescribing short-acting nifedipine in the treatment of hypertension" (Furmaga et al 277-291).
} 
they had promised they would follow up (Standing Committee, Evidence, Mar. 26, 1998). As of today, this has not happened. Standing Committees' powers are extensive and are conferred by the Constitution Act, 1867 and the Parliament of Canada Act (Davidson 12). They have virtually unlimited powers to compel the attendance of witnesses and to order the production of documents, to require a witness to give testimony under oath and if untrue statements are made under oath, the witness would be subject to prosecution for perjury under the Criminal Code (Davidson 13). However, as noted by Diane Davidson, General Legal Counsel for the House of Commons, "The extensive powers which a parliamentary committee enjoys are not commonly understood and therefore, at times, not properly respected" (12). There is no record that any hearings took place to investigate or orders issued for production of documents or witnesses in this case.

\subsection{Study Findings}

The data was organized under the following themes flowing from the research questions:

Theme 1: What were the participant's perceptions and experiences that motivated her decision to blow the whistle?

Theme 2: What were the participant's perceptions and experiences of reprisals as she attempted to have the organization correct what she believed was wrongdoing?

Theme 3: What were the participant's perceptions and experiences regarding why she was unable to get the problems corrected and why the reprisals occurred?

Theme 4: What were the participant's perceptions and experience regarding the role of law in these events? 
Theme 5: What were the participant's perceptions and experience regarding the role of culture in these events?

The evidence from the document reviews supporting or otherwise these perceptions and experiences is included as each theme is discussed. A summary of the tracing of the internal whistleblowing process and the external whistleblowing process from initiating event to outcome is presented in Figure 4.2 and Figure 4.3 respectively.

\section{Theme 1: Why blow the whistle.}

The findings in this theme are presented in two main parts parts - the motivation of the whistleblower and perceptions and experiences of the organizational culture that led her to blow the whistle and the data and document review.

\section{Motivation of the whistleblower}

The motivation of the whistleblower to blow the whistle according to her account, was rooted in medical ethics, and her sense of duty to uphold the law when faced with what she perceived as wrongdoing. Her job description when she was appointed as Assistant Director Medical in 1988 gave her authority for the final word on medical issues/decision-making in the drug approval process. Her underlying motivation to act is best described in her own words:

[. . .] I have to say that to some extent I was already immunized against the notion of secrecy and allegiance to a system that may be undertaking wrongdoing in the sense that as a Doctor, at a young age you have been schooled that your primary duty is always to serve the health, and well-being of the patient. 
Figure 4.2 Process Tracing - Internal Whistleblowing from Event to Outcome

\begin{tabular}{|c|c|c|c|c|c|c|c|}
\hline $\begin{array}{c}\text { Whistleblower } \\
1991\end{array}$ & $\begin{array}{c}\text { Regulatory } \\
\text { Agency- } \\
\text { Health } \\
\text { Canada } \\
1991\end{array}$ & 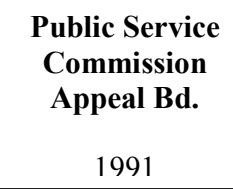 & $\begin{array}{c}\text { Whistleblower } \\
\text { and Colleague } \\
\text { Jan. } 1992\end{array}$ & $\begin{array}{c}\text { Federal Court } \\
\text { Feb. } 1992\end{array}$ & $\begin{array}{c}\text { Public } \\
\text { Service } \\
\text { Commission } \\
\text { Appeal Bd. } \\
\text { July } 1992\end{array}$ & $\begin{array}{c}\text { Federal Court } \\
\text { Aug. } 1992\end{array}$ & $\begin{array}{l}\text { Outcome } \\
1995-1996\end{array}$ \\
\hline $\begin{array}{l}\text { Perceived wrong- } \\
\text { doing- unsafe } \\
\text { labelling of Imitrex } \\
\text { and improper } \\
\text { appointment of } \\
\text { Director, BHPD } \\
\text { who lacked } \\
\text { requisite } \\
\text { qualifications. } \\
\text { Some believed this } \\
\text { appointment } \\
\text { facilitated } \\
\text { prioritizing of } \\
\text { industry needs over } \\
\text { public safety needs. } \\
\text { Raised issue } \\
\text { internally up to } \\
\text { DM. }\end{array}$ & $\begin{array}{l}\text { Responded. } \\
\text { Did not correct } \\
\text { perceived } \\
\text { wrongdoing. } \\
\text { Non-physician } \\
\text { Director } \\
\text { overruled } \\
\text { WB's medical } \\
\text { decision \& } \\
\text { authority. } \\
\text { Initiated } \\
\text { approval of } \\
\text { inadequately } \\
\text { labeled drug } \\
\text { Imitrex for } \\
\text { marketing. } \\
\\
\text { Another } \\
\text { Scientist } \\
\text { challenged } \\
\text { appointment }\end{array}$ & $\begin{array}{l}\text { PSC upheld } \\
\text { complaint. } \\
\text { Director found to } \\
\text { lack } \\
\text { qualifications for } \\
\text { the position } \\
\text { indicating } \\
\text { removal } \\
\text { warranted. } \\
\text { Health Canada } \\
\text { did not comply. }\end{array}$ & $\begin{array}{l}\text { Provided } \\
\text { affidavits to } \\
\text { support } \\
\text { complaint by } \\
\text { other Scientist to } \\
\text { Public Service } \\
\text { Commission. } \\
\text { Concerns for } \\
\text { public safety } \\
\text { expressed. } \\
\text { Scientist applied } \\
\text { to Federal Court } \\
\text { to gain } \\
\text { compliance of } \\
\text { Health Canada to } \\
\text { remove Director } \\
\text { found unqualified } \\
\text { by PSC. }\end{array}$ & $\begin{array}{l}\text { Ordered } \\
\text { removal of } \\
\text { Director and a } \\
\text { new, properly } \\
\text { conducted } \\
\text { hiring process } \\
\text { agreed to. } \\
\text { Same Director } \\
\text { reappointed still } \\
\text { lacking } \\
\text { requisite } \\
\text { qualifications. } \\
\text { A/Asst. Dir.- } \\
\text { Medical post } \\
\text { eliminated same } \\
\text { day as } \\
\text { reappointment. } \\
\text { Reappointment } \\
\text { challenged as } \\
\text { no medical } \\
\text { expertise }\end{array}$ & $\begin{array}{l}\text { PSC denied } \\
\text { application as } \\
\text { reappoint- } \\
\text { ment was } \\
\text { "management } \\
\text { prerogative". } \\
\text { Scientist and } \\
\text { WB applied } \\
\text { for Federal } \\
\text { Court Review } \\
\text { of decision. }\end{array}$ & $\begin{array}{l}\text { Federal Court } \\
\text { dismissed } \\
\text { application } \\
\text { and upheld } \\
\text { PSC's } \\
\text { "management } \\
\text { prerogative" } \\
\text { rationale. } \\
\text { Parties appeal } \\
\text { to Federal Crt. } \\
\text { of Appeal on } \\
\text { basis of public } \\
\text { safety } \\
\text { implications. } \\
\text { Appeal } \\
\text { abandoned as } \\
\text { WB resigned } \\
\text { and could not } \\
\text { continue. }\end{array}$ & $\begin{array}{l}\text { Nothing } \\
\text { improved. WB } \\
\text { unable to effect } \\
\text { change. } \\
\text { International } \\
\text { controversy } \\
\text { arose re: safety } \\
\text { of nifedipine- } \\
\text { heart drug on } \\
\text { market for } \\
\text { fifteen years. } \\
\text { More } \\
\text { questionable } \\
\text { decision- } \\
\text { making } \\
\text { occurred. } \\
\text { Outcome was } \\
\text { external } \\
\text { whistleblowing. } \\
\text { WB resigned to } \\
\text { speak openly. }\end{array}$ \\
\hline
\end{tabular}

Source: Adapted from Beach and Pederson (2013) as qtd. in "Applying Process Tracing in Five Steps" by Melanie Punton and Katharina Wells, Centre for Development Impact, Practice Paper Annex", 10 April 2015. 
Figure 4.3 Process Tracing - External Whistleblowing from Event to Outcome

\begin{tabular}{|c|c|c|c|c|c|}
\hline $\begin{array}{c}\text { Whistleblower \& } \\
\text { Fifth Estate } \\
\text {-External } \\
\text { Whistleblowing } \\
1996\end{array}$ & $\begin{array}{c}\text { Expert Advisory } \\
\text { Committee to } \\
\text { Health Canada } \\
1996\end{array}$ & $\begin{array}{c}\text { Health Canada } \\
\text { Senior Officials } \\
\text { DM, ADM, \& } \\
\text { DG } \\
1996\end{array}$ & $\begin{array}{c}\text { Judge's decision } \\
\text { in Ottawa } \\
\text { Defamation } \\
\text { Case } \\
2000\end{array}$ & $\begin{array}{c}\text { Parliamentary } \\
\text { Standing } \\
\text { Committee on } \\
\text { Health } \\
\text { 1997-2008 }\end{array}$ & Outcome \\
\hline $\begin{array}{l}\text { WB and other } \\
\text { concerned MD's in } \\
\text { medical community } \\
\text { exposed issue of } \\
\text { flawed drug approval } \\
\text { process and handling } \\
\text { of nifedipine } \\
\text { controversy in CBC } \\
\text { Fifth Estate } \\
\text { documentary. } \\
\text { Evidence pointed to } \\
\text { conflict of interest } \\
\text { and Health Canada } \\
\text { prioritized self- } \\
\text { interest over public- } \\
\text { interest. }\end{array}$ & $\begin{array}{l}\text { Two MD's - Ad } \\
\text { Hoc Expert } \\
\text { Advisory } \\
\text { Committee (EAC) } \\
\text { members- sue Fifth } \\
\text { Estate for } \\
\text { defamation. } \\
\text { This stopped } \\
\text { showing of } \\
\text { documentary } \\
\text { within days of first } \\
\text { broadcast. }\end{array}$ & $\begin{array}{l}\text { Gave Minister, } \\
\text { Parliament and } \\
\text { the Canadian } \\
\text { public incorrect } \\
\text { information } \\
\text { regarding the } \\
\text { facts around the } \\
\text { safety of the } \\
\text { controversial } \\
\text { drug-- } \\
\text { nifedipine. } \\
\text { Deputy Minister } \\
\text { eventually } \\
\text { moved on to } \\
\text { become } \\
\text { Chair of the } \\
\text { International } \\
\text { Committee on } \\
\text { Bioethics at } \\
\text { UNESCO. }\end{array}$ & $\begin{array}{l}\text { Found for Plaintiff } \\
\text { and awarded largest } \\
\text { amount for } \\
\text { defamation against } \\
\text { media in Canadian } \\
\text { History. } \\
\text { Overlooked key } \\
\text { information, four } \\
\text { precedents and } \\
\text { conflict of interest. } \\
\text { Dismissed WB } \\
\text { concerns. Called } \\
\text { WB "disgruntled", } \\
\text { "biased". Decision } \\
\text { did not make a } \\
\text { finding on the safety } \\
\text { of nifedipine } \\
\text { Plaintiff appointed } \\
\text { Research Chair } \\
\text { funded by Pfizer. }\end{array}$ & $\begin{array}{l}\text { WB made eight } \\
\text { presentations to } \\
\text { House and Senate } \\
\text { Committees. } \\
\text { Standing } \\
\text { Committee on } \\
\text { Health } 1998 \text { invited } \\
\text { WB to present and } \\
\text { subsequently } \\
\text { requested more } \\
\text { information on an } \\
\text { urgent basis. } \\
\text { There is no } \\
\text { evidence that any } \\
\text { open, public } \\
\text { investigation by this } \\
\text { oversight } \\
\text { committee on the } \\
\text { information } \\
\text { urgently provided } \\
\text { ever took place. }\end{array}$ & $\begin{array}{l}\text { WB lost career and } \\
\text { reputation impugned. } \\
\text { She was unable to } \\
\text { work in Ottawa for } \\
\text { four years. Family } \\
\text { suffered. } \\
\text { Government and } \\
\text { Pharmaceutical } \\
\text { industry prevailed. } \\
\text { Deregulation in full } \\
\text { force - industry } \\
\text { becomes client, risk to } \\
\text { public increased, and } \\
\text { death rate from adverse } \\
\text { reactions continued } \\
\text { unabated (documented } \\
\text { in Academic Journals). } \\
\text { Resulting ground- } \\
\text { breaking medical } \\
\text { research changed } \\
\text { approach to conflict of } \\
\text { interest }\end{array}$ \\
\hline
\end{tabular}

Source: Adapted from Beach and Pederson (2013) as qtd. in "Applying Process Tracing in Five Steps" by Melanie Punton and Katharina Wells, Centre for Development Impact, Practice Paper Annex”, 10 April 2015. 
Other professional groups have similar schooling - i.e. professional engineers, who from the outset have a responsibility to never accept designs that may be inherently unsafe. So I think that people who are loyal to their own professional ethics to some extent are better off when they are faced with these circumstances. Not that that's true of everybody. There are lots of people who saw their duty and had no professional background. It was implicit in their nature that they speak out in public. On the other hand, there were professionals who would gladly set that aside if it were to help them career wise $[\ldots]$ (pers. comm. April 8, 2014)

\section{Perceptions and experiences of the organizational culture}

Dr. Brill-Edwards describes her perceptions and experience of the organizational culture as follows:

There were these factions that I'm roughly breaking into people who knew their duty and wanted to do their duty and those who didn't know their duty and didn't want to do it even if they did. At that time, the branch we worked in was called the Health Protection Branch. But internally the black humor was that we called ourselves the "Self Protection Branch". And a further joke was the "Wealth Protection Branch." So these things mean that as people could see that decisions were being taken that weren't protecting the public at all, we would let things go that we should jump in and stop. We would allow things at meetings that we knew shouldn't be allowed. So it was evident that as far as the hierarchy was concerned - the Minister, the Deputy 
Minister and the ADM - as long as they could fool the public into thinking that these decisions were appropriate and that no one had done anything wrong, they were home free, hence the "Self Protection Branch". Just make sure this lapse in our duty isn't visible to the public. (pers. comm. Apr. 8, 2014).

[...] For myself, when we won the Federal Court challenge [to the improper appointment of the non-medical director of BHPD] I expected there would be a knock at my door, or a quiet phone call "Michele, what prompted all this? It's clear you've never harmed the department. It's clear you have stood on your head doing your job. How did it come to the point where you had to go to court to get it through to us what was going on?" The call never came. That knock never happened. The conversation never took place. Instead there was an institutional response to bring the Deputy Minister (DM) to a meeting with the entire Bureau to try to quell the unrest because when we won that court case, the entire staff -100 odd of us - knew what it meant. What we had shown was that our bosses are trying so hard to parachute unqualified people in to boss us around to get us to do stuff we shouldn't be doing, that we had to go to the Federal Court to stop this. That's pretty serious. So the department, rather than saying "Oh my God, how did this happen?" they just wanted to shut it down. It was like "Get over there Deputy and make sure these people understand that they have to come to heel or there is going to be trouble." That was the atmosphere of the meeting. And I remember at one point the Deputy asked why we would not trust the 
Director General to keep a commitment that things would be different and I answered "Because he has already lied under oath at court." And there was a round of applause. Everybody applauded because that was indeed what happened. That wasn't just me making that up. We could point them to the evidence that he went to the preliminary hearings and lied. This was the motion before the Federal Court to remove the Director. There was definitely an attitude of rebellion and it took a long time before that settled down. (pers. comm. April 8, 2014)

On the effect of deregulation on culture she said:

What deregulation did - the effect of deregulation - was to pit allegiance to the law that protects Canadians, against allegiance to the hierarchy. So you have people who have spent their careers in protecting the public and working to that end, who know the law inside out and they know their duty, and all they want is to allowed to come to work every day and do their work properly. They are pitted against people who have not only no medical knowledge, no scientific knowledge, no legal knowledge of the Food \&Drugs Act, no understanding of how it is implemented or the historical precedents we have to go on- not only do they not know that- they don't want to know. It's like "I don't care that this is the law. I have been put in place by this hierarchy that doesn't believe in regulation that wants to get rid of regulation and wants to please the Minister and cabinet who want to please the industry that we are supposed to regulate. So forget it. We are 
not going to do this regulatory task. We are going to do what the boss

wants. (pers. comm. April 8, 2014)

\section{Data and Document Review}

\section{Motivation of the Whistleblower and Organizational Culture}

It is hard to prove people's motivations for what they do, however, motivations can be inferred by considering behaviour and the evidence. The documents show that Dr. Brill-Edwards career aspirations were diverted. She was offered a position by the World Health Organization which she did not and/or could not accept. Acceptance would have required "release" i.e. leave of absence by the Department. Dr. Brill-Edwards asserts she was not released by the Department as she claimed to have refused to sign a document to the effect that she would keep silent about what she learned during her duties, and would not be involved in any legal actions against the Department. This she states she would not agree to. There is nothing in writing that confirms what was said, however, Dr. BrillEdwards was involved in legal action against the Department at the Federal Court Level in 1991-1992. She was supporting other colleagues who were challenging the appointment of a non-physician Director of BHPD who had made unsafe decisions regarding drugs (Federal Court file no. T-3026-91). There was another challenge in 1992 to the reappointment of this Director. By this time, she had previously been found by PSC and the court to lack the basic knowledge and qualifications for the job (Federal Court file no. T-2143-92). This was still the case, so an appeal of the Federal Court Justice J.E. Gibson decision to dismiss the challenge to the reappointment was launched (Federal Appeal Court file no. A-729-93). The major grounds for the challenges cited in the records were issues of public safety. Dr. Brill-Edwards was not arguing she was 
upset because her job was eliminated per se, but rather that she was concerned that there was no longer medical expertise in the Director's office. This view was supported by nineteen other MD's in the Bureau (Memo from Physicians of Bureau to Director Messier Apr. 27, 1992). This was the threat to public safety she perceived which motivated her to act. Further, Dr. Brill-Edwards continued to try to have her concerns about public safety addressed for many years after she resigned. She made eight presentations to the Senate and Parliamentary Committees including the Standing Committee on Health. (See Appendix 5 for a listing of these presentations). Her stated goals in each presentation were

(a) to protect Canadians from health hazard and save lives by ending the secrecy regarding the life and death decisions that Health Canada was making.

(b) to spark an open public investigation of a drug approval process where the regulator has become enmeshed with the industry it was supposed to regulate rendering it ineffective.

(c) to advocate for the creation of a Drug Safety Board to rapidly investigate and independently investigate "drug crashes" and correct the errors causing them.

The documents suggested there were problems in the organizations culture which could interfere with its ability to carry out its mandate as regulator of public safety effectively. The key documents pointing to this are

(a) the minutes of the Ad Hoc EAC meeting of Sept. 18, 1995 suggesting regulators ignored the clear advice of the experts they had called in to advise them and who advised removal of the unsafe drug nifedipine from the market. Instead the departmental officials left the public at risk by not doing so. 
(b) the letter from the Chief of the Cardiovascular Division pointing to the motivations for not removing the drug nifedipine from the market as discussed. These motivations were "to better reflect our regulatory environment" and "not to leave the Health Department open to legal challenges" and to make sure those manufacturers "are neither favoured nor disadvantaged unfairly" (Krupa, letter to H. Leenen Jan. 24, 1996).

(c) the letters from the Deputy Minister and her senior officials to the Minister on the nifedipine controversy with conflicting information on nifedipine (Jean,M., Foster, K., Michols, D., letter to Minister Feb. 29, 1996 ) and repeating incorrect information on conflict of interest and nifedipine (Jean, M. letter to Minister March 19,1996). The correct information was contained in the minutes of the Sept. 18, 1995 EAC meeting. This different information had the effect of pointing to doctors' use of the drug for unapproved "off label" uses i.e. hypertension, as the cause of the controversy and deflecting attention from the approved use for coronary artery disease. In fact, the approved use was also a problem for which the Department was responsible and accountable as they had approved it in 1981 under the Food and Drugs Act (Reviewer's report Dec. 1981).

(d) the Information Letter No. 810, April 12, 1994 - a directive regarding committees and conflict of interest which was in place at the time but was not supplied to the Minister by the Deputy Minister when he asked questions and not applied by the officials to the EAC. It was a directive (as opposed to a "guideline") specifying the processes to be followed in establishing expert 
advisory committees and in dealing with the administration and functioning of the committees. Section 5 provided detailed instructions on how to handle Conflict of Interest and required full disclosure before appointment to any committee (4).

(e) the Department's internal Human Recourses study done at the time to address the changes and uncertainty in staffing. It recommended the establishment of a Council and an ongoing consultative process "to resolve conflicts between the demands of professional accountability and public service regulations or requirements" considered necessary "to avoid any adverse consequences of politically based scientific or health decisions or policy" (4). Such a committee was not established.

(f) the letter to Dr. Messier, interim Director of BHPD, April 27, 1992, from nineteen MD's in the Bureau on the subject of "Lack of Medical Representation at Junior or senior managerial levels in BHPD.”

Challenges to the ability of Health Canada to carry out its mandate were noted by others. Regarding deregulation and the shifting priorities at Health Canada in the 1990s, Wiktorowicz proposed:

[...] realignment of the Health Protection Branch's (HPB) roles and responsibilities may be characterized as leading to a shift from a comprehensive approach to public health protection to one based on strategic risk management, with responsibilities dispersed among government, industry, academia, and consumers. The rebalancing of goals in the redesign of the regulatory process suggests a change in the role of the state in the context of public-health protection 
and highlights issues of concern to the public interest that may not be fully recognized as deregulation occurs in other sectors of the economy" (1-22).

\section{Theme 2: How reprisals occur.}

The findings in this theme are presented in four parts corresponding to the parts of the whistleblowing process described by Near and Miceli (Dissidence 4-6) and from which reprisals often emerge:

(a) What was the observed incident/s perceived as wrongdoing?

(b) What were the actions of the participant to try to address the problem?

(c) What was the response of the organization?

(d) What was the outcome? (Near and Miceli, Dissidence 4-6).

There were two observed incidents perceived as wrongdoing. The first resulted in internal whistleblowing, and the second in external whistleblowing. To facilitate a clearer understanding, the findings in each incident will be described separately. The focus of this paper is on the organization. However, unforeseen events occurred after the external whistleblowing took place as a direct result of the act of whistleblowing - two defamation lawsuits, and a requested presentation to the Parliamentary Standing Committee on Health. Both these events will be addressed briefly under Theme $4-$ the role of law.

\section{The first observed critical event - Imitrex}

Dr. Brill-Edwards related that the Director of the Bureau of Human Prescription Drugs (BHPD) who was not a physician, signed-off on approval for marketing (a Notice of compliance) for a new drug for migraine headaches called sumatriptan or Imitrex in 
January 1992, contrary to her advice. Her role and duty in her position as Acting/Asst. Director-Medical- was to provide the medical expertise needed to make evaluations and decisions about new drug submissions. She was worried about the cardiac side effect on the heart such as vasospasm which could be lethal and thus wanted to make sure doctors were aware of this potential by ensuring it was adequately described in the labelling in accordance with the regulations. However, in the rush to get the drug to market the information was not adequately described leaving the public and doctors at risk (pers. comm. April 6, 2014).

\section{Actions taken to address the first observed critical event - Imitrex}

Dr. Brill-Edwards described her perceptions and experience in raising the Imitrex issue internally and trying to get the problem addressed as follows:

When I intervened in the matter, I thought it would be pretty straight forward, as part of the Food and Drugs Act provides that if anything is known about a drug, that information has to be included in what is called the Product Monograph- that is the labelling that allows MD's to know how to manage the drug. What happened when I intervened to say to the unit responsible, "I would like you to take another look at this", I was met with a brick wall. The non-medical director to whom I reported insisted that this drug was going to market and I was aghast because the matter was so straight forward. This was not debatable. The data were very clear that this drug had the capacity to kill people by its cardiac side effects and that cardiac side effects had not been properly described in the monograph. 
What later came to light was that the political forces were being pushed by trade agreements to get this drug through in a hurry.

My objections were properly registered within the Department. I met in the usual manner, quietly in a very ordinary business meeting with the Director and the Head of the unit responsible, neither of whom were medical people. I tried to explain the medical impact of this drug going to market without proper description even to the point of having to explain to them what a "dose response curve" was. ${ }^{28}$ This tells you the ridiculously low level of understanding of the people who were making the decisions. At any rate that was not met with much success, so I wrote a memo to the Director in very clear language, courteously, but clearly explaining the dangers that this decision was creating for the doctors and patients who would be using this drug [...].. [...]That was ignored and a few days later I was informed that the drug had received a Notice of Compliance (NOC) which is the technical term for being approved to go to market in Canada. (pers. comm. April 6, 2014)

The US Food and Drug Administration (FDA) was going through its approval process at the same time in January 1992. Dr. Brill-Edwards relayed to them her concerns about the risks for actions on the heart that could be lethal, informing them of

\footnotetext{
${ }^{28}$ A dose response curve refers to the relationship between some effect-i.e. lowering of blood pressureand the amount of a drug. These mathematical relationships signify that a medicine is working according to a specific interaction between different molecules in the body. (Guzman 2017).
} 
relevant studies and the importance of this information being in the labelling. She further explained the FDA process:

The expectation after the FDA has an Expert Advisory Committee, is that if the drug is given a green light it will go to market within a month or two. Instead [after I contacted them] they took a year to go through the salient features of the cardiac side effects and when they approved it, they had the language in [the Product Monograph] that clearly set forth the risks of the drug. So to me, that was very much an acknowledgement of the validity of my position. (pers. comm. Apr. 6, 2014)

The next step Dr. Brill-Edwards took was to join with others in challenging the appointment of the BHPD Director who had - in Dr. Brill-Edwards view- wrongfully approved Imitrex. This action resulted in a Federal Court order- Joyal, J. in Chopra and Dept. of National Health and Welfare 1992 - for the Department to remove the unqualified Director and conduct a new hiring process. The new hiring process resulted in the reappointment of the same Director Claire Franklin on an indeterminate basis (CHRT 16).

\section{Data and Document Review- Actions to Address Imitrex}

The data and document review suggest support for Dr. Brill-Edwards account of the problems with the approval of Imitrex. The relevant section of the Food and Drugs Act Regulations that represented the statutory duty of the Department, in effect states that no person shall sell or advertise for sale a new drug unless all the relevant information has been submitted and a Notice of Compliance issued. It then lists the information that shall be included in the information submitted such as detailed reports of the tests made 
to establish the safety of the new drug for the purpose and under the conditions of use recommended and a statement of all the representations to be made for the promotion of the new drug respecting among other things the contra-indications and side effects of the new drug (Food \& Drugs Act 1990 - Section C.08.002).

Nicholas Regush, an investigative journalist, ${ }^{29}$ gives a full description of and documents the issues and events regarding Imitrex (1-11). After reviewing the file herself, she became concerned about not only the drug's labelling but she noted that the dose was too large when a smaller dose would be enough for the majority of migraine patients and thus less potentially damaging to the heart (Regush 5-8). She wrote a memo to the then Acting Director, Claire Franklin describing the threats and pressures by Glaxo representatives to speed up approval and requesting that changes be made in the labelling/Product Monograph to remedy the deficiencies and include the potential dangers (Brill-Edwards memo to Claire Franklin, Jan. 7, 1992).

The missing clarifications of safety information pointed out by Dr. Brill-Edwards, the most senior medical regulator at the time with authority in medical-decision making, were ignored by bureaucrats who were not doctors. On Jan. 13, 1992, Imitrex was signed off for marketing by the non-physician Director Ms. Franklin and subsequently by senior managers at National Health and Welfare as it was then known (memo BrillEdwards to Franklin, Jan. 15, 1992; Regush 6). On Jan. 16, 1992, Glaxo announced that it would construct a $\$ 70$ million manufacturing facility in Canada, promising more jobs and research spending (Regush 6). Changes in the labelling for Imitrex by regulators in

\footnotetext{
${ }^{29}$ Nicholas Regush was an award-winning investigative journalist specializing in medical and science news. Prior to his death in 2004 he produced medical features for ABC News' World with Peter Jennings. $\mathrm{He}$ also did work for the CBC and was the producer of the CBC's Fifth Estate documentary "The Heart of the Matter".
} 
Canada and the UK to more adequately inform doctors and the public of the dangers were eventually instituted over the months and years that followed, but not before numerous deaths and harm had been reported and lawsuits instituted (Regush 5-11).

A review of the information in the first Imitrex Product Monograph approved by Health Canada in Jan. 1992 and contained in the Compendium of Pharmaceuticals and Specialties (CPS) demonstrates Dr. Brill-Edwards concerns regarding the description of cardiac side effects (CPS 1993). In contrast, first Product Monograph approved by the US Food and Drug Administration (FDA) in Dec. 1992 shows a clear description of cardiac side effects i.e. coronary vasospasm, arrhythmias, and potentially death (Pharma Intelligence - Pink Sheet 1993).

Regarding the first challenge to the Public Service Commission (PSC) of the acting appointment of the Director of BHPD and subsequently of the indeterminate reappointment, the records indicate that Barkley, Helen, in Chopra and the Department of National Health and Welfare, July 19, 1991, found the Director did not have the necessary qualifications for the position of Director (Federal Court file no. T-3026-91). The Director did not have the "required knowledge of marketed drugs available for human use or the actual knowledge of existing programs and activities relating to the scientific and medical appraisal of drugs" (Federal Crt. File T-3026-91). In overruling the decision of the public service management, she cited the case of the A.G. of Canada v. Appeal Board and concluded that "where the appropriate management officers consider it is in the best interests of the public service not to conduct a competition, an appeal board may not overrule that decision unless it is "so unreasonable that no reasonable person could form that opinion"' (CHRT 14). The second challenge to the 
indeterminate appointment was dismissed in 1993 (Federal Court file no. T 2143-92) and appealed in 1993 (Federal Court of Appeal A-729-93). The appeal was abandoned in 1996 after Dr. Brill-Edwards resignation as she was no longer an employee. The record of the Canadian Human Rights Tribunal decision in S. Chopra v. Canada-Dept. of National Health and Welfare, Mar. 08, 1996 contains further detailed information regarding how the struggle to remove the unqualified Director of BHPD unfolded and is consistent with Dr. Brill-Edwards account regarding legal actions as noted above (CHRT 13-19).

\section{Response of the Organization - Imitrex}

Dr. Brill-Edwards relates her perceptions and experience of the response of the organization to her actions to try to rectify the problem as follows:

After the Imitrex debacle, I did challenge the department on the [other] debacle of the "dangerous director" and the department was very eager to get that settled. They were very worried about the impact of somebody with my expertise and credentials and credibility openly challenging the competence of Health Canada to take decisions in the public interest. I had been working with the World Health Organization (WHO) on the Aids issues and in due course they had offered me a position there and it was part of convention that you need the approval of your own government to accept a WHO position. So, after winning that federal case [in Feb. 1992] and challenging the reappointment, I had to go and ask the Deputy Minister if the Department would concur with the decision of the 
WHO to offer me the post. I had won the post in an international competition, so it was in a way, a formality to get this approval.

So I met with the DM and she was very gracious - "Oh this is lovely Michele". She said she would be happy to sign the documentation endorsing the appointment to WHO and I, of course, in turn would sign a legal document agreeing to keep silent on all matters I had learned in the course of my duties. Also, I would agree to not participate in any legal proceedings involving matters pertinent to the department. Of course, the key legal proceeding was the challenge to the Director's reappointment. So basically, I realized, I could proceed with my career only if I would agree to a "gag order" on the safety issues. And much as I would have liked to accept the offer at WHO - I had prepared for it, I had been overseas many times, I had looked at housing, I had looked at schooling for my daughter in Geneva, and really had pursued this enthusiastically- I realized that day in her office that it was not going to happen if the price was to remain silent about quite serious safety issues. I said that I would sleep on it. I went back the next day and told her it wasn't what I would do. She said things like "I don't understand. You seem to have this personal sense of safety." I said to her "Deputy, it is nothing to do with me personally. This is a matter of the will of Parliament in passing the Food and Drugs Act. This is a statutory duty we have as Health Canada to safeguard the public by upholding the Food and Drugs Act, so you can take me out of the equation, and we still have that duty and I particularly will not betray that duty." I could see it 
was not in her mindset. It was not within her realm of thinking that somebody with my potential would refuse such career advancement on the basis of duty. I remember coming away from that thinking - “ 'Duty' really is a four letter word for these people." She said "But you have so much to gain. I know you feel that your career has been damaged but this can all be repaired. This can all be forgotten. You have a future. This is a very important post for you." I said "It is not for me to negotiate for my private gain a matter of public safety. You can't ask me to do that." Her face was like a stone. I had no sense that she understood at all where I was coming from. It was kind of like "why aren't you agreeing with me?" So, I came away from that thinking "I don't know what is going to happen, but I know that the one thing I cannot do, I cannot take the post at WHO, knowing that I am literally walking on the bodies of the dead - climbing over them to get up to this post. That's not going to happen.”

I didn't know what I was going to do, but I thought "I still have a job" - a lower ranking job at that point. I had been the Asst. Director Medical, and in re-appointing the non-medical Director, they eliminated the senior medical position, which was me, and I went back to my substantive position as a medical reviewer. They thought that this was such an insult I would leave, and I expect for most people they probably would have. Again, I thought that I can't walk away and let this continue. I didn't know 
what I was going to do, but I did know what I was not going to do. I was not going to go along with "evil". 30 (pers. comm. April 6, 2014).

\section{Data and Document Review - Response of the Organization to Imitrex}

A review of relevant documents suggests some support for Dr. Brill-Edwards recounting of events regarding the response of the organization to her attempts to address her public safety concerns regarding Imitrex. Regarding her demotion, there is no available written evidence that the Department demoted her because of her actions to correct what she saw as threats to public safety. However, the proximity of the abolition of her position of Asst. Director - Medical to the reappointment of that same Director i.e. on the same day, and two months after Dr. Brill-Edwards had supported legal proceedings which forced the Department to remove the Director and hold a new competition, could suggest a link.

This was followed a few months later by her inability to take the appointment to the WHO post, a career advancement opportunity, as she had declined to sign an agreement to keep silent on all matters she had learned of during the course of her duties - matters Dr. Brill-Edwards considered wrongdoing. While it was not possible to validate what the Deputy Minister said, the selection of Dr. Brill-Edwards for the post of Scientist with the Global Programme on AIDS, Office of Research, World Health Organization (WHO), was validated (Letter from Verzelloni, F. to Dr. Brill-Edwards, May 22, 1992). There was further validation via a letter from WHO containing a formal offer of appointment on the understanding she had obtained her release [leave of absence] from the Dept. of Health and Welfare (Letter from Verzelloni, F. to Dr. Brill-Edwards Nov. 16,

\footnotetext{
${ }^{30}$ For an in-depth discussion of evil in organizations see Jurkiewicz, C. ed. (2015) The Foundations of Organizational Evil,
} 
1992). There was also a letter acknowledging that since she was unavailable, alternative plans were made to carry out the duties of the post (Letter from Verzelloni, F. to Dr. Brill-Edwards Jan. 11, 1993).

\section{Outcome in the case of the first critical incident -Imitrex}

The above document review obtained from public records provide some support for the view that despite efforts made by the participant Dr. Brill-Edwards and other colleagues, they were unable to change the actions deemed a threat to public safety. These unsafe actions were

(a) approving the migraine drug Imitrex without including in the labelling clear, precise wording to adequately describe to doctors the conditions of use that would safeguard patients from potentially lethal adverse effects.

(b) appointing a Director who was not qualified to evaluate and make decisions regarding drugs for human use.

(c) eliminating the position of Asst. Director Medical leaving the Office of Director with no medical expertise.

As Dr. Brill-Edwards perceived and experienced it, and the document review suggested, she suffered reprisals from the organization in the form of demotion, and impeding her ability to accept a position offered her by the WHO after she won an international competition. These experiences are consistent with patterns described by others (Glazer and Glazer 1989, Alford 2001, Jackall 1988). To conclusively prove reprisals is very difficult as managers do not admit to it, a fact recognized by others in the literature. Transparency International has stated one of the reasons measures outlawing reprisals for whistleblowing do not work is the burden of proof issue. They state, "dismissal and other 
reprisals are always likely to be presented as being carried out for other reasons, so a legal presumption that whistleblowing was the cause is essential" (3). This reverse onus is also being recommended by Canada's Public Service Integrity Commissioner Joe Friday as an amendment to Canada's PSDPA (Butler 1).

\section{The second observed critical event - short-acting nifedipine/Adalat}

The second event was sparked by a New York Times article, March 12, 1995 discussing the results of a study led by Dr. Psaty indicating that people using a class of drugs called calcium channel blockers (CCB's) to treat their hypertension were more likely to have heart attacks than those taking other drugs (Kolata 1995). Dr. BrillEdwards had decided to stay in the Department after her demotion in 1992 and on her own time, worked with public interest groups to help them understand the damage that is done when as she put it "Health Canada doesn't do its job". She hoped this might help create the momentum for change. She related that by about 1994-1995 she began to realize that a cleanup from within" wasn't going to happen (pers. comm. April 6, 2014). Then the 1995 CCB controversy arose. She described her perceptions and experience as follows:

The part of Health Canada that I was working in had to do with Cardiovascular Drugs and I was interested to see that there was an immediate defensive position being taken- "This [Psaty study] must be wrong." Calcium Channel blockers (CCB's) as a class of drugs were the top sellers, and in particular, nifedipine, one of the particular CCB's, was the top selling drug in the world at the time. So it was a huge slap in the face for our regulatory agency and every regulatory agency to have this 
information out in the public domain making us look like we had missed the boat. These drugs had gone to market about fifteen years earlier - I think it was the 80 's - so roughly 10 to 15 years earlier. Prior to this expose, we had reviewed the company's information and put these drugs to market. The implication was “well, why didn’t you know that this particular drug would cause deaths?” (pers. comm. Apr. 6, 2014)

She related that eventually a decision was made to establish an Ad Hoc Expert Advisory Committee (EAC) which met on Sept. 18, 1995 to help decide regulatory action. The establishment of the committee had been criticized prior to the meeting by other colleagues because the reviewers in the Cardiovascular Division had been told they couldn't attend. Eventually it was agreed they could attend but only as observers. There was also concern amongst the reviewers as to the makeup of the committee as the four expert cardiologists all were known to have relationships with manufacturers of CCB's. They were respected in the communities they came from but had ties with the drug companies who own the drugs that were then under scrutiny (pers. comm. April 6, 2014).

During the meeting concern was expressed by one of the outside experts about what the companies might think about any regulatory decision that was made and getting their involvement and concurrence first. According to Dr. Brill-Edwards:

Of course, that is a very questionable action for a regulatory agency. A regulatory agency functions very much like the referee in a hockey game or the umpire in a baseball game. So you call the shots as you see them. You don't go to the team and say "Do you agree with me that I am going to make this decision?" Now, you may discuss when they complain. You 
may hear their complaints, but you don't start looking to the teams before you make your call. (pers. comm. Apr. 6, 2014)

For Dr. Brill-Edwards, this stance was wrong as the priority should have been what can be done to safeguard the public, not the reaction of the companies. As she put it: And all the other things that might be priorities - what the companies think, what kind of media lines are we going to write for this, how it's going to influence the economy, what it's going to do to the pharmaceutical industry in Canada - and so on - that is all downstream and secondary. Your first duty as the regulator is enforce the Food and Drugs act. It's the will of Parliament, it's your statutory duty, and it says that patient safety comes first above all else. That was never said in that room that day. It should have been. (pers. comm. Apr. 6, 2016)

The consensus of the discussion was that enough evidence had accumulated over the years pointing to harm from the approved use of short-acting nifedipine for angina, and "off-label" for the unapproved use for hypertension, there was no reason to keep it on the market. However, the Department backed away from taking such action. Dr. BrillEdwards considered the implications of removing the drug from the market as the EAC medical specialists had advised the bureaucrats at the Sept. 18, 1995 committee meeting:

The implications were that if the only approved use is now known to be so dangerous that its use cannot be advised and there is no other official use for this drug then it has no business being on the market. If you then say, if that's your official advice [as a committee] to Health Canada, it would be very hard for Health Canada, given our laws, to refuse that advice. So that 
would be an official panel saying "the official use is dangerous, there is no other approved use", our consequent regulatory action would be that this drug needs to be removed from the market. Once you say that the shortacting form needs to come off the market, then a big spotlight goes on the other forms - the intermediate acting, and the long acting forms. Worse yet, if one $\mathrm{CCB}$ is withdrawn from the market, it casts a pall over all CCBs. So each of those four men would then be in a position of going to the companies who fund their research and saying, "By the way, I was just in Ottawa and we decided to pull the earliest CCB from the market. Oh, I am the beneficiary of your funding and I suppose you will continue to fund my research?" Do you see the implication? Once you withdraw one drug in a class from the market, the commercial value of all the others drops - like the stock market. If the commercial value drops, then the companies are angry at the people who made that happen. So you can see the self-interest all the way around, that everybody wanted to back away. (pers. comm., Apr. 6, 2014)

She explained further why the regulators were hesitating: Actually they could not say in the letter "it should not be used" as then the question would be "Well, why didn't you take it off the market?" So, they came up with this fancy phrase, the same used in the US, saying "It should be used rarely, if at all." Again, if you look at the Food and Drugs Act, a drug that should be used "rarely if ever" needs to have a Product Monograph that is totally revamped to say that. You don't leave the 
Monograph as it was. None of this makes sense [...]. ( pers. comm. April $8,2014)$

She explained there were further influences at play:

“[...] By the mid 90's we were under the full influence of de-regulation.

We had become like the hunting dog that won't hunt. It was like "Do the minimum. Don't get in the way of the companies." So, nobody asked for the data [on nifedipine]. The Department put out statements that were defensive and said we were studying the issue but in fact we weren't (pers. comm. Apr. 8, 2014).

\section{Actions to address the second critical event - short-acting nifedipine/Adalat}

Based on the attitudes Dr. Brill-Edwards witnessed in the meeting of the Ad Hoc Expert Advisory Committee meeting of Sept. 18, 1995 and the nature of the Dear Doctor letter being crafted - she knew short-acting nifedipine would not be taken off the market. Instead, doctors would be advised to use it "with great caution if at all". Dr. BrillEdwards decided it was time to act. She believed that more harm would be done to many people by leaving it on the market and she knew busy physicians have little time to spend reading caution letters. As she related, "That meeting, or the dismal failure of that meeting was what made me decide to cooperate [with the media] in exposing the failure of the Department to undertake its statutory duty. At that meeting, I realized that this system is hopeless. That's when it became very clear that it was time to leave and time to talk" (pers. comm. Apr. 6, 2014).

In November 1995, the draft Dear Doctor letter from Dr. Leenen was circulated in the BHPD for comment confirming Dr. Brill-Edwards fears that the drug would remain 
on the market. In December 1995, Dr. Brill-Edwards reviewed the archived files containing the reports of two reviews on which the approval of short-acting nifedipine had been based. She found that the Reviewer had stated he would be willing to issue a Notice of Compliance if the company would immediately commence a long-term trial of one year to demonstrate safety with long term use (Reviewer's Report, Sept. 23, 1981). The long-term trial was not commenced and the Reviewer approved the submission in a second review in December 1981 while at the same time expressing concern that long term efficacy and safety was an area of concern which "remained unresolved" (Reviewer Report, Dec. 30, 1981, 27). In December 1995, Dr. Brill-Edwards spoke with V. Krupa, $\mathrm{PhD}$, Chief of the Cardiovascular Division, to whom she reported at the time and told him of her findings. She put this and other matters in a memo she wrote him Jan.3, 1996. On January 19, 1996, she wrote her letter of resignation to the Deputy Minister documenting once again her concerns for public safety and the omissions of the Department. On February 26, 1996, the CBC's Fifth Estate documentary called “The Heart of the Matter" became public. In it, Dr. Brill-Edwards spoke of her experiences and concerns as did other physicians, some of whom had conducted the alarming studies regarding short-acting nifedipine (pers. comm. Apr. 6, 2014, transcript of "Heart of the Matter"). The appearance of conflict of interest was a big part of the documentary.

\section{Data and Document Review - Actions to address short-acting nifedipine/Adalat}

The following lists the documents reviewed. They suggest support for Dr. BrillEdwards account of why she took the action she did - resignation - and the basis for 
resigning to address the problems with the regulatory response to the heightened public awareness of safety concerns regarding the use of nifedipine. ${ }^{31}$

(a) Minutes of the September 18, 1995 Ad Hoc Expert Advisory Committee meeting during which the expert advisors discussed more than thirty times the potential for harm and that given what was known, the drug should not remain on the market. See Appendix 3 for a listing of where these remarks can be found in the Minutes. They also discussed how the drug could be removed from the market which was for Health Canada to ask the manufacturer (Bayer) for safety and efficacy information. The onus was then on the company to prove efficacy and safety (1617).

(b) Food and Drugs Act - Section C.01.013 - This Regulation gives the Director the power to request from the manufacturer evidence of safety to be submitted to the Director on a specified date. If the evidence submitted is not sufficient the manufacturer will be notified in writing of this and shall make no further sales until sufficient evidence is submitted and he is notified in writing of this.

(c) Food and Drugs Act - Section C.08.006 - This Regulation gives the Minister the power to, in effect, stop sales if there are safety concerns about a drug. It indicates a Notice of Compliance may be suspended if new information reveals that the drug is not shown to be safe for the use represented in the new drug submission.

(d) Food and Drugs Act - Section C.08.003 (h) iv - This section requires that no person shall sell a drug which has a Notice of Compliance if, among other things, the contra-indications and side effects of the new drug are significantly different

\footnotetext{
${ }^{31}$ The governing Regulations are those that were in place during the 1990's - the era under discussion.
} 
from the information and material contained in the information filed originally unless they file the supplemental information with the regulator including the final labelling and the drug is sold in accordance with the representations contained in the new drug submission or in the supplemental new drug submission.

(e) Food and Drugs Act - Section C.08.007 - This section stipulates the records the manufacturer is to keep once a Notice of Compliance is received as described in (a) to (i) and includes among other things, studies, investigations, reports, change, unexpected side effects, injury or failure of the new drug to produce its expected pharmacological activity.

(f) Food and Drugs Act - Section C.08.008 - This section stipulates that no manufacturer shall sell a new drug unless, he has, with respect to all his previous sales of that new drug, furnished to the Director on request, reports in duplicate of all records respecting the information contemplated in Section C.08.007.

(g) Letter from Dr. Susan Robertson to Dr. V. Krupa, April 4, 1995, outlining her concerns regarding conflict of interest and ties of members of the committee to pharmaceutical companies and lack of participation of Bureau staff in the meeting.

(h) Fax memo from Pfizer to Dr. Leenen thanking him for agreeing to accept media calls on their behalf to respond to the publication of the Patsy study on increased mortality of patients treated for hypertension with short-acting CCB's, August 22, 1995. 
(i) Letter from Dr. Leenen to Dr. Krupa containing draft Dear Doctor letter indicating s/a nifedipine should not be used for patients with stable coronary artery disease (CAD) - its approved use, Nov. 10, 1995.

(j) Email from Ken Gruchalla to Vincent Krupa dated Nov. 22, 1995 with feedback on draft Dear Doctor letter stating they could not leave in the sentence about not using nifedipine for CAD as it was the indication for which it was first approved.

(k) Letter from Dr. Krupa to Dr. Leenen dated Nov. 10, 1995 regarding the reasons for taking out the sentence to not use nifedipine for CAD in the Dear Doctor letter i.e. "to better reflect our regulatory environment", "not to leave the Health Department open to legal challenges" and "[. . .] to make sure that manufacturers of these drugs are neither favoured nor disadvantaged unfairly."

(1) Dear Doctor letter No. 44, Jan. 23, 1996 stating use it if other medications don't work in CAD, however, do so with "great caution if at all".

(m) Studies by medical researchers indicating potential harm to users of short-acting nifedipine. See Appendix 4 for a listing of some of the more prominent studies.

(n) Transcript of the Fifth Estate documentary "The Heart of the Matter”, Feb. 27, 1996.

\section{Response of the organization - short-acting nifedipine/Adalat}

Through its senior managers, including the Deputy Minister, Health Canada responded to the whistleblower's resignation and allegations in the Fifth Estate Documentary regarding conflict of interest and nifedipine. They defended their version of events in the media, to the Minister, and through the Minister to Parliament and the people of Canada. Eventually, they also asserted the same version of events to the Court 
in the defamation lawsuit and to the Standing Committee on Health. However, the version they espoused and the information given to the Minister by the Deputy Minister differed from that which was contained in the Minutes of the Sept. 18, 1995 Ad Hoc EAC meeting, from memos and letters written by members of Health Canada, from the Food and Drugs Act and Regulations and other policy documents. These differences are documented below. Further, they did not correct the problem of having an acknowledged unsafe drug on the market - which had been there for almost fifteen years - despite accumulating information that more people were dying on this drug than other drugs used for the same problems. Instead the evidence shows the responses at a minimum clouded the issues.

\section{Data and Document Review Response of Organization - nifedipine/Adalat}

The document review suggested support for Dr. Brill-Edwards account of events. The senior officials' version of events supplied to the Minister and the Court diverged from the account in the official records in the Department as well as that of Dr. BrillEdwards. The information which follows demonstrates this finding. The broadcasting of the Fifth Estate's documentary in February 1996 garnered the attention of the highest levels in the bureaucracy and government. This is demonstrated in briefing notes to the Minister of Health obtained through Court files and represents attempts by senior officials to account for the allegations of conflict of interest in the documentary. In a Memorandum to the Minister dated February $29^{\text {th }}, 1996$, just two (2) days after the first broadcast of the Fifth Estate's documentary, the "Heart of the Matter", the Deputy Minister (DM) Michele Jean, the Assistant Deputy Minister (ADM) Kent Foster, and Director General (DG) Dann Michols gave their account of events. The assertions the 
most senior bureaucrats made were different from information accessible to them and contained for the most part in the minutes of a meeting of the Department's Ad Hoc Expert Advisory Committee (EAC) of September 18, 1995. This differing information supplied to the Minister by the most senior bureaucrats in their Memo to the Minister, which he subsequently gave to Parliament and Canadians is as follows:

(a) With regards to the assertion the Drugs Directorate and BHPD tracked studies and investigated if a problem was raised - the record shows many studies were done since the 1981 approval and prior to 1995 that raised concerns about nifedipine in treating angina. However, it is not apparent that any investigation took place until reports of the 1995 Pasty study in the New York Times caused a sensation worldwide. These studies are well documented in the minutes of the September 18, 1995 Ad Hoc EAC meeting held by BHPD and include one as early as 19861987 done by Dr. Myers group and published in the Canadian Journal of Cardiology. In discussing this study, the EAC minutes state "At a time when nifedipine was approved for the treatment of angina, the investigators noted the detrimental effect of the nifedipine capsule in unstable angina" and the study had to be stopped (4-5). ${ }^{32}$ See Appendix 4 for a listing of the relevant studies.

(b) The assertion that the scientific/medical community "has not determined that the risks presented are greater than was known at the time of approval for the indications approved" - angina- differed from the information outlined in the September 18, 1995 Minutes of the meeting of the Ad Hoc EAC. The minutes are the official account of what happened. More than thirty times participants in the

\footnotetext{
${ }^{32}$ In medical research, trials are stopped without absolute proof of harm as to continue until there was absolute proof could cause serious harm and/or death which would be unethical (Brill Edwards, pers. comm. April 6, 2014).
} 
meeting noted the safety concerns around short acting nifedipine in the treatment of angina and recommended that the companies be asked for safety data on the assumption they would withdraw it from the market themselves when they couldn't provide it. See Appendix 3 for a list of the location of these concerns in Minutes.

(c) The assertion that the studies done and reported by the Fifth Estate have been regarding “off-label” uses for s/a CCB's, or, in other words, for hypertension rather than the approved use angina, is also contrary to the official records. ${ }^{33}$ See Appendix 4 for a list of studies most of which were on CAD. Notably the Minutes record a discussion regarding study results and the potential for harm in the stable angina population. Dr. Leenen pointed out that "[ . . .] the most clear data is with coronary artery disease (CAD); there is very little data for hypertension" (Minutes 16).

(d) The further statement by the Deputy Minister and her most senior officials that the studies therefore do not warrant regulatory action, and for this reason a Dear Doctor letter was issued to remind physicians of the approved indications and the risks involved, again differ from the verifiable information in the Minutes. In reality, the advice given to her officials by their Ad Hoc Expert Advisory Committee as captured in the Minutes state clearly that " $[\ldots]$ there was no indication to keep either nifedipine capsules or rapid short-acting calcium channel blockers on the market for coronary artery disease" the very indication for which it was approved (16).

\footnotetext{
${ }^{33}$ Interestingly, this assertion is the same explanation offered by Pfizer when it sent out its Dear Colleague advertising letter Aug. 22, 1995 to Canada's doctors reassuring them their long acting CCB was safe .
} 
(e) The assertion there were no complaints from outside the Department about the drug or the Drug Directorate's response, conflicts with the transcript of the Fifth Estate's “Heart of the Matter" which documents Dr. Yusuf's attempts to get the attention of Health Canada regulators. He took slides related to his concerns about the harmful effects of s/a nifedipine to a talk he was asked to give at HPB in 1995 on an unrelated topic and asked if he could present them at the end of the talk. They agreed. At that time, his hope was the regulators would act. His information came from a variety of studies including his own 1989 and 1991 published work (7).

(f) The statement that the findings of the studies published between March and September 1995, reinforced the fact that short-acting nifedipine should not be used "off-label" for the treatment of hypertension again is misleading. One study was on hypertension and the other two were on Coronary artery disease or Angina. See list of studies at Appendix 4. These studies reinforced the fact that there were also concerns about the approved use, angina, which was mentioned in her Department's Dear Doctor letter (Dear Doctor letter No. 44, Jan. 23, 1996).

(g) The statement that after considering the advice of the Ad Hoc Expert Advisory Committee the HPB issued its Dear Doctor letter and "No further regulatory action could be taken" differs from the information in the minutes. The minutes include both the recommendations of the expert advisors about the potential for harm of short-acting nifedipine indicating removal from the market was warranted, and, the information provided by the regulators about how this could 
be done. ${ }^{34}$ This differing information was repeated in a letter from the DM to the Minister on March 19, 1996.

(h) The statement that "CCB's are still considered to be safe when prescribed for the indications approved by the Drugs Directorate" is inconsistent with everything that was recorded in the minutes of the EAC meeting and with the numerous studies on the subject. This differing information was repeated in a letter from the DM to the Minister on March 19, 1996.

(i) The statement by the Deputy Minister that the directive on conflict of interest applied only to standing committees differed from the Department's Directive on conflict of interest in Information Letter No. 810. This Directive states that advisory committees may be appointed to do a "specific short-term job" i.e. an ad hoc committee, and others may have a "long- term existence" i.e. a standing committee (4.1). It then goes on to state the "Conduct and Conflict of Interest" policy for all committees - with no distinction between short and long term committees. "Guidance on conflict of interest will be provided to potential members at the time of appointment. Prior to appointment, advisory committee members will be required to submit conflict of interest declarations [. . ] " (5.0). An example of appropriate conduct was provided: "i.e. the use of their position cannot reasonably be construed to be for their private gain or that of other persons or organizations. They must refrain from conflict of interest and, indeed its very appearance" (5.1).

\footnotetext{
${ }^{34}$ The Food and Drugs Act Section C.01.013 provides the power to stop sales if the Director asks for evidence to establish the safety of a drug and the effectiveness of the drug before a specified day and that evidence is not supplied. The day after the specified date the drug cannot be sold. This was discussed in the Sept. 18, 1995 meeting (Minutes 16).
} 


\section{Outcome in second critical incident - short-acting nifedipine/Adalat}

The outcome was that the efforts of several whistleblowers from within Health Canada and from without saw a result that was based on priorities that did not put patient safety at the top of the list. Health Canada addressed the problem of an acknowledged unsafe drug on the market which had been shown to cause more deaths than other drugs used for the same reasons, by deciding to keep it on the market. Instead they decided to send a Dear Doctor warning letter advising Canada's doctors to use it "with great caution if at all" leaving the public at risk. The document review provided documentation that raised questions about the motivations of the bureaucrats in taking the actions they did in the nifedipine case. The written word of the key person on the file, Dr. Krupa, suggested the first priorities were "to better reflect our regulatory environment", "not to leave the Health Department open to legal challenges" and "[. . . ] to make sure that manufacturers of these drugs are neither favoured nor disadvantaged unfairly." See data and document reviews above for more specific examples. The intent of the Food and Drugs Act and regulations in place at the time points to a different priority - public safety. ${ }^{35}$ The policy of deregulation continued, Dr. Brill-Edwards was without a job, and Canada's national television broadcaster - CBC - was sued by Drs. Leenen and Myers for defamation. The legal decisions found for the plaintiffs and both received awards from the courts to compensate them. Dr. Brill-Edwards remained unemployed for four years and she and her family suffered as a result (pers. comm. April 6, 2014)

\footnotetext{
${ }^{35}$ The intent of the Food and Drugs Act is contained in the Foreword which is "to protect the public against health hazards and fraud in the sale and use of foods, drugs, cosmetics and medical devices" (iv). The Food and Drugs Act is part of Canada's Criminal law and as such, its breach is subject to criminal prosecution (Historica Canada).
} 
However, the medical community became alert to the issue of conflict of interest as a direct result of the Fifth Estate documentary "The Heart of the Matter". It directly sparked medical research on conflict of interest in the calcium channel blocker controversy which was published in the New England Journal of Medicine (Stelfox et al 1998). The reason for the research was that it was not then known how much influence industry support for medical education and research had on the opinions and behaviour of clinicians and researchers (Stelfox et al 101). Stelfox et al examined medical literature published from March 1995 to September 1996 regarding the CCB controversy. The study concluded that there was a strong association between authors' published positions on the safety of calcium-channel antagonists and their financial relationships with pharmaceutical manufacturers. The authors recommended a disclosure mechanism for authors regarding relationships between physicians and pharmaceutical manufacturers. This was necessary "to affirm the integrity of the medical profession and maintain public confidence" (105). In response, major North American Medical organizations and the Food and Drug administration tightened rules on disclosure and management of conflict of interest (Brill-Edwards, pers. comm. April 8, 2014).

\section{Theme 3: Why reprisals occurred?}

This theme will be discussed in two parts- the whistleblower's perceptions and experiences regarding why reprisals occurred, and the data and document review supporting or otherwise those views. 


\section{Whistleblower's Perceptions and Experience of Why Reprisals Occurred}

Dr. Brill-Edwards was demoted from her management position as A/Asst.

Director-Medical to Reviewer of new drug submissions. ${ }^{36}$ Further, she states she was blocked from accepting a position with the World Health Organization as she refused to sign a "gag order" swearing her to secrecy and requiring she give up legal actions against the Department. As she described it, the reason this was happening was that she was standing in the way of what was "probably the most important public policy of our lifetime - deregulation" (pers. comm. Apr. 8, 2014). She believed there was a deliberately dysfunctional structure in the BHPD which was accomplished by "deprofessionalizing" the Department to facilitate deregulation. She asserted that there was also a dysfunctional culture which facilitated wrongdoing. Further, she had also breached the legal and policy imperative of secrecy and loyalty which she had been required to adhere to by signing an oath to that effect when she was hired. She did this by openly challenging the Department's appointment of an officially acknowledged unqualified Director, refusing to sign an agreement to keep silent about her knowledge of the Department's activities she was questioning and refusing to desist from legal action against the Department. So from her perspective, reprisals occurred due to three things: (1) she challenged authority and deregulation, (2) there was a dysfunctional structure and a dysfunctional culture, and (3) loyalty and secrecy oaths contributed to the dysfunction.

\footnotetext{
${ }^{36}$ The hierarchy consisted of: reviewers who reported to a Chief (heading a Division); a Chief reported to a Director (heading a Bureau with a number of Divisions); a Director reported to a Director General (DG) (heading a Directorate with a number of Bureaus); a Director General reported to an Assistant Deputy Minister (ADM) (heading a Branch with a number of Directorates) and an ADM reported to a DM responsible for the whole Department ( CHRT-Chopra and Department of National Health and Welfare, 1996 (3, 13-17).
} 
On deregulation she said:

$[\ldots]$ it was always accepted that there was an absolute need, not questioned, but an absolute need for government intervention in the marketplace to specifically safeguard the interests of consumers. In the 70's that concept of the necessity of government intervention went out the window, because very powerful people took this position - "Government regulation is an encumbrance - it slows down industry, it slows down innovation, it slows down economic growth. It's nothing but bad, and we need to get rid of it as much as possible". So you have the transition to an era where the old framework is gone and the new framework is "trust industry". It will handle everything properly with as little intervention as we can manage. So in Canada we start in the 70's switching away from the 60's where the idea that the tragedy of thalidomide - which was a huge regulatory failure - led to the public view that we need regulators, we need people scrutinizing these things. There was the experience of Frances Kelsey - a Canadian, working for the US FDA - keeping thalidomide off the American market. So regulators have a good name in the 60 's but by the 70 's it was, "that's old hat and regulation is nothing but red tape". So you have the denigration of regulation. Then in the 80 's in our agency and in many agencies around the world you have the de-professionalization of the agencies so the people who were well schooled and experienced as regulators all got their marching orders. (pers. comm. Apr. 28, 2014)

On dysfunctional organizational structure she said: 
There is one thing that we haven't spoken about and that is, what in my judgement was a deliberately dysfunctional structure within the bureau. In previous times there was a Director who was always medical, and roughly five medical divisions and two manufacturing divisions and they all reported to the director. So there were very clear lines of authority- and authority and responsibility went together. What happened in roughly 1988 was, the Director who was medical was basically forced out - was given another job in the department and taken out of that role and a non-medical director who was a $\mathrm{PhD}$ in pharmacology was appointed. The "medical knowledge" was provided by a new job position called the AssistantDirector - Medical, and there was an Assistant - Director - Pharmaceutical I think. So suddenly the five medical units - things like the Cardiovascular, Renal and Arthritis, the Endocrine division, the Oncology division, the Neurology division - these units that handled these specific types of drugs who were headed by Chiefs, now reported to a non-medical Director. Only some of those chiefs were medical and some were scientific. So what you had was a mixture of front line troops - the members of each of these divisions - a mixture of doctors and scientists. Some of them were reporting to scientists who then reported to a scientific Director - a Director with a PHD, so it was quite possible that no medical eyes would see a file. And so here is this Assistant Director - Medical with the responsibility to ensure the medical appropriateness of the decisions we take, but suddenly with no line authority at all. (pers. comm. April 8, 2014) 
On dysfunctional culture she said:

What deregulation did - the effect of deregulation - was to pit allegiance to the law that protects Canadians, against allegiance to the hierarchy. So you have people who have spent their careers in protecting the public and working to that end, who know the law inside out and they know their duty, and all they want is to be allowed to come to work every day and do their work properly. They are pitted against people who have not only no medical knowledge, no scientific knowledge, no legal knowledge of the Food \&Drugs Act, no understanding of how it is implemented or the historical precedents we have to go on- not only do they not know that- they don't want to know. It's like "I don't care that this is the law. I have been put in place by this hierarchy that doesn't believe in regulation, that wants to get rid of regulation and wants to please the Minister and cabinet who want to please the industry that we are supposed to regulate. So forget it. We are not going to do this regulatory task. We are going to do what the boss wants.” (pers. comm. Apr. 8, 2014)

On loyalty she said:

I had to go to somebody's office in Human Resources and swear allegiance to the crown when I joined in 1980. It was a requirement on joining the Public Service that you had to swear an oath of allegiance. So that, for starters, impresses on every employee - that they have sworn an oath. This is not just like “Oh, yeah. You're a public servant and wouldn't it be nice if you were loyal." No. You have sworn an oath and this is your prime duty. 
When I was going farther along - you know initially when you swear an oath you take it for granted you are not going to be asked to do things that are morally wrong let alone illegal. So you don't even anticipate that this could be problematic so you never ask what the limitations are. It's not going to happen. As time went on I started to realize that there is wrongdoing here. At a more junior level I often could see the wrong doing was more incompetence than purposeful, and intentional. But at the more senior level, I kept cleaning up these messes [i.e. the Aid drugs] - thinking “Oh good. That's done." And then turn around and Boom! It's happening all over again. And that's when you start to realize somebody is making this happen, allowing this to happen. When I realized this, I went and got legal advice from a group that were often working with Unions, a legal group. And the case in law that spelled out the answer to your question about the limits of loyalty was the case of the fellow [Neil Fraser] who publicly questioned the switch to the metric system. That case was interesting because he lost the case on the basis that he was disagreeing with government policy, he was not being asked to do anything unsafe. But happily, the Judges spelled out the circumstances that they could conceive of where a public employee would not only be allowed to speak out, but had a duty to speak out. (pers. comm. Apr. 8, 2014)

\section{Data and Document Review on Why Reprisals Occurred}

The evidence suggests support for Dr. Brill-Edward's perceptions and experience. That de-regulation was in progress is demonstrated by the 1985 publication of the report of the Ministerial Task Force on Program Review - otherwise known as the Neilson Task 
Force and had to do with deregulation. A Study Team Report to the Ministerial Task force described deregulation as "reduced economic regulation" or "the reduced control by government or its agencies of such critical factors as prices, conditions of entry and exit and other competitive or market-related issues" (16). The Study Team commented "Regulatory reform is all about freedom" and "Regulation is the removal of freedom $[\ldots] "(11)$.

This report was to respond to a concern about government performance and the search for more efficient, effective and economical ways to govern. ${ }^{37}$ It was followed up by various initiatives at strengthening the renewal process including PS 2000, the 1994 Program Review and the designation of a Minister for Public Service Renewal (Paquette and Shepherd 2-4). Other researchers also point to de-regulation and how it has influenced why managers resist correcting wrongdoing and punish whistleblowers. For example, Neilsen, in more recent literature cites political pressure and de-regulation as part of the picture $(385-87)$. Neilsen points out that "regulators are often under systemic pressure from the politicians who appoint them to ignore whistleblowing cases relevant to their sources of financial and/or ideological political support” (385).

The organizational structure changes which Dr. Brill-Edwards considered made it a dysfunctional structure are described in documents in the case of Chopra and Deputy Minister of Health and Welfare 1992 (Federal Court file no. T-3026-91). The information is also in the CHRT decision Chopra and Department of National Health

\footnotetext{
${ }^{37}$ Neilson Report - This was the Report of the Ministerial Task Force on Program Review established by the Mulroney government in 1984 and chaired by Deputy Prime Minister Erik Nielson. It was part of an on-going process of regulatory reform that began in the 1970's and led to a new ministry of Privatization and Regulatory affairs and de-regulation. The aim of regulatory reform was to cut costs and red tape in the interest of business competitiveness, job creation and economic growth. A feature of this thrust was establishing partnerships with the private sector (Treasury Board - Regulatory Reform - Appendix A). .
} 
and Welfare, $1996(3,13-17)$. The following is an example. The former Director of the BHPD, I. W. Henderson, MD, FRCPSC, Director from 1977 to 1988 was no longer Director by 1988 but rather "Special Medical Advisor" to Health Protection Branch. He described the changes in his affidavit in Chopra and Deputy Minister, Health and Welfare 1992 (Fed. Crt. file no. T-3026-91). Dr. Henderson was qualified in medicine and pharmacology. His qualifications were - he was a medical specialist (General and Thoracic Surgery) and Fellow of the Royal College of Physicians and Surgeons of Canada, had studied Pharmacology and Pathological Oncology, and was Assistant Professor of Surgery and Pharmacology at McGill University as well as Associate Professor of Surgery and Pharmacology at the University of Ottawa and Clinical Pharmacologist at the Ottawa General Hospital. He stated in his affidavit that when a Director in the BHPD had made a decision, there was no medical person at a higher level to take a serious second look at the submission (Fed. Crt. file No. T-302691). He further stated, "During the past decade, the number of medical officers in the Bureau of Human Prescription Drugs has been insufficient to ensure that every submission is critically examined by even one medical person on its way up to the desk of the Director" (Fed. Crt. file no. T-3026-91). Dr. Henderson was replaced in 1988 by a Director who had no medical experience. The required medical expertise was subsequently vested in the post of A/Asst. Director - Medical to support the new Director. The job description described responsibility and authority on medical-decision making regarding drugs as residing in this position (Job description, Asst. Dir. Medical Dec. 1989, 2). However, this was not the actual practice under the new regime. This is suggested by the evidence that deficiencies in the original Product Monograph/labelling for Imitrex were not corrected 
as Asst. Dir. Medical, Dr. Brill Edwards had directed before the approval was signed-off by a non-physician Director. Dr. Brill-Edwards lack of authority in practice to make the necessary changes is supported by the fact that she wrote letters within the Department to try to get adequate wording included (Brill-Edwards, memo to Claire Franklin, Jan. 7, 1992; Jan. 8, and Jan. 15, 1992).

Regarding dysfunctional culture, the document review supports the suggestion there were problems. The key documents pointing to this are discussed in detail under Theme 1 above and in summary are

a) the minutes of the Ad Hoc EAC meeting of Sept. 18, 1995;

b) the Jan. 24, 1996 letter from the Chief of the Cardiovascular Division Dr. Krupa to Dr. Leenen, pointing to the motivations for taking the above action or inaction as the case may be;

c) the differing letters from the Deputy Minister and her senior officials to the Minister on the nifedipine controversy (Memo to Minister from Jean, M., Foster,K., Michols, D., Feb. 29, 1996 ) and conflict of interest and nifedipine (Memo to Minister, from Jean, March 13, 1996 );

d) the Information Letter No. 810, April 12, 1994, a directive on committees and conflict of interest which was in place at the time; and

e) the Department's internal Human Recourses study done at the time to address the changes and uncertainty in staffing.

In addition to political pressure and de-regulation, Near and Miceli have also noted dysfunctional cultural reasons why top managers resist correcting wrongdoing and punish whistleblowers like the whistleblower's experience in this case (Wrongdoing 274- 
5). Sawyer, Johnson \& Holub also point to cultural dysfunction as contributing to reprisals. They summarize why reprisals occur - "[...] the continuing legitimacy of the organization necessitates the illegitimacy of the whistleblower. This helps explain the continual blacklisting of the whistleblower and their vilification, resulting in the destruction of both their professional career and their reputation [. . .]" (85).

Regarding secrecy, the current Public Service Employment Act prescribes, in Part 4, Section 54 the following oath to be taken by employees:

I, - - - -, swear (or solemnly affirm) that I will faithfully and honestly fulfil the duties that devolve on me by reason of my employment in the public service of Canada and that I will not, without due authority, disclose or make known any matter that comes to my knowledge by reason of such employment.

There would likely be some exception contained under the "without due authority" phrase. However, there is legal precedent established in the 1985 Fraser case allowing for an exception in the case of illegality or actions that may harm the person or others (Treasury Board 1). This is important as it is not likely that one would receive "due authority" to expose wrongdoing.

\section{Theme 4: The Role of Law in Reprisals}

The previous data and document reviews suggested problems in Health Canada at the time, regarding how it carried out its statutory duty to enforce the Food and Drugs Act. This law was a major factor in this case as the perceived inadequate upholding of the law was what sparked the whistleblowing and lead to reprisals. The perceptions of 
Dr. Brill-Edwards regarding the role of law in reprisals are described in detail in Themes 1 to 3 above and are summarized below.

The unforeseen circumstance of Dr. Brill-Edwards experience as a witness for the CBC in Dr. Leenen's defamation lawsuit against the CBC's Fifth Estate, and the experience of presentations to the 1998 Standing Committee on Health, the oversight body for Health Canada, are briefly touched on.

Dr. Brill-Edwards recounting of her experience suggested she began from a place of commitment to fulfill what she saw as her statutory duty to uphold the Food and Drugs Act. The law and its institutions were to be respected and trusted. However, in the final analysis she believed the law failed her and the people of Canada. It provided Dr. BrillEdwards with the direction on what her duty was, however, when it came to fulfilling her duty under the law, she perceived there were no effective mechanisms to assist when problems arose. Dr. Brill-Edwards saw her role and the law as being "[ . . .] a matter of the will of Parliament in passing the Food and Drugs Act. This is a statutory duty we have as Health Canada, to safeguard the public by upholding the Food and Drugs Act [...] and I will not betray that duty" (pers. comm., April 6, 2014). See direct quotes on statutory duty under - Theme 2 , pages 102,108 and 110 . This law provided responsibilities for Health Canada as regulator of public safety (Carter 222) and as such, informed Dr. Brill-Edwards of her statutory duty in her role as A/Asst. Director Medical. From her perspective - at one time the most senior, medically competent regulator - as expert in the administration and implementation of the Act, its intent to protect the public against health hazards or risks in the manufacture and sale of drugs was being altered without due authority from Parliament. This was being done by the most 
senior, non- medically competent bureaucrats who were ultimately responsible for enforcing it. It seemed the power of the law and responsibility of Health Canada under that law for public safety was now being dispersed among a number of actors (Wiktorowicz 1-22). This involved a newer, looser regulatory environment in order that manufacturers were "neither favoured nor disadvantaged unfairly" (Krupa, V. letter to Leenen, H. Jan. 24, 1996). Deregulation was also about enhancing government's performance by making it more efficient, effective and economical (Paquette and Sheppard 2-4). What deregulation meant in terms of public safety was not part of the equation (Wiktorowicz 1-22; Brill-Edwards, pers. comm. April 6, 2014).

The Food and Drugs Act is the legislation under which regulations are made which define the application and enforcement of the legislation. The enabling legislation, the Department of National Health \& Welfare Act, RSC 1985, c.N-10, gave the authority and responsibility to the Minister of Health to make regulations and enact them, for which he/she was accountable (Health Canada, Legislation and Guidelines). ${ }^{38}$ Unfortunately, the Act did not provide a mechanism through which concerns regarding enforcement of the Act by regulators could be registered and investigated making accountability problematic. For example, under the PSDPA, the Auditor General is the mechanism stipulated in the Act for investigation when problems arise with the Office of the Public Service Integrity Commissioner. He also openly reports results of investigations.

\footnotetext{
${ }^{38}$ Interestingly, when the government moved the "Welfare" responsibility from the Department, new enabling legislation was created called the Department of Health Act 1996. It was noted by activists and a lawyer working on their behalf that the Draft legislation - Bill C-95 - had omitted the section giving the Minister the "powers, duties, and functions" relating to health including "the administration of such Acts of Parliament and of orders or regulations [. . .] relating in any way to the health of the people of Canada" (Section 4(2)(a)). They believed this omission would have resulted in the loss of ministerial accountability. The Section was ultimately included in the new Act (Memo L. Stoltz to Hon. Andy Scott, Nov. 10, 1995).
} 
The application and interpretation of the Public Service Employment Act 1985 by the Public Service Appeal Board and the Federal Court in supporting the removal of the improperly appointed, under- qualified, non-physician Director of the BHPD provided initial encouragement when removal of this Director was indicated. This encouragement was subsequently neutralized when the senior managers reappointed the same Director in a new competition even though her qualifications had not changed and she was underqualified. This, according to subsequent legal decisions, was a "management prerogative". The Public Service Commission and Justice Gibson of the Federal Court thus dismissed the second challenge - done jointly this time by Drs. Chopra and BrillEdwards - to the permanent appointment of this Director in 1992 (T-2143-92 ). This meant there was no medical expertise at the Director level of BHPD overseeing the safety of new drug approvals.

There was no legislation protecting whistleblowers at the time in the 1990's. However, there was legal precedent encouraging public exposure of wrongdoing established in the Supreme Court decision in Fraser v. Public Service Staff Relations Board (PSSRB), [1985] 2 S.C.R. 455. This was permissible if the Government were engaged in illegal acts, or if its policies jeopardized the life, health or safety of the public servant or others (Treasury Board 1). This precedent was not well known nor had it been tested at the time in the early 90's (pers.com. Apr. 8, 2014). As well, a Treasury Board review of the outcome in court cases since indicates the application of the precedent by the courts is "inconsistent" and a "maturing concept" (1). Given this information - it is not clear that it would have provided protection. 
Dr. Brill-Edwards summed up her perspective on the law and legal institutions as a result of her experience as follows:

[. . . I had given up everything to speak up, in a system that now dismissed any notion of duty, integrity, and my obligation as senior physician to uphold the drug safety laws intended to protect human life [...]. (email interview Nov. 26, 2016)

\section{The Defamation Lawsuit}

This lawsuit was reviewed briefly as while it was not about reprisals per se, it was about whistleblowing and occurred as a direct result of the act of external whistleblowing in this case under study. The Cunningham, J. Douglas, decision in Leenen v. CBC, 2000, upheld by the Ontario Court of Appeal, made legal history in April 2000 as it was the largest award against the media in Canada (Lexpert). ${ }^{39}$ The plaintiff, Dr. F. Leenen, complained that the "sting" of the defamation was in the libelous innuendos which were

(a) innuendo that Dr. Leenen supported the prescribing of killer drugs

(b) innuendo that Dr. Leenen was in a conflict of interest

(c) innuendo that Dr. Leenen was receiving a pay-off or a kickback from Pfizer

(d) innuendo that Dr. Leenen acted negligently or dishonestly as chair of the ad hoc advisory committee (Leenen v CBC 54).

The decision found for the plaintiff on all counts. In this view, the way the Fifth Estate set up the program, using eerie music, sound, exaggerated words and by not giving the plaintiff time to express himself suggested he was guilty of the libelous innuendos. I make no comment on the decision's finding of defamation. Separate and apart from that is the information that is in the official documents that are now on the public record. I

\footnotetext{
${ }^{39}$ Cunningham, J.D. in Leenen $v C B C$, 2000, awarded the plaintiff general damages, aggravated damages, and punitive damages all with interest, for a total of some $\$ 1,190,214.65$. In addition the plaintiff was awarded over $\$ 1,000,000.00$ legal costs.
} 
consider only the negative attitude toward the whistleblower which is of interest as the official written documents provided support for the whistleblowers views on the lack of safety of the drug and the behaviours of the Department officials. This is important as the perception of how whistleblowers are treated in official fora could impact whether they decide to come forward or not. It could also encourage wrongdoers to continue with impunity if whistleblowers are seen to be treated unfairly in such fora or no corrective action is taken when they expose wrongdoing. One of the chief reasons why whistleblowers do not come forward is if they believe nothing will get done to correct the situation (Near and Miceli - Wrongdoing 278).

Cunningham, J. D., in Leenen v. $C B C, 2000$, used several descriptors to characterize the whistleblower such as "disgruntled" $(51,58,86)$, "biased" $(19,86,87$, 91), “chagrined” 56, and leaker of "confidential information" $(20,23,44,56)$. He asserted Dr. Brill-Edwards was a "biased source" for the CBC documentary because she had "long standing labour grievances" with the Department which the CBC did not disclose in the documentary as to do so would have "tarnished this image" of her as hero (86). The CBC did in fact mention that Dr. Brill-Edwards had been in a dispute with the Department when she had tried to stop Imitrex being approved without stronger warnings Further they noted she had not been rewarded but rather "had lost her authority to oversee the review of new drugs" (CBC Heart 8). In addition, this decision gives little weight to or appears to overlook four precedents ${ }^{40}$ and conflict of interest (Stelfox et al 1998).

The decision of Justice Bellamy in the "sister" defamation lawsuit, Myers $v C B C$, 1999, while finding for the defendant, was more reserved and circumspect. The award

\footnotetext{
${ }^{40}$ This decision was found troubling by advocates of free expression in the media lawyers group Ad IDEM as it "affirmed concepts of "meaning", "fair comment", "privilege" and "malice" that are contrary to earlier precedent" and troubling for freedom of expression (Ad IDEM 2001).
} 
was also a fraction of the award in Leenen v. $C B C$ in the amount of $\$ 200,000$ For example, she had no harsh descriptors for the whistleblower but rather described the events factually. She noted that the minutes were "dense and replete with medical terminology" and "[. . .] are not intellectually accessible to a person who is not a physician" (5). Justice Bellamy found that the documentary was in the public interest while Justice Cunningham found it was contrary to the public interest. He also found there was no conflict of interest while the Minister of Health did not agree (Dingwall, D., letter to Deputy Minister, March 11, 1996). Further, the medical community did not agree as evidenced by ground-breaking medical research published in the New England Journal of Medicine (Stelfox et al 1998). The decision also clouded the issue of whether the drug was safe or not as the implication that if Dr. Leenen was defamed the drug must be safe was likely, which was contradictory to the evidence. The "legal chill" of the decision at the time was not likely conducive to further examination of the events. These issues suggest further research into this case and others on the treatment of whistleblowers in courts in Canada is warranted for the reasons described above.

\section{The Parliamentary Standing Committee on Health (March1998)}

A cursory review of Dr. Brill-Edwards experience before the Standing Committee on Health was conducted as her interactions with the members of this and eight committees in all between 1997 and 2008 were a direct result of her act of external whistleblowing. While an in-depth examination was not possible in this study, this review would suggest further in-depth examination is likely warranted as how whistleblowers are treated before an oversight body could send strong messages to the people over whom they are exercising oversight and thus influence their actions. 
While the committee was not examining reprisals per se, they had invited Dr. Brill-Edwards to appear and give evidence about natural health products. She believed this opportunity to inform them of what she had witnessed was important because the committee had oversight responsibility for Health Canada and its performance as regulator of public safety (pers. comm. April 6, 2014). It also had extensive investigatory powers should the members choose to use them (Davidson 12-13). Her goals, as stated in each of her presentations were

(a) to protect Canadians from health hazard and save lives by ending the secrecy regarding the life and death decisions that Health Canada was making

(b) to spark an open public investigation of a drug approval process where the regulator had become enmeshed with the industry it was supposed to regulate, rendering it ineffective

(c) to advocate for the creation of a Drug Safety Board to rapidly investigate "drug crashes" ${ }^{\prime 1}$ and correct the errors causing them.

Furthermore, Dr. Brill-Edwards used the word "contemptuous" in describing her experience. While the members were respectful in the way they spoke, they showed contempt in their response in that they did not investigate as promised or give any reason why not (Proceedings, Standing Committee on Health on Natural Health Products, March 26, 1998). Dr. Brill-Edwards had informed the members of the Standing Committee that active bureaucrats from Health Canada two weeks before had misinformed them about the issues they were investigating. The committee in turn asked her for an urgent briefing

${ }^{41}$ A "drug crash" refers to a drug that has been on the market but has become controversial due to indications of lack of safety. A Drug Safety Board when a drug "crashes" would investigate and operate in a way similar to a Transportation Safety Board does when an airplane crashes (Wood, Stein \& Woosley, 1998). 
for their next meeting a few days later on March 31, 1998 with evidence of her allegations which she provided (Brill-Edwards, extended brief 1998). For example, one of the issues which the Departmental officials had spoken about was different from their own internal documents regarding who was the client of the department. ${ }^{42}$ They also gave the diverging information on nifedipine to the Committee that other senior officials had given earlier to the Minister. In it she also gave an in-depth description of how the Health Committee could structure a Parliamentary inquiry supported by an audit inquiry for compliance with the law. An audit inquiry or investigative audit could incorporate a forensic audit for evidence of wrongdoing where appropriate. The Auditors conducting the inquiry would determine reasonable performance standards for health hazard management for foods and drugs at Health Canada as indicated by the Food and Drugs Act as opposed to those the Department itself created. They would then assess whether these performance standards had been and were being met reliably, in the public interest. They could request the assistance of the Auditor General in this work with final results being reported to the House of Commons. Advantages over other options such as Royal Commissions were explained, a few being it would be faster, cheaper, would not have the opportunity for political/legal interference by governments, and the evidence could be used in any subsequent criminal investigation (Brill-Edwards - Extended Brief 1998).

The committee held the meeting in-camera. According to the House of Commons Archives, there is a record of the Minutes of the Standing Committee's meeting on March 31, 1998. The minutes were brief and state "[. . .] the Committee resumed consideration

\footnotetext{
${ }^{42}$ In Quality Initiative Bulletin \#2, Drugs and Medical Devices Programme, issued by DG Dan Michols the client is "the direct recipient of your services. In many cases, this is the person or company who pays for the service." Further, the public "[. . .] are not your direct client in most cases [ . . ]" (1). Feb. 1997.
} 
of natural health products [...]" (1) and "The Committee proceeded to consider its future business" (1). The meeting was adjourned at 11:25 am, to the call of the Chair. There was no further contact with Dr. Brill-Edwards after that.

\section{Theme 5: The Role of Culture}

The previous data and document reviews pointed to problems in the organizational culture as an important factor in the case. The main findings in this section are summarized below and described in detail in Themes 1 to 3 above. The findings that stood out in considering the details of the case-study were mainly about culture - the behaviour modeled by leaders, articulated policies and rewards for behaviours that are demonstrated. There was evidence which suggested there was dysfunction in the culture that required attention. The behaviours in the organization which gave rise to the whistleblowing leading to reprisals were

(a) non-physician officials overturning the direction of the Asst. Dir. Medical, who had the final responsibility and authority on regulatory and medical decisionmaking regarding drugs in the Imitrex labelling incident

(b) not providing the Minister, Parliament, the Standing Committee on Health and the Canadian public with complete and correct information regarding issues related to their health and safety on an acknowledged unsafe drug - short acting nifedipine

(c) appointing without competition the Director of BHPD who did not have the qualifications to fill the position which decision was found by the PSC not to be in the best interest of the Department 
(d) reappointing the same Director who still did not have the required knowledge of drugs for human use and eliminating the position of Asst. Director Medical leaving the Bureau with no medical expertise

(e) not implementing the Department's Human Resources recommendation to establish an official process for improving communication and/or resolving disputes between professional accountability and public service requirements to avoid any adverse consequences of politically based scientific or health decisions or policy when there was unrest in the Department

(f) allowing the short-acting nifedipine capsule to go to market in 1981 without the requested one year clinical trial and missing evidence of long-term safety

(g) apparently not following up and taking appropriate action in the light of an accumulation of studies containing evidence of potential harm over almost fifteen years (15) in the nifedipine case

(h) changing Dr. Leenen's Draft Dear Doctor letter to remove the remark that stated short-acting nifedipine should in general not be used for stable coronary artery disease (CAD) - an indication for which it had been originally approved

(i) not removing nifedipine from the market as recommended by the Ad Hoc EAC. 


\section{Chapter: Discussion}

The purpose of this research was to examine censure and reprisals against whistleblowers to better understand the dynamics involved so this contradiction can be corrected. This would encourage the exposure of wrongdoing and strengthen accountability in organizations and government. The following research questions framed the study and were answered from the perspective of the whistleblower in the selected case:

(a) Why do whistleblowers decide to blow the whistle?

(b) How do reprisals against whistleblowers occur?

(c) Why do reprisals against whistleblowers occur?

(d) What is the role of law? and

(e) What is the role of culture?

Research was conducted through in-depth, semi-structured interviews and through the review of documents obtained from court records of related court and tribunal proceedings.

This chapter discusses the answers to the research questions suggested by the findings in the light of relevant literature and theory, and the implications for public safety, accountability and democratic government if the problem of reprisals against whistleblowers is not corrected.

The study findings suggest that to address reprisals effectively attention needs to be directed to culture as well as law in the organizations that whistleblowers work in. A preliminary review also suggests further inquiry is warranted into the functioning of the organizations whistleblowers rely on to give them a fair hearing when they stand up for 
their convictions regarding wrongdoing in public organizations such as courts and Parliamentary Standing Committees.

Put another way, the study findings suggest support for the thesis that law and culture perpetuate reprisals against whistleblowers because of poorly implemented laws, lack of adequate whistleblower protection legislation, as well as dysfunctional cultures in organizations. If this is so, it means that citizens cannot assume that because a law exists it will be implemented or interpreted and applied as it was intended to be, or that it is designed to do what it says it will do, or that what a senior bureaucrat does or tells a Minister is correct or in the public interest, or that consequently, when a Minister speaks to reassure citizens - what he/she says is accurate. It also means that if reprisals continue, the expertise, knowledge and commitment that enabled whistleblowers to know when wrongdoing was occurring and to act to correct it will be lost to society as their careers will be destroyed and their lives radically changed. Further, organizations will lose an opportunity to learn and grow when mistakes are made or they face criticism. And, lastly, the outlook for public safety and accountable, democratic governance will be uncertain.

\subsection{The Research Questions}

The answer to the first research question - why do whistleblowers decide to blow the whistle - revolved around Dr. Brill-Edwards motivation to act and her perception of the organizational culture that led her to make the decision to first, blow the whistle internally and then externally. The findings as elaborated in Chapter 4- Results, Theme 1, offer some insight. They support the notion that apart from professional ethics and legislated duty, the overarching motivation was her perception of the culture within 
which she worked. She described the existence of "factions" that consisted of "people who knew their duty and wanted to do their duty and those who didn't know their duty and didn't want to do it even if they did" (Brill-Edwards, pers. comm. April 8, 2014). There was also black humor where staff dubbed their Branch the "Self-Protection Branch" or "Wealth Protection Branch" rather than its real name the Health Protection Branch (Brill-Edwards, pers. comm. April 8, 2014). In other words loyalty to the law that protects Canadians from health hazard- the Food and Drugs Act - was pitted against loyalty to the hierarchy. This law also provided the mandate for the Department as regulator of public safety with regards to food and drugs. An important stimulus for this tension was deregulation. Such motivations regarding professional ethics, duty, and perceptions of dysfunctional culture have been discussed and supported in the works of many authors such as Glazer and Glazer (1989), Jackall (1988), Alford (2001), Heffernan (2011), Miceli and Near (1992), Near and Miceli-Myth (1996), Near and MiceliWrongdoing (2008). The similar impact of deregulation on regulatory organizations has also been examined in Neilsen (2011), and Campbell (2010) among others.

The answer to the second research question of how reprisals occur as elaborated in Chapter 4 - Results, Theme 2 support the suggestion that the whistleblower was punished inside the organization for her ethical and legal stand on unsafe drugs by being demoted, and prevented from accepting a major opportunity for career advancement at the WHO which would have conferred international recognition of the whistleblower's expertise. This occurred even though her concerns were validated regarding both drugs sumatriptan/Imitrex (Regush 1995; Pharma Intelligence 1993) and nifedipine/Adalat (Reviewers reports 1981; Minutes of Ad Hoc EAC Sept. 18, 1995) and the issue of 
conflict of interest. This information was accessible to the decision-makers at the time as the public record currently shows. The product monographs in the Compendium of Pharmaceuticals and Specialties (CPS) 1992 regarding Imitrex were reviewed as was the CPS 1996 regarding nifedipine and provided further validation.

This apparent pattern of censure within the organization was encountered in the Court where she was characterized as a "disgruntled", "biased" employee in the decision of Cunningham, J. D. Leenen $v C B C, 2000$, a defamation lawsuit against the Fifth Estate. While the case did not deal with reprisals per se, it was the direct result of a whistleblowing event. Its treatment of the whistleblower was negative even though her position was supported by the evidence. This decision seemed to equate the fact she was in a dispute with her employer and the CBC's behaviour in not mentioning her dispute with the Department in its documentary, to evidence she was biased. The CBC did in fact mention that Dr. Brill-Edwards had been in a dispute with the Department when she had tried to stop Imitrex being approved without stronger warnings (Heart 8). Further, they noted she had not been rewarded but rather "had lost her authority to oversee the review of new drugs" (Heart 8). What the $\mathrm{CBC}$ did and how they presented the story was their sole responsibility. However, that is separate and apart from what is in the official documents, which for the most part supported Dr. Brill-Edwards' position. Noteworthy is the fact that Dr. Brill-Edwards agreed with the plaintiffs' recommendation to Health Canada that short-acting nifedipine should not be on the market. Where they differed was when Health Canada did not remove it, the committee members said nothing but acquiesced. However, Dr. Brill-Edwards, on the other hand, decided she must not remain silent. 
This pattern of censure and disregarding whistleblowers continued when she was apparently ignored by the oversight body responsible for how Health Canada functioned - the 1998 Standing Committee on Health. While, like the Court, the Standing Committee on Health, 1998, was not asked to consider reprisals against her per se, Dr. Brill-Edwards appearance was the direct result of the act of whistleblowing. The perception that whistleblowers are treated unfairly in these fora could have a negative impact. These entities are meant to provide checks and balances on organizational abuses of power. Their attitudes could negatively impact whistleblowing and whistleblowers decisions to come forward in the future. The belief that nothing will get done is one of the main reasons for remaining silent about wrongdoing (Near and Miceli: Wrongdoing 278).

The answer to the third question of why reprisals occurred as supported by the findings in Chapter 4 - Results Theme 3, point to the reasons as threefold; namely, (1) the whistleblower challenged authority and deregulation -a political imperative, (2) there were problems that suggested a dysfunctional structure and culture, and (3) the loyalty and secrecy oaths which contributed to the dysfunction. Standing in the way of deregulation, "[ . . ] probably the most important public policy of our lifetime" (BrillEdwards, pers. comm. April 8, 2014) was to challenge not only the Department but also the Government of the day. The dysfunctional structure in the BHPD occurred with "deprofessionalizing"43 the Department. Further, it led to having an Assistant-Director Medical with responsibility and paper authority i.e. her job description, but no actual authority due to the actions of a Director found to lack the necessary qualifications to

\footnotetext{
${ }^{43}$ De-professionalizing refers to the removal of professionals with expertise in relevant fields (BrillEdwards, pers. comm. April 8, 2014).
} 
perform the task. See Joyal, J., Chopra V. National Health and Welfare 1992 (Federal Court file no. T-3026-91).

Furthermore, Dr. Brill-Edwards had breached the legal and policy imperative of secrecy and loyalty which she had been required to adhere to by signing an oath to that effect when she was hired. She did this by openly challenging the Department's appointment of a Director with no knowledge of marketed drugs for human use in the BHPD, refusing to sign an agreement to keep silent about her knowledge of the Department's activities she and others were questioning, refusing to desist from legal action against the Department and finally, working with the media to try to expose and correct the problems.

Regarding secrecy and loyalty, even though the precedent of the Supreme Court decision in Fraser v. Public Service Staff Relations Board (PSSRB), [1985] 2 S.C.R. 455 created an exception to the loyalty/secrecy imperative in the case of illegality or a threat to the health and safety of the individual or others, it was not well known or understood at the time. Its application currently is "inconsistent" and "maturing" (Treasury Board 1) and not very helpful to whistleblowers (Hoque 1). Others contend that loyalty and whistleblowing are compatible (Lewis 2011; Larmer 1992; Vandekerckhove 2004) and its application in the public service is confused and suggests a need to reconsider it (Sossin 2005; PSC 2011). The findings raise such questions as what were/are the cultural understandings and imperatives regarding the role of public servants? To whom do they owe their first loyalty - the Canadian state and the law or the Minister/party in power? What comes first policy or the law? Who regulates the regulator? 
To answer the fourth question regarding the role of law in reprisals - it was inconsistent - sometimes helpful and sometimes not. The Food and Drugs act was pivotal, as it provided the mandate for Health Canada as regulator of public safety (Carter 222) and as such, informed Dr. Brill-Edwards of her legislated duty in her role as A/Asst. Director - Medical. However, when it came to upholding this law, there was no independent mechanism to assist when problems arose. Regulations regarding public safety were seemingly ignored by those in authority and there were no consequences. The Public Service Employment Act 1985 was not respected by the Department in its hiring processes. Further, when the PSC and the Federal Court tried to correct the problem it was not successful, as ways were found to get around the 1992 decision to remove the Director who did not have the requisite qualifications for the job.

The Court judgement of the whistleblower in the defamation lawsuit Cunningham, J.D. in Leenen $v C B C 2000$, was puzzling in its treatment of the whistleblower and has been discussed previously. The following analysts have raised similar concerns regarding the question of how whistleblower cases fare in the courts indicating further inquiry could be warranted: (1) the experience in the UK has lead them to suggest that under present [whistleblower protection] legislation as applied by UK courts, "the defense of employers trumps the public-interest matters about which whistleblowers express concerns" (Ramage 1-2); (2) and in the US, a study done of state court whistleblower cases by Modesitt ${ }^{44}$, similarly suggests "[ . . .] that courts are denying claims based on employer-favorable legal standards as well as by considering the evidence in a light favorable to the employer" (194).

\footnotetext{
${ }^{44}$ Nancy M. Modesitt is Associate Professor of Law, University of Baltimore School of Law.
} 
The Parliamentary Standing Committee on Health 1998, while not dealing with the reprisals per se, was involved as the direct result of the act of whistleblowing in this case. As far as can be determined, it was ineffectual in its role as oversight body for Health Canada which was responsible and accountable for its performance in implementing the Food and Drugs Act. While its members requested detailed information from the whistleblower regarding her allegations of Departmental officials misleading them and promised an investigation (Standing Committee on Health March $\left.28^{\text {th }}, 1998\right)$, there is no evidence that they ever took meaningful action to get to the bottom of things but rather met in secret, behind closed doors. They met in-camera March $31^{\text {st }}$, 1998. However, there was no further contact with Dr. Brill-Edwards and no evidence that an open, transparent investigation took place.

With regard to the fifth and last question - the role of culture- the evidence supports its central importance. It was the leadership behaviours modelled, policies articulated, rewards for behaviours demonstrated and the collective practices of organizational members that allowed the paradoxical behaviour of reprisals as well as other questionable behaviours to occur. This discovery was somewhat surprising as, at the outset, it seemed the solution to the problem was to have iron-clad, whistleblower protection legislation prohibiting reprisals. However, because of the evidence uncovered by the case study, and information gleaned from the work of others such as Tweedie 2010; Fennessy 2010; Thomas 2014; Saunders \& Thibault 2010; Near \& MicelliWrongdoing 2008; Modesitt 2011; Neilsen 2012; Miethe \& Rothschild 1994; Rothschild \& Miethe 1999; along with the experience of Dr. Brill-Edwards, I have come to the realization that this evidence indicates that strong legislation is only part of the 
picture. What matters most is how those who are responsible for interpreting, implementing, and enforcing the law perform those duties. If they are operating in a system which allows for systematically ignoring the law or the checks and balances in the system such as the courts and Parliamentary oversight committees are not working well, then it really does not matter how "ironclad" the law is. In such circumstances, it will be as if there is no law as it will be ignored or otherwise circumvented. One analyst, commenting on what happens when laws become ineffectual because other mechanisms or instruments in the system are weak or flawed stated "Laws are reduced to statements of aspiration, of an unrealistic ideal" (Quintos de Jesus 9-10). The resulting culture of impunity, deception and worse could lead to not only an increase in reprisals but to the flourishing of wrongdoing, a concern of many throughout the world $\left(13^{\text {th }}\right.$ International Anti-Corruption Conference (IACC) 1).

\subsection{Understanding Reprisals - The Literature and Theory}

Why then, did reprisal for the whistleblower occur and why does it matter? The literature and theory reviewed for this study can provide some insights. To begin, an understanding of the societal cultural context in which public and private organizations operate is instructive. Building on work by Merton, Vaughan proposes organizational misconduct is socially and culturally produced. Elements that facilitate this process are competition, economic success as a culturally approved goal, and erosion of norms supporting legitimate procedures for achieving success (Controlling 54-55). Vaughan made these observations in 1983 and 1996 and they seem to resonate even more today, especially in the light of the 2008 global financial meltdown. 
With regard to reprisals, we know from the literature and theory that reprisals will occur regardless of whistleblower protection legislation or if the allegations of wrongdoing are right or wrong (Near \& Miceli-Wrongdoing 2008; Rothschild \& Miethe 1999; Latimer \& Brown 2008; Sumanth, Mayer \& Kay 2011). In the US, whistleblowing has increased but so have reprisals (Near \& Miceli- Wrongdoing 271; L. Lewis 1) despite a thirty-seven-year history of whistleblower protection legislation and enhancements to the legislation (Near \& Miceli Wrongdoing 264). Near and Miceli proposed a number of potential explanations for this increase in whistleblowing (and also reprisals) one of which is apt in this case - that whistleblowers may consider it more important to get the wrongdoing stopped than the potential retaliation (271; BrillEdwards, pers.comm. April 6, 2014 ). We also know that whistleblowers are more likely to blow the whistle externally if they are ignored internally (Near \& MiceliWrongdoing 274) and external whistleblowing is more likely to incur management's condemnation and reprisal (Miethe \& Rothschild 342, Sumanth, Mayer \& Kay 168). These propositions correspond to the experience in this case, where the whistleblower's concerns were ignored internally and she was subjected to professional reprisals. This eventually led to external whistleblowing where she was described by the Court in Leenen v CBC 2000 as "disgruntled", "biased" and a "leaker". This occurred even though the information in official documents concurred with her views. She was ignored by the official oversight body for Health Canada - the Standing Committee on Health which did not investigate as proposed. The exception was the specific issue of conflict of interest, where medical researchers took notice of the negative impact of this on unbiased reporting of the safety of pharmaceuticals. This research found that scientific bias is 
associated with financial conflicts of interest (Stelfox et al 105). The study recommended full disclosure of relationships between medical researchers and pharmaceutical companies before publication of their work (105), and resulted in important changes in this area.

A pattern has been demonstrated in initial research findings by Near \& Miceli that “employees are more likely to blow the whistle when wrongdoing is serious, frequent, long-lived or widespread, and the evidence is clear - but under these conditions they are also less likely to be effective in persuading the organization to terminate wrongdoing and more likely to suffer reprisal themselves" (Wrongdoing 277). It seems in this case, the events fit this described pattern. This is demonstrated by the fact the problems had gone on for a long time, were not corrected and the reprisals occurred regardless of the verifiable validity of the claims of the whistleblower.

\section{Why Managers Resist Correcting Wrongdoing}

Near and Miceli and others have noted several reasons for resistance by top managers to correcting wrongdoing (Wrongdoing 274-5). Another reason cited in more recent literature is political pressure and de-regulation (Neilsen 385 - 87). Neilsen points out that "regulators are often under systemic pressure from the politicians who appoint them to ignore whistleblowing cases relevant to their sources of financial and/or ideological political support” (385). Dr. Brill-Edwards description of her experience as she witnessed the impact of the political imperative/policy of de-regulation on Health Canada suggests a similar theme. As she describes it, the Department transitioned from performing its legal duty under the Food and Drugs Act as "regulator of public safety" 
(Carter 222) ${ }^{45}$ to acting as the facilitator of economic success of the pharmaceutical industry in Canada (pers. comm. April 8, 2014; Min. Task Force 11, 17; Paquette \& Sheppard 2-4). This was in line with the views of other "critics" who assert that deregulation had played a role in "institutional corruption" of pharmaceutical policy (Light,Lexchin, \& Darrow 2013; Lessig 2012) ${ }^{46}$ With regard to de-regulation and reconfiguration of regulation, according to Campbell, this global trend permits and encourages more latitude for market actors and a self-regulating market and also includes fewer resources for regulation that might restrict market actors along with a belief that this is better for the economy (66). Campbell, along with others, also partially attributes to de-regulation the cause of the 2008 U.S. financial market melt-down (qtd. in Neilsen 386, Havemann 1-3). That this approach is better for the economy is increasingly under scrutiny influenced by regulatory failures such as the damage caused by the meltdown in the US and global economy and anger and indignation due to lack of consequences to the Executives responsible (Apuzzo and Protess 1).

\section{Individual Cognitive and Emotional Factors and Reprisals}

In addition to the above mentioned reasons for resistance to correcting wrong doing and its attendant discrediting of and reprisals for whistleblowers, Sumanth et al (2011) identify underlying cognitive and emotional forces in individuals, and factors in organizations that help understand the paradoxical behaviours in whistleblower cases as expanded on in Chapter 2. With regard to individuals, Dr. Brill-Edwards was willing to assert her concerns through channels open to her within the system and externally. These

\footnotetext{
${ }^{45}$ Carter notes that in C.E. Jamieson v. Canada, 1987, The Canadian Federal Trial Court confirmed that the dominant subject matter of the Food and Drugs Act is the regulation of public safety and that this role is constitutional as it is a matter of national importance (222-223).

${ }^{46}$ The Journal of Law, Medicine and Ethics in 2013 sponsored a Symposium in which Dr. Lexchin and other academics contributed sixteen (18) papers investigating the corruption of pharmaceutical policy.
} 
centered around the conflict between the demands of her professional duty as a physician and her legal duty as a regulator of public safety under the Food and Drugs Act versus the demands of the politically based policy decision of de-regulation and its adverse consequences for public health and safety (Brill-Edwards, pers. comm. April 8, 2014). It is reasonable to postulate that this stance could have been perceived as threat to ego, group and system by her managers and some co-workers as it implied there was something wrong with them, thus triggering justification motives and moral emotions of anger, fear, and shame as well as moral disengagement. These processes could have allowed for reprisals to take place and at the same time served to reduce "anxiety, guilt, dissonance, discomfort and uncertainty" for those inflicting the punishment (Jost and Hunyady, qtd in Sumanth, Mayer \& Kay 169). They could also have allowed for the partial information on an important drug safety issue, short-acting nifedipine, being provided to the Minister in this case that was different from the information in official records of the Department and had the effect of protecting individual careers and the organization's reputation as well as potentially increasing risk to patients.

\section{Organizational Factors and Reprisals}

With regard to the organization, Sumanth et al's (2011) factor of ethical climate and legitimated behaviour appear to be factors contributing to the paradoxical treatment of the whistleblower in this case. As espoused by Jurkiewicz \& Giacalone and others, three important elements influence the development of either an ethical or unethical climate - structure, culture and leadership (1-3). The first, structure- in a bureaucracy which is a strict vertical hierarchy such as Health Canada - is a key element that fosters dysfunctionality. This is so because it "constrains communication and offers little to no 
recourse for employees to circumvent the authoritative reporting relationship in the event of top-down unethicality" (Jurkiewicz and Grossman as qtd in Jurkiewicz \& Giacalone 2). Other elements are lack of transparency programs, and reputational strain caused by resource-deficiency, scandal, litigation, or negative media reports (Jurkiewicz \& Giacalone 2).

With regard to the second element, culture, these researchers point out that organizational culture is a function of leaders' modeled behaviour, policies that are articulated, and rewards for behaviours that are demonstrated among others (3). One of many aspects of culture that is more likely to contribute to ethical dysfunction than others, is a reward system that rewards unethical behaviour, for example, pressuring for goal attainment while communicating a lack of concern for how this is done (4). The third element, leadership dysfunction, is important as leaders exert a powerful influence on the culture of an organization through their behaviours. Some will engage in moral disengagement to justify to themselves unethical behaviour and reframe it as morally acceptable. Those most likely to engage in moral disengagement have four personality characteristics: lack of moral identity, low empathy, a chance/external locus of control orientation and trait cynicism (3).

It is reasonable to suggest that all three - structure, culture and leadership - could have played a role in the cultural problems highlighted by this case. The organization, Health Canada, was and is a vertical hierarchy where lack of transparency was endemic and reputational strain was obvious considering there were scandals, three criminal 
investigations ${ }^{47}$ and negative media reports taking place at the time (Brill Edwards, pers. comm. April 6, 2014). The culture seemed to allow some employees to push the political goal of de-regulation and the needs of its clients - the pharmaceutical industry.

Leadership and ethical climate are suggested as possible issues by the issuance of a Notice of Compliance for sumatriptan/Imitrex without adequate safety labeling by senior officials and a Director who was acknowledged by the PSC and the Federal Court in Joyal, J., Chopra V. National Health and Welfare 1992 to lack the knowledge required to make such a decision (Federal Crt. file no. T-3026-91). It was also suggested by the letters from the Deputy Minister and her sub-ordinates to the Minister providing him with information that was not congruent with the reality as set out in the official Minutes of Sept. 18, 1995 confirming the lack of safety, of the drug nifedipine for the use it was originally approved for - angina.

The foregoing and other issues cited in Chapter 4 - Results, suggest the ethical audit tool of Jurkiewicz \& Giacalone - the Dysfunctional Dozen - might have been helpful in the Health Protection Branch at the time to establish a baseline ethical climate.

See Table 2.6 for details. The behaviours suggest a culture characterized by tensions between whether the priorities should be loyalty/accountability to the law or to the political imperative of deregulation.

The element of impunity is important in this discussion as it is one of the characteristics of an organizational culture which supports ethical dysfunctionality and a potential increase in wrongdoing which includes reprisals. There are a number of theories that can provide some clarity, for example, Diane Vaughan (1996) proposes

\footnotetext{
47 The three criminal investigations were the tainted blood scandal, the destruction by Bureaucrats of related Blood Committee documents and the harm from Meme breast implants (Brill Edwards, pers. comm. April 6, 2014).
} 
culture, structural secrecy and normalized deviance as motivating unlawful organizational conduct similar to Sumanth, Mayer \& Kay (2011), Jurkiewicz \& Giacalone (2014), and Near \& Miceli in Wrongdoing (2008). Solomon Asch's conformity theory regarding often subtle, unrecognized pressure in groups for individuals to conform to the group's ways of thinking and behaving, whether right or wrong $(1955,1961)$ and Stanley Milgram's work on obedience to authority regardless of the damage that may be inflicted on others (2009), also help to explain why, at times, human beings are blind to behaviours that are contrary to their own ethical values, and sometimes the law as well, often with disastrous results. These theories are apt in beginning to understand why people not only remain silent in the face of organizational wrongdoing but also participate in the wrongdoing. These forces serve to insulate the wrongdoers from consequences and permit impunity to flourish.

Near and Miceli were also alert to the impunity factor. They observed in 2008 that lawmakers "may have more impact on the incidence of whistleblowing than laws aimed at reducing retaliation against whistleblowers" (Wrongdoing 278) by taking policy actions which increase the penalties for wrongdoing and thus increase sensitivity to wrongdoing (Wrongdoing 278). They speculate that executives and managers would be more likely to listen and terminate wrongdoing if they were aware of penalties they would suffer if wrongdoing were to continue. Seeing wrongdoing terminated would then likely encourage others to blow the whistle (278). ${ }^{48}$

\footnotetext{
${ }^{48}$ The new US Attorney General is in accord with Near and Miceli here. She announced her new policies on Sept. 9, 2015, "that prioritize the prosecution of individual employees - not just their companies - and put pressure on corporations to turn over evidence against their executives" (Apuzzo and Protess 1).The Deputy Attorney General agreed. "It's only fair that the people who are responsible for committing those crimes be held accountable. The public needs to have confidence that there is one system of justice and it applies equally regardless of whether that crime occurs on a street corner or in a boardroom" (Apuzzo and Protess 1).
} 
Finally, the theories of Argyris and Schon regarding learning organizations inform us of how impunity can flourish in organizations which use defensive reasoning in response to error and criticism. This approach, as described in Chapter 2, is characteristic of a learning system which uses only single loop learning and does not engage in double loop learning, or reflective, productive reasoning which leads to negative results. The key effect is that the values underlying the practices and processes leading to the error or criticism will not be surfaced, criticized or changed. Such defensive routines, especially evident when issues are embarrassing or threatening, create a learning system or behavioural world (culture) characterized by anti-learning conditions and dysfunctional responses such as vagueness, ambiguity, untestability, scattered information, information withheld, undisscussability, uncertainty, and inconsistency/incompatibility. A more productive learning system would see processes and decisions open to scrutiny by those expected to use them, and double loop, productive learning would flourish. The two elements - theories-in-use and the organizational learning system - with the two being interdependent - create the conditions that will make it more or less likely that "crucial issues will be addressed or avoided, that dilemmas will be publicly surfaced or held private, and that sensitive assumptions will be publicly tested or protected" (Argyris \& Schon 29).

The behavioural world or culture which thrived in Health Canada at the time appeared to be characterized by defensive routines which are one of the most important causes of organizational rigidity and stickiness (Argyris and Schon 101). These defensive behaviours could be seen in the behaviours at Health Canada at the time such as restricting the participation of the staff in the Ad Hoc EAC of September 18, 1995 to 
observers who could not speak. Another example was providing information to the Minister which was only partially correct, while the most important part, the lack of safety of short-acting nifedipine for its original approved use was omitted. Could this have been an error or misunderstanding rather than purposeful? Possibly, however, either way it would not reflect well on the functioning of the Department, particularly in times of crisis. A further example is the decision by the Director to push through a drug approval, Imitrex, despite the authority and expertise of the person qualified and authorized to make such a decision. Another indication of lack of openness or willingness to discuss difficult issues was not establishing the recommended Council of representatives of the various professions and Managers "to resolve conflicts between the demands of professional accountability versus public service regulations or requirements" considered necessary "to avoid any adverse consequences of politically based scientific or health decisions or policy" (Health \& Welfare Canada, HR Study 4).

While organizations that are less rigid and more innovative may be less threatened by whistleblowers and more willing to halt wrongdoing (Miceli et al., 2008), the responsible people in organizations do not believe that much can be done to change the rigidity or that to try would be dangerous (Argyris and Schon 101). Thus, defensive reasoning becomes sanctioned as correct and another paradox arises: "[. . .] the behavioural strategies [double-loop, productive learning] that are defined as effective also reduce the likelihood of productive learning at all levels of the organization" (Argyris and Schon 107). The Whistleblower's experience indicated that Health Canada at the time was not an open, reflective Learning Organization but rather operated on defensive 
routines characterized by secrecy and impacted by strains in the environment affecting the culture and ethical climate.

\section{Institutional Corruption, Legal Ideology and Reprisals}

The pronouncement of the Court that Dr. Brill-Edwards was a disgruntled, biased, disloyal employee is puzzling as the evidence before it showed her concerns were founded. Further, as a physician and regulator. expert in regulatory law, she agreed with the plaintiff that an unsafe drug should be taken off the market. Lessig's thinking on institutional corruption could shed some light on this. Could it be that "[ . . ] individuals within the institution had become dependent upon an influence that distracts them from the intended purpose of the institution? The distracting dependency corrupts the institution" (Lessig 15). On institutional corruption he states "It is a systemic and strategic influence which is legal, or even currently ethical, that undermines the institution's effectiveness by diverting it from its purpose or weakening its ability to achieve its purpose, including, to the extent relevant to its purpose, weakening either the public's trust in that institution or the institution's inherent trustworthiness [...]" (553). As an example he suggests one form of institutional corruption could be ideology (a set of beliefs or ideas) within a judiciary without any money changing hands (553). Sargent's example of a legal ideology - there is a difference between "true crimes" and regulatory or public welfare offenses with the latter being less serious or important than the former - is relevant (107). This legal double standard sees enforcement of regulatory offences "continually subordinated to the enforcement of conventional Criminal Code offenses by the police, crown prosecutors and the judiciary" (108). 
While the decision in the defamation lawsuit may have been correct about defamation of the plaintiff, it leaves unexplained the reason for its criticism of the whistleblower when the official documentation showed support for her position. Could legal ideology be implicit in this decision where the court in Leenen $v C B C, 2000$ determined the issue was not important or in the public interest? Perhaps beliefs about loyalty could have been at play? Could the opinion as stated in Bellamy, J, Myers $v$ CBC, 1999 that "The minutes are not intellectually accessible to a person who is not a physician" have played a role? Could ideology also be implicit in the apparent inaction of the Parliamentary Standing Committee on Health? Or was it more political and policy imperatives or defending the reputation of the Department, the Minister and the Government in the case of the Standing Committee?

The question of how Health Canada uses its powers to safeguard the public has been highlighted in this case. Such beliefs by the Courts as in Sargent's example and the belief that regulators should not be held liable in negligence (Canadian Press 1) suggest, in effect, that immunity has been conferred on regulators for issues with how they implement the law. ${ }^{49}$ If this is so, this is problematic for whistleblowers in this field and for public safety and accountability as there would be no consequences for less than vigilant performance thus no incentive for them to be otherwise.

\footnotetext{
49 Another example of legal ideology or belief is in a ruling of the Ontario Appeal Court Judges to disallow a class-action lawsuit against Health Canada relating to the Meme breast implant (which damaged thousands) that regulatory bodies should not be held liable in negligence as it could lead to decreased vigilance by the regulated entity (Canadian Press 1). This speaks of a similar attitude as, Regulators have the same information about a product or drug as the manufacturer who are required by law to give it to them. In effect, it confers immunity on the Regulator if they are less than vigilant.
} 


\subsection{Alternative Explanations}

I must consider what might be other explanations for what motivated the behaviour of the whistleblower and the behaviours of the others in the Department. Regarding the whistleblower, was she motivated by medical ethics and duty or could her actions have been driven by the fact her position as Asst. Director Medical was eliminated in 1992? Was her credibility tarnished as she was a "disgruntled", "biased" employee who had been in a labour dispute with her employer as suggested in Cunningham, J.D., Leenen v. CBC, 2000? This might be plausible, except the evidence shows several things which do not support this thesis:

(a) The PSC and Federal Court agreed that the new Director of the BHPD did not have the required knowledge of marketed drugs for use in humans among other requirements and she was ordered removed by the Federal Court in Feb. 1992.

(b) The concern was that with the Director's reappointment and the elimination of the Asst. Director Medical position, there was now no medical expertise in the Director's office as the Director still did not have the required knowledge and expertise to do the job. This was seen to pose a potential risk to public safety.

(c) The concern expressed in (b) above was also expressed in a Memo to the Director, BHPD on April 27, 1992 signed by 19 other physicians in the Bureau. The subject was "Lack of Medical Representation at Junior or Senior managerial levels in BHPD" and copied up the line to the Deputy Minister (April 27, 1992).

(d) The documents in the court records such as the Minutes of the EAC meeting Sept. 18, 1995 and the original Reviewer's reports on nifedipine, all suggest support for the whistleblower's position. 
Could the reason Dr. Brill-Edwards blew the whistle to the CBC's Fifth Estate have been motivated by wanting to somehow exact retribution on her employer? Possibly, except it is hard to conceive of giving up an appointment to the World Health Organization won in an international competition and representing career advancement to harm ones employer. Why would she refuse to sign a secrecy agreement and/or cease legal proceedings against the department if it meant she could have gone on with her life and advanced in her career? Why would she have preferred to resign, give up her career and live four years in the "wilderness" before again finding meaningful work? Why would she have continued to make presentations to the Parliamentary Standing Committees, especially the Standing Committees on Health regarding drug safety for more than a decade until $2008 ?$

With regard to the Director and the other members of the Department who Dr. Brill-Edwards regarded as loyal to the hierarchy rather than the law, could this rush to approve Imitrex against medical direction have been a purposeful decision of self-interest i.e. to do what the boss wants regardless of who is harmed or what the law said? It is possible other powerful, unconscious forces were at play, such as those described by Milgram on obedience to authority (2009) and Asch on conformity in groups (1955, 1961) and Argyris and Schon (1996) regarding learning organizations and defensive approaches to error or criticism versus reflective approaches. It is also possible that the Director did not understand the implications for harm of doing what she did regarding Imitrex labelling as she did not have the requisite qualifications to make decisions regarding drugs. It may have been that she believed her first loyalty should be to the Minister and other considerations second, i.e. law, the Canadian state and the public 
interest. Loyalty as it is currently understood is being re-thought by scholars such as Sossin (2005). The Public Service Commission observed that linking impartiality to loyalty is a paradox causing confusion on what is the role of the public servant (PSC 2008). The possibility that the disputes about Imitrex and nifedipine/Adalat were simply about personality clashes and people just not getting along should also be considered. However, the evidence does not support this. The Asst. Director Medical worked for two years with the previous Director with no issues and with the replacement Director Franklin for one year before major concerns arose. The documents reviewed for this study suggest that the disputes arose around questions of safety and the application of appropriate expertise to medical questions and thus were about matters of principle rather than personalities.

Vaughan suggests that the organizational structures and forces that transformed deviance into acceptable behaviour were to blame for the Challenger disaster and not individuals. On the other hand, those of Sumanth, Mayer, \& Kay (2011), and Jurkiewisz \& Giacalone (2014) allow for individual responsibility in the face wrongdoing. It is likely that all or many of these things could have been at play and a lesson from this study suggests a need to focus on how to help employees maintain some autonomy as individuals subjected to powerful forces pushing them in the opposite direction. Such forces disconnect them from recognizing and addressing ethical dilemmas and breaches of law.

\subsection{Implications of this work}

Why does it matter if the problem of reprisals against whistleblowers is not corrected? It matters as there are important negative implications for public safety, 
accountability and democratic government. If whistleblowing is not facilitated by better legislative protections, and more open, transparent, reflective, ethical workplaces where dissent is permitted and even encouraged, then wrongdoing will have fertile ground to flourish. Further, Canada's Access to Information legislation is not working as hoped, making it difficult to know what is going on in government, and, without this knowledge accountability and participating in the decision-making process is diminished (Kazmierski 613). This makes it even more imperative that attention be paid to improving the situation for whistleblowers.

If we believe that whistleblowers are our best hope for finding out about organizational misconduct (Miethe \& Rothschild 1994, Rothschild \& Miethe 1999, Latimer and Brown 2008, Near and Miceli - Wrongdoing 2008, Wolfe et al 2014) and appreciate what this means for a better functioning society, improving legislative protections for public interest whistleblowers is critical. However, in tandem with this must be a focus on ensuring that public organizations and oversight bodies pay attention - openly, effectively and transparently investigating when important issues arise. This includes correcting wrongdoing when whistleblowers inform them of their observations and they are confirmed. This is important - as without ethical cultures, laws will not be very helpful as they will not be upheld (Lachman 394, Latimer \& Brown 2008, Thomas 2005, Thiessen 1998, Hutton 2017 ) thus undermining the rule of law. This implies more attention to cultural and ethical dysfunctionality and modifying the structural, cultural and leadership conditions that allow reprisals and misconduct to occur in the first place (Jurkiewicz and Giacalone 2014, Near \& Miceli - Wrongdoing 2008). Important among these characteristics or conditions is impunity and researchers such as Near and 
Miceli have suggested penalties as likely being more effective in discouraging wrong doing, including reprisals, than legislation prohibiting reprisals (Wrongdoing 2008 ).

The import of this work for whistleblowing policy in organizations is brought into sharp focus when considering the consequences for Health Canada and thus to those it serves, since the whistleblower's and other scientists' concerns in this case were ignored. These consequences are laid bare in reports from the Office of the Auditor General of Canada, the media, the Department itself and indeed the government of Canada through new legislation which I cite below.

The Auditor General (AG) as early as 2000 began flagging the major challenges to health and safety regulatory programs from, among others, funding and staff reductions, regulatory failures to increasing conflict with the growing application of the precautionary principle. There were also recurring findings in this report about the major difficulties of such programs to meet the expectations of regulatory policy (AG Report December 2000, 24.142- 24.144). Some six years later, in the AG's February 12, 2007 statement to the Public Accounts Committee, the Auditor General stated, "The audit found that Health Canada does not know if it is fully meeting its regulatory responsibilities as the regulator of product safety, medical devices, and drug products" (1). Funding had decreased over the previous three years making it difficult for program managers to "fully meet the Department's regulatory responsibilities of protecting the health and safety of Canadians" (1). On March 29, 2012, in a Statement to the Standing Committee on Public Accounts, the Assistant Auditor General spoke of their Fall 2011 report examining how Health Canada fulfilled its key responsibilities regulating pharmaceutical drugs. These were timeliness, consistency, transparency, conflict of 
interest, and risk-based post-market activities. He stated, "We found that the Department had not adequately fulfilled most of these key responsibilities related to clinical trials, submission reviews, and post-market activities" (1). On October 3, 2012, he spoke to another Committee - the Senate Standing Committee on Social Affairs, Science and Technology - again on findings in the 2011 Fall Report of the Audit regarding Regulating Pharmaceutical Drugs. This time he focused on the finding that the Department had not adequately fulfilled most of its key responsibilities related to postmarket activities and in particular identification of "potential safety issues" as it did not have adequate mechanisms to receive foreign adverse drug reaction reports electronically in a database (1).

It is not clear if the Auditor General's Reports influenced the government's recent actions to reassure Canadians about drug safety. However, on Nov. 6, 2014 the government of Canada passed a new law called "Vanessa's Law" 50 to give Health Canada certain powers in health regulatory matters. In reality, the Department already had those powers but failed to use them. The discrepancy was noticed by lawyers in one law firm who noted that practically speaking, the Minister of Health already had all the powers the publicity around the new law described as "enhanced powers" to regulate drugs and medical devices (VanderElst \& Squire 2). The most significant changes found in the legislation were the increased penalties for non-compliance with the law. They wondered if this signaled the advent of a more aggressive approach to enforcement (VanderElst and Squire 2).

${ }^{50}$ This law was named after the 15 year old daughter of Mr. Terence Young, former Conservative Member of Parliament who lobbied for tightening drug regulations after the death of his 15 year old daughter Vanessa. Her death in 2000 was associated with the Johnson and Johnson prescription drug Prepulsid or Cisapride which was subsequently withdrawn from the market. Following her death he wrote the book Death by Prescription published in 2009. 
This incongruity of giving Health Canada powers it already has, reinforces the point that the law may be in place but will not necessarily be administered and implemented appropriately depending on other forces and/or dynamics for example, cultural and political (Neilsen 2011). Transparency in the form of giving physicians open access to the data on which a decision to approve a drug is based would go farther to restore public trust than such tactics and improve the prospects for public safety. An independent Drug Safety Board, like the Transportation Safety Board, to investigate when "drug crashes" occur would also help (Wood, Stein, \& Woosley 1998). The findings in this study and the current work of academics indicating the ongoing relevance of the findings, suggest a need for an investigative mechanism is urgent. The powerful influence of the drug industry in getting faster reviews of new drugs from regulators gives cause for concern considering the following: (1) the results of three studies conducted in 1998 (Lazarou, Pomerantz and Corey), 2004 (Pirmohamed et al), and 2006 (van der Hooft et al) were analyzed and the analysis concluded that 6.8 percent of hospital patients i.e. 2.7 million hospitalized Americans each year, had "serious ADR's" ((Light, Lexchin, Darrow 593), (2) of all hospitalized patients, "0.32 per cent died due to adverse drug reactions (ADR's)" i.e. 128,000 patients. This is the fourth leading cause of death annually, matching stroke (Light, Lechin and Darrow 593), and according to these authors, a 2011 analysis came to similar conclusions (593). Other works report similar concerns about unsafe drugs (Davis \& Abraham 259-285; Young 13; 7).

Dr. Joel Lexchin, an expert in Canadian Health Policy, believes the closely interconnected relationship between Health Canada and the pharmaceutical industry has far deeper roots than that marked by the institution of user fees in the 1990's and eliminating 
such fees would not change much. Rather, it just accelerated a previously existing pattern and "speaks to the need for a much more sweeping analysis of the culture within Health Canada and the political system within which it exists" (28).

\subsection{Conclusion}

The law and culture played important roles in perpetuating the paradoxical behaviour of reprisal for the whistleblower in this case. In Canada, our whistleblowing law has been criticized as falling short of its goal of adequate protection for whistleblowers. However, the events in this case and the testimony of many current Canadian whistleblowers (Fennessy 2010, Canadians for Accountability, Hutton 2017) indicate that culture plays an equally, if not more important role, in attitudes and behaviours towards whistleblowing and wrongdoing. The fact that the PSDPA review by Parliament, which was due under the Act itself in 2012, is just now taking place at the beginning of 2017 is current testimony of how culture trumps law at times.

This work illustrates and supports a conclusion that to correct the paradoxical behaviour of reprisals against whistleblowers a many-faceted approach should be used. A focus on culture reform in any organization includes understanding individual and organizational determinants of dysfunctional behaviour at the structural, leadership and cultural level that can be improved: (1) through awareness raising and (2) through strategies that individuals and leaders in organizations can initiate themselves without depending solely on the law. This is particularly important in Canada since it seems, according to legal ideology, regulatory law breaking is considered less important than "real crimes" such as street crimes (Sargent), and the courts have reinforced this belief by 
declaring that regulators should not be held liable for negligence among other arguments (Canadian Press 1).

The questions raised also point to other areas for research such as on the impact of culture on the functioning of mechanisms such as the courts (Modesitt 2011, Ramage 2013) and parliamentary committees (Rathgeber 2014) that should provide checks and balances on government and organizational power and its potential abuse. Others have pointed to the need for research in these areas such as the research project on "Regulating Judges: Expanding the Horizons" bringing together twenty scholars from around the world including Canadian researchers Professor Dodek, University of Ottawa and Professor Devlin, Dalhousie University (Carleton University, Juris Talk notes 1); and Donald Savoie on increasing the oversight capacities of Parliament through establishing a new parliamentary committee on public administration (274). Such studies of court decisions regarding federal whistleblowers in Canada should also include the role of legal ideologies in reprisals, such as beliefs about the common law imperative of loyalty, or regulatory breaches are not as serious as "real" crime, or employer favourable standards or other factors that may be implicit in the decisions. Another area would be a study of the functioning of Parliamentary Standing committees in other whistleblower cases, for example, the Senate Standing Committee on Agriculture, 1999 in the case of rBST, examining why did it use its powers to support whistleblowers when others did not? And finally, more in-depth case studies of other Federal whistleblower cases which may support or not the findings in this case, or point to other areas for research focus and action. 


\section{Limitations of the Study}

It is acknowledged that a limitation of this case study is that it is just that - one case study. However, the findings are important in and of themselves regardless of generalizability. This is so as the subject matter is regarding an area of national importance and concern, and of vital public policy import - the role of Health Canada as the regulator of public safety under the Food and Drugs Act, a role that has changed significantly since the 90's. The subject matter also highlights the critical nature of getting it right when it comes to the protection of whistleblowers, without whom it would be very unlikely we could know of wrongdoing nor could we correct or prevent it.

Further, as previously discussed, some qualitative researchers have proposed a more appropriate term in qualitative research is "transferability" as generalizability is a term associated with quantitative research. From a qualitative perspective, transferability is primarily the responsibility of the one doing the generalizing. This person is also responsible for making the judgment of how sensible the transfer is.

It must also be acknowledged that the managers the whistleblower worked with in BHPD - from the Chief, through the Director, the Director General, the Assistant Deputy Minister to the Deputy Minister - were not interviewed for this study so their motivations for their actions have not been expressed by them.

While this work does not have all the answers, it does suggest areas for future research that could help identify patterns that create obstacles to changing the whistleblowing paradox of reprisals as discussed above. 


\subsection{Recommendations}

The problematic paradoxical behaviour of reprisals against whistleblowers which negatively impacts the prevention of wrongdoing could be improved with the implementation of a number of strategies. The recommendations below are suggested to address the findings in answer to each research question.

(a) Why blow the whistle? To address the findings of dysfunctional cultures and conflicted loyalties likely exacerbated by deregulation

i. institute training for staff on ethics, barriers to ethical behaviour and how to overcome them as understanding and knowledge of such forces can foster prevention of wrongdoing (Zimbardo 443);

ii. institute training for staff on the role of public servants as elaborated by Sossin. His propositions seek to "improve the effectiveness of the civil service in executing the policy preferences of the government of the day $[\ldots]$ " while at the same time "[ . . ] revitalizing the role of civil servants as guardians of the rule of law and the public trust" (59);

iii. institute training for staff on the intersection of politics and law, accountability to law and democratic governance (Tardi 2011);

iv. provide consultant assistance to managers to help them surface their theoriesin-use vs espoused theories leading to more effective, productive rather than defensive reasoning when dealing with error or criticism (Argyris \& Schon 1996);

v. conduct ethical climate audits done by internal auditors and/or external auditors (Jurkiewicz and Giacalone 2014); 
vi. engage independent ethicists with whom employees can consult;

vii. establish a council of professionals and senior managers and an ongoing consultative process "to resolve conflicts between the demands of professional accountability versus public service regulations/policy to avoid any adverse consequences of politically based scientific or health decisions or policy" (Health and Welfare Canada - HR Study 4);

viii. evaluate the impact of deregulation on the ability of Health Canada to fulfil its statutory responsibilities (Wiktorowicz 2000, Auditor General's Reports of 2000, 2007 and 2011).

(b) How reprisals occur? To address the findings of reprisals against whistleblowers (i.e. demotion, prevention of career advancement, harassment etc.)

i. create firmer, less symbolic whistleblower protection laws (Latimer and Brown 2008), include the Five Gold Standards for such legislation ${ }^{51}$, ensure regular reviews of legislation and amend according to "international best practice";

ii. prosecute individuals responsible for regulatory wrongdoing in organizations - both private and public - rather than merely fine their organizations under civil law in private organizations (Near and Miceli - Wrongdoing 2008; Apuzzo and Protess 1), and conferring immunity from prosecution on regulatory wrongdoers in public organizations as in Canada currently.

\footnotetext{
${ }^{51}$ The Five Gold Standards recommended by FAIR for whistleblowing legislation are: (a) Full free speech rights. (b)The right to disclose all illegality and misconduct. (c) No harassment of any kind. (d) Forum for adjudication, with realistic burden of proof and appropriate remedies; and (e) Mandatory corrective action.
} 
(c) Why reprisals occur? To address the findings of why reprisals occurred, i.e. for challenging authority and deregulation, dysfunctional structure and culture, and loyalty and secrecy oaths, there is overlap with section (a) why blow the whistle. These recommendations also apply here. Those that apply most directly to challenging authority are

i. institute training for staff on the role of public servants as elaborated by Sossin. His propositions seek to "improve the effectiveness of the civil service in executing the policy preferences of the government of the day [...]" while at the same time "[. . . revitalizing the role of civil servants as guardians of the rule of law and the public trust" (59). This training would include clarification of loyalty and to whom public servants owe their first loyalty;

ii. institute training for staff on the intersection of politics and law, accountability to law and democratic governance (Tardi 2011).

(d) The role of law in reprisals? To address the issue of inconsistencies in how the law was/is upheld, and the question of who regulates the regulator

i. research and implement ways to make Parliamentary committees with oversight responsibilities for departments more proactive, transparent, and effective so that they use their constitutionally conferred powers to get at the real facts when serious controversies arise;

ii. empower the Auditor General to conduct not only regular performance audits of departments, but also special audit inquiries of departments to ensure they are 
operating in compliance with the law, especially when serious allegations of wrongdoing arise and before they become public scandals;

iii. as Donald Savoie proposes, establish a new parliamentary committee on public administration to increase the oversight capacity of Parliament (2003);

iv. establish an independent Drug Safety Board to investigate drug "crashes" (Wood, Stein and Woosley 1998); and

v. research the treatment of whistleblowers in the courts and the role of ideology in decisions in whistleblower cases.

(e) The role of culture in reprisals? To address the central problem of culture and prevent wrongdoing - which includes reprisals against whistleblowers - it is incumbent on leaders at the political level to attend to culture and ethical climate proactively rather than wait until wrongdoing has taken place and then relying on the law to protect those who expose it (Saunders and Thibault 2010, Thomas 2014, Lachman 2010, Jurkiewicz and Giacalone 2014, Sumanth, Mayer \& Kay 2011).

Many of the above recommendations could be implemented proactively by Deputy Ministers, however, the potential obstacle to this taking place without political direction is the poorly defined relationship of the public service with elected officials and with Canadians (Savoie 2003; Heintzman 2014). The blurring of the distinction between elected and non-elected officials has threatened "to undermine the very values and ethics of public service, especially its non-partisan ethos, and its value of speaking truth to 
power" (Heintzman 8). ${ }^{52}$ The impetus for change would thus necessarily need to come from the most senior echelons of the political level of government. This requires a government which takes the safety concerns of whistleblowers seriously, wants to know about the legality and effectiveness of its departments and is willing to openly scrutinize its own political culture as well as the culture in its oversight and enforcement mechanisms.

\footnotetext{
${ }^{52}$ An example of this is the way successive Clerks of the Privy Council have played their role, blurring the line between the political and the bureaucratic (Heintzman 9). He cites Savoie who suggests that the Clerks have emphasized their role as the Prime Minister's representative to the Public Service rather than more correctly as the institutional representative of the public service to the prime minister (Savoie 112).
} 


\section{Appendices}

\section{Appendix A}

\begin{tabular}{|c|c|}
\hline \multicolumn{2}{|c|}{ List of Key Documentation and Sources } \\
\hline Document & Source \\
\hline $\begin{array}{l}\text { Canadian Human Rights Tribunal Decision } \\
\text { T.D.3/96. Mar. 8, } 1996 \text { - Shiv Chopra and Human } \\
\text { Rights Commission and Dept. of National Health } \\
\text { and Welfare. }\end{array}$ & CHRT web site. \\
\hline $\begin{array}{l}\text { Helen Barkley, decision of Public Service } \\
\text { Commission re: improper appointment of Director, } \\
\text { BHPD, upholding Health Canada Scientist's Dr. } \\
\text { Shiv Chopra's application re: improper } \\
\text { appointment. }\end{array}$ & Federal Court File No. T-3026-91. \\
\hline $\begin{array}{l}\text { Order of Federal Court in Chopra v Department of } \\
\text { National Health and Welfare } 1992 \text { to remove } \\
\text { Director and hold new competition. }\end{array}$ & Federal Court File No. T-2143-92. \\
\hline $\begin{array}{l}\text { Decision of Federal Court re:permanent } \\
\text { appointment of DirectorofBHPD. Dismissed } \\
\text { application for review of indeterminate } \\
\text { appointment. }\end{array}$ & Federal Court File No. T-2143-92. \\
\hline $\begin{array}{l}\text { Minutes of Health Canada Ad Hoc Expert Advisory } \\
\text { (EAC) Committee on Calcium Channel Blockers } \\
\text { meeting Sept. 18, } 1995 \text {. }\end{array}$ & $\begin{array}{l}\text { Superior Court of Ontario Records - File No. '96 C.V. } \\
\text { 099908, Ottawa, ON. }\end{array}$ \\
\hline $\begin{array}{l}\text { Memo from Dr. Susan Robertson, Secretary to } \\
\text { EAC, to Dr. Krupa, April 4, } 1995 \text { expressing } \\
\text { concern with how EAC was constituted, } \\
\text { participation of staff, etc. }\end{array}$ & Ontario Court of Appeal, File No. C 34272. \\
\hline $\begin{array}{l}\text { Memo to Minister (David Dingwall) from Deputy } \\
\text { Minister Michele Jean, ADM Foster \& DG Michols } \\
\text { - Feb. 29, } 1996 \text { - Re: Fifth Estate Controversy } \\
\text { surrounding Health Canada's approval and } \\
\text { monitoring CCB's. }\end{array}$ & $\begin{array}{l}\text { Appeal Court of Ontario - File No. C } 34272 . \\
\text { Compendium of Appellants. }\end{array}$ \\
\hline $\begin{array}{l}\text { Letter to Deputy Minister, Michele Jean from } \\
\text { Minister David Dingwall, March 11, } 1996- \\
\text { concerned re: Conflict of Interest. }\end{array}$ & $\begin{array}{l}\text { Appeal Court of Ontario records - File No. C } 34272 . \\
\text { Compendium of Appellants }\end{array}$ \\
\hline $\begin{array}{l}\text { Letter to Minister from Deputy Minister Jean, } \\
\text { March 13, } 1996 \text { in response to C of I concerns. }\end{array}$ & Access to Information and Privacy 1999 \\
\hline $\begin{array}{l}\text { Information Letter, Health Protection Branch, } \\
\text { Health Canada. April 12, } 1994 \text { regarding } \\
\text { appointment of Expert Advisory Committees and } \\
\text { including direction on conflict of interest. }\end{array}$ & $\begin{array}{l}\text { Appeal Court of Ontario records - File No. C } 34272 . \\
\text { Compendium of Appellants }\end{array}$ \\
\hline $\begin{array}{l}\text { Dr. Leenan's Draft Dear Doctor letter circulated for } \\
\text { comments in BHPD - Nov. } 10,1995 .\end{array}$ & Appeal Court of Ontario records - File No. C. 34272. \\
\hline
\end{tabular}




\begin{tabular}{|c|c|}
\hline \multicolumn{2}{|c|}{ List of Key Documentation and Sources - cont'd } \\
\hline Document & Source \\
\hline $\begin{array}{l}\text { Dr. Gruchala's email to Krupa Nov. } 22,1995 \\
\text { re: why Dr. Leenen's Draft Dear Doctor letter could } \\
\text { not be sent out the way it was received. }\end{array}$ & Appeal Court of Ontario records - File No. C. 34272. \\
\hline $\begin{array}{l}\text { CBC Transcript of Documentary "Heart of the } \\
\text { Matter" Feb. 27, } 1996\end{array}$ & Appeal Court of Ontario records - File No. C. 34272 \\
\hline $\begin{array}{l}\text { Dr. Krupa's letter to Leenen re: why he changed the } \\
\text { Draft Dear Doctor letter Jan. 24, } 1996 .\end{array}$ & Appeal Court of Ontario records - File No. C. 34272. \\
\hline $\begin{array}{l}\text { Health Canada's Dear Doctor Letter No. 1- Jan. 23, } \\
1996 .\end{array}$ & $\begin{array}{l}\text { Superior Court of Ontario Records - File No. '96 C.V. } \\
\text { 099908, Ottawa, ON }\end{array}$ \\
\hline Job description - Assistant Director Medical 1989. & Participant's records. \\
\hline $\begin{array}{l}\text { Pfizer's Fax memo to Dr. Leenen re: agreement to } \\
\text { be their spokesperson to the media on CCB's. }\end{array}$ & Appeal Court of Ontario records File No. C. 34272 \\
\hline Food and Drugs Act - 1990 Regulations. & Authors records. \\
\hline $\begin{array}{l}\text { Dr. Leenen and colleagues promotional letter to } \\
\text { Canadian MD's under cover of Pfizer's introductory } \\
\text { letter, Aug. 22, } 1995 \text { assuring them long acting } \\
\text { amlodipine (a CCB) was safe when he had told } \\
\text { Health Canada he did not know if it was safe. } \\
\text { Pfizer acknowledged the letter constituted } \\
\text { advertising, and it has Pharmaceutical Advertising } \\
\text { Board (PAAB) stamp of approval. }\end{array}$ & Appeal Court of Ontario records File No. C. 34272. \\
\hline $\begin{array}{l}\text { Decision of Justice Cunningham in defamation } \\
\text { lawsuit Leenen vs } C B C \text { and of Justice Bellingham in } \\
\text { defamation lawsuit Myers v. } C B C\end{array}$ & Web. CanLII \\
\hline $\begin{array}{l}\text { Letter from nineteen MD's in BHPD, April 27, } \\
1992 \text { re: elimination of Asst. Dir. Medical post and } \\
\text { lack of medical expertise in office of Director as a } \\
\text { result }\end{array}$ & Participants records. \\
\hline $\begin{array}{l}\text { Affidavit of M. Brill- Edwards, MD, FRCPC- Jan. } \\
13,1992\end{array}$ & Court File No. T-3926-91 \\
\hline $\begin{array}{l}\text { Affidavit of I. W. Henderson, MD, FRCPSC, } \\
\text { Director of BHPD from } 1977 \text { to } 1988 \text { - Jan. 16, } \\
1992 .\end{array}$ & \\
\hline
\end{tabular}




\section{Appendix B}

Interview Questions: Interviews of Dr. M. Brill-Edwards were conducted April 6, 2014 and April 8, 2014 in Ottawa, ON - lasting approximately two hours each.

\section{Questions to Guide Interview of Informant}

1. What was it that led you to first raise your concerns in your organization?

2. What was the reaction of the hierarchy when you raised these concerns?

3. How would you explain this reaction?

4. Describe the reaction of colleagues to the stance you were taking?

5. How would you explain their reactions?

6. How did you feel about this and why?

7. Were your claims subsequently validated or was it not possible to validate them?

8. How would you describe the external environment your organization was operating in at the time (competition, resources, norms)?

9. How were the elements of the external environment you describe implicated in the violations or lapses that concerned you?

10. How would you describe the internal environment that you worked in for example organizational characteristics (the law, structures, decision-making processes, transactions with other orgs.)?

11. How would you describe the culture (behavioural world or how people treated each other) that you worked in?

12. What made you decide to go public?

13. What was the regulatory environment your organization was operating in and how would you describe the relationship between regulator and regulated from your perspective?

14. How would your organization identify mistakes?

15. How did your organization deal with mistakes? 


\section{Appendix C}

Listing of Interventions Indicating Harm or Potential Harm Caused by CCB's at Sept. 18, 1995 Expert Advisory Committee Meeting, Health Canada

1. Dr. Myers - Minutes, page 5, paragraph 1

2. Dr. Myers - Minutes, page 5, paragraph 2

3. Dr. Myers - Minutes, page 8, paragraph 1

4. Dr. Parker - Minutes, page 8, paragraph 3

5. Dr. Myers - Minutes, page 11, paragraph 1

6. Dr. Leenen - Minutes, page 12, paragraph 3

7. Dr. Leenen - Minutes, page 13, paragraph 1

8. Dr. Leenen- Minutes, page 13, paragraph 2

9. Dr. Leenen - Minutes, page 14, paragraph 2

10. Dr. Parker - Minutes, page 14, paragraph 3

11. Dr. Leenen - Minutes, page 15, paragraph 3

12. Drs. Leenen and Myers - Minutes, page 16, paragraph 2

13. Dr. Leenen and Myers - Minutes, page 17, bottom of paragraph 1

14. Dr. Leenen - Minutes, page 18, paragraph 1

15. Dr. Krupa - Summarizing - Minutes, page 18, paragraph 2

16. Dr. Leenen - Minutes, page 18, paragraph 2

17. Dr Parker - Minutes, page 18, paragraph 2

18. Dr. Myers - Minutes, page 20, paragraph 2

19. Dr. Myers - Minutes, page 22, paragraph 1

20. Dr. Myers - Minutes, page 24 bottom of paragraph 2 to page 25, paragraph 1

21. Dr. Leenen - Minutes, page 26, paragraph 1

22. Dr. Leenen - Minutes, page 26, paragraph 2

23. Dr. Leenen - Minutes, page 27, paragraph 1

24. Dr. Parker - Minutes, page 28, paragraph 1

25. Dr. parker - Minutes, page 29, paragraph 3

26. Dr. Myers - Minutes, page 31, paragraph 2

27. Dr. Parker - Minutes, page 31, paragraph 2

28. Dr. Leenen - Minutes, page 31, paragraph 2

29. Dr.Leenen - Minutes, page 32, paragraph 1

30. Dr. Gruchalla - Minutes, page 32, paragraph 2

31. Dr. Leenen - Minutes, page 33, paragraph 1

32. Dr. Uscinowicz - Minutes, page 33, paragraph 1

33. Dr. Myers - Minutes, page 33, paragraph 1

34. Dr. Leenen - Minutes, page 33, bottom of paragraph 1

35. Dr.Leenen - Minutes, page 34, paragraph 


\begin{tabular}{|c|c|c|c|c|}
\hline Appendix D: & \multicolumn{4}{|c|}{ Studies Showing Clear Indication of Harm in CAD Using Certain CCB's } \\
\hline Journal & Year & Author \& Title & CAD & HTN \\
\hline 1. JAMA & $\begin{array}{l}\text { Aug. } 23 \\
1995 \text { vol. } \\
274,8\end{array}$ & $\begin{array}{l}\text { Psaty, et al } \\
\text { The Risk of Myocardial Infarction associated with anti-htn } \\
\text { Drug therapies }\end{array}$ & & HTN \\
\hline 2. Circulation & Sept., 1995 & $\begin{array}{l}\text { Furberg, Psaty, Mayer } \\
\text { Dose related increase in mortality in patients with coronary } \\
\text { heart disease }\end{array}$ & $\mathrm{CAD}$ & \\
\hline 3. Circulation & Sept. 1, 1995 & $\begin{array}{l}\text { Yusuf, Salim. } \\
\text { Calcium Antagonists in Coronary Artery Disease and HTN. }\end{array}$ & CAD & HTN \\
\hline 4. $\mathrm{BMJ}$ & $\begin{array}{l}\text { Nov. 11, } \\
1989\end{array}$ & $\begin{array}{l}\text { Peter Held, Salim Yusuf, Curt D. Furberg } \\
\text { Calcium channel blockers in acute myocardial infarction and } \\
\text { unstable angina: an overview }\end{array}$ & $\begin{array}{l}\text { CAD- } \\
\text { MI and } \\
\text { unstable } \\
\text { angina }\end{array}$ & \\
\hline $\begin{array}{ll}\text { 5. } & \text { American } \\
\text { Journal of } \\
\text { Cardiology }\end{array}$ & $\begin{array}{l}\text { June 1, } \\
\text { 1991, vol. } 67\end{array}$ & $\begin{array}{l}\text { Salim Yusuf, Peter Held, and Curt Furberg. } \\
\text { Update of Effects of Calcium Antagonists in Myocardial } \\
\text { Infarction or Angina in Light of the Second Danish Verapamil } \\
\text { Infarction Trial (DAVIT-II) and Other Recent Studies }\end{array}$ & $\begin{array}{l}\text { CAD- } \\
\text { Stable } \\
\text { angina }\end{array}$ & \\
\hline $\begin{array}{l}\text { 6. Canadian } \\
\text { Journal of } \\
\text { Cardiology } \\
\text { (Minutes of } \\
\text { HPB Ad Hoc } \\
\text { EAC meeting } \\
\text { Sept.18, 1995) }\end{array}$ & 1986-1987 & $\begin{array}{l}\text { Dr. Myers } \\
\text { "Report on a 1986-87 double-blind, randomized parallel group } \\
\text { study of nifedipine caps }(10,20,30 \mathrm{mg} \text { Tid) vs Propranolol as } \\
\text { monotherapy in the treatment of unstable angina in pts } 65 \mathrm{yrs} \\
\text { and above. Problems were noted in the nifedipine arm. This } \\
\text { study was stopped, and published in the Canadian Journal of } \\
\text { Cardiology. At a time when nifedipine was approved for } \\
\text { treatment of angina, the investigators noted the detrimental } \\
\text { effect of the nifedipine capsule in unstable angina." (Minutes } \\
4-5) .\end{array}$ & $\begin{array}{l}\text { CAD- } \\
\text { Unstable } \\
\text { angina }\end{array}$ & \\
\hline & & $\begin{array}{l}\text { "Thereafter a series of } 5 \text { publications of post-MI unstable } \\
\text { angina showed that nifedipine caps were either no better than } \\
\text { placebo or slightly worse. There is uniform agreement that } \\
\text { nifedipine caps should not be used in these circumstances." } \\
\text { (Minutes 4-5) }\end{array}$ & $\begin{array}{l}\text { CAD- } \\
\text { Post MI } \\
\& \\
\text { Unstable } \\
\text { angina }\end{array}$ & \\
\hline
\end{tabular}




\section{Appendix E}

Presentations to Parliament and Senate Committees by Dr. Michele Brill-Edwards

1. March 20, 1997. Industry Committee - Re: C $91-$ a review of section 14 of the Patent Act Amendment 1992, chapt. 2, Statutes of Canada 1993.

2. April 22, 1997. Standing Committee on Health. Misuse and abuse of substances.

3. March 26, 1998. Standing Committee on Health on Natural Health Products.

4. March 30, 1998. Extended briefing provided by MBE to above Health committee on a priority basis at the Standing Committee's request for their consideration the next day.

5. December 7, 1998. Presentation to Standing Senate Committee on Agriculture and Forestry.

6. Evidence August 30, 1999 (afternoon meeting). Standing Senate Committee on Energy, the Environment and Natural Resources.

7. Evidence October 23, 2003. Standing Committee on Health.

8. Evidence. March 6, 2008. Standing Committee on Health. Pharmaco surveillance. 


\section{Works Cited}

A\&E Television Networks. "Daniel Ellsberg." Bio. A\&E Television Networks, 2015. Web. Jan 19, 2015.

A\&E Television Networks. "Karen Silkwood." Bio. A\&E Television Networks, 2015. Web. Jan 19, 2015.

A\&E Television Networks. "Jeffrey Wigand.” Bio. A\&E Television Networks, 2015. Web. Jan. 19, 2015.

Ad IDEM/Canadian Media Lawyers Association. Leenen v. CBC et al and Myers v. CBC et al. March 23, 2009. Web. July 11, 2014.

Alford, C. Fred. Whistleblowers: Broken Lives and Organizational Power. New York: Cornell University Press, 2001. Print.

Angell, Marcia. "Drug Companies \& Doctors: A Story of Corruption". The New York Review of Books. Vol. 56, No. 1, January 15, 2009. 1-10. Web

Apuzzo, Matt and Ben Protess. "Justice Department Sets Sights on Wall Street Executives." The New York Times. Sept. 9, 2015. Web. Oct. 2016.

Argyris, Chris and Donald A. Schon. Organizational Learning II. Theory, Method, and Practice. Don Mills, Ont.: Addison-Wesley, 1996. Print.

Asch, Solomon E. "Effects of Group Pressure On the Modification and distortion of Judgement". Documents of Gestalt Psychology. Mary Henle, Ed. Berkeley, CA: University of California Press 1961. 222- 36. Web. March 10, 2015.

- - " “Opinions and Social Pressure." Scientific American. November 1955. Vol. 193, No. 5. 31-35. Web. March 10, 2015.

Bok, Sissela. "Whistleblowing and Professional Responsibilities." New York University Education Quarterly 2 (1980): 3. Web. Feb. 2015.

Bowie, Norman. Business Ethics. Englewood Cliffs, N.J: Prentice Hall, 1982. Print.

Brewer, G.A \& Selden, S.C. "Whistleblowers in the Federal Civil Service: New evidence of the public service ethic." Journal of Public Administration Research and Theory. 1998. 8, 413-439. Web. Sept. 2016.

Burke, Ronald J., "Crime and Corruption in Organizations.” Ronald J. Burke, Edward C. Tomlinson and Cary L. Cooper Eds. Crime and Corruption in Organizations. Surrey: Gower Publishing Ltd., 2011. Print. 
Butler, Don. "Legal 'reverse onus' needed to ease whistleblower reprisal fears." Ottawa Citizen. June 23, 2016. Print.

Campbell, J.L. "Neoliberalism in crisis: Regulatory roots of the U. S. financial crisis." In M. Lounsbury \& P.M. Hirsch (Eds.), Markets on trial: The economic sociology of the U.S. financial crisis: Part B., New York: Emerald, 2010.

Canada. Commission of Inquiry into the Sponsorship Program. Gomery. Restoring Accountability: Recommendations, Minister of Public Works and Government Services. Ottawa: 2005: 186-187. Web. May 2016.

- - - Health Canada. Drugs and Medical Devices Programme, Quality Initiative Bulletin. Bulletin \#2, February 1997. Print.

- - -. Health Canada. "Legislation and Guidelines.” Dec. 6, 2006. Web. Feb. 20, 2017.

- - -. Health and Welfare Canada. Human Resources Management Bureau, Personnel Administration Branch. Study of Health and Welfare Canada's Scientific and Professional Community. October 1991. Print.

- - . House of Commons. $36^{\text {th }}$ Parliament. Minutes. Standing Committee on Health. March 31, 1998. Web. Sept. 20, 2015.

- - -. House of Commons. $39^{\text {th }}$ Parliament. Evidence. Standing Committee on Public Accounts. Asst. AG. "Allocating Funds to Regulatory Programs". Feb. 12, 2007. Web. Sept. 23, 2015.

- - - House of Commons. $41^{\text {st }}$ Parliament. Evidence. AG. "Regulating Pharmaceutical Drugs." Web. Sept. 23, 2015.

- - Justice Canada. Public Servants Disclosure Protection Act (S.C. 2005, c. 46). Wrongdoings. Section 8. April 9, 2015. Web. April 20, 2015.

- - -. Ministerial Task Force on Program Review. A Study Team Report. 1985. Print.

- - -. Office of the Auditor General of Canada. Dec. 2010 Report of the Auditor General. "The Public Sector Integrity Commissioner of Canada." Dec. 2010. Web. January 2014.

- - -. Office of the Auditor General of Canada. Dec. 2000. Report of the Auditor General. "Protecting Health and Safety." Chapters 24 to 28. Dec. 2000. Web. Jan. 10, 2013.

- - -. Office of the Auditor General of Canada. Fall 2011Report. "Regulating Pharmaceutical Drugs - Health Canada." Chapter 4. Fall 2011. Web. August 20, 2014. 
- - -. Public Sector Integrity Commissioner. "Reprisals". October 6, 2015. Web. March 20, 2016.

- - -. Public Service Commission of Canada. Furi, Megan. "Public Service Impartiality: Taking Stock.” Aug. 7, 2008. Web. Feb. 1, 2017.

- - -. Senate. $41^{\text {st }}$ Parliament. Issue 21 - Evidence. Standing Committee on Social Affairs, Science and Technology. AG. "Regulating Pharmaceutical Drugs." Oct. 3, 2012. Web. Sept. 21, 2015.

- - -. Treasury Board of Canada Secretariat. "Duty of Loyalty". Jan. 17, 2011. Web. April 10, 2015.

- - -. Treasury Board of Canada Secreratiat. "Duty of Loyalty, the Fraser Case". Jan. 17, 2011. Web. June 1, 2016.

- - -. Treasury Board of Canada Secretariat. "Number 14: Regulatory Reform through Regulatory Impact Analysis: The Canadian Experience". July 23, 2001. Web. July 21, 2014.

Canadian Broadcasting Corporation. The National. "The Heart of the Matter". Fifth Estate Documentary. Transcript 34899-2. Feb. 27, 1996.

Canadian Press. "Judge rules against lawsuit over breast implants." The Canadian Press. September 30, 2008. Web. June 14, 2015.

Canadian Superior Court Judges Association. "The Role of the Judge". 2006. Web. Feb. 09, 2017.

Canadians for Accountability. Cases and Issues. Other Canadian Whistleblowers. June 17, 2009. Web. February 18, 2015.

- - . About Accountability and Whistleblowing. Who is a Whistleblower. Sept. 11, 2008. Web. March 10, 2015.

Carleton University. Devlin, Richard, Adam Dodek. "Regulating Judges: Expanding the Horizon." Juris Talk Presentation. May 6, 2015. Ottawa. Print.

Conference Board of Canada. Golden, Dr. Anne. Convocation Speech for McMaster University. November 18, 2011. Web. December 5, 2011.

Cutler, Alan. "Harper's Man Friday". The Hill Times. April 2, 2015. Web. April 20, 2015.

Davidson, Diane. "The Powers of Parliamentary Committees." Canadian Parliamentary Review. Spring 1995, 12-15. Web. September 15, 2015. 
Davis, Courtney and John Abraham. "Unhealthy Pharmaceutical Regulation. Innovation, Politics and Promissory Science". Hampshire, UK: Palgrave, Macmillan 2013. Print.

Denhardt, Robert B. and Janet V. Denhardt. "The New Public Service: Serving Rather than Steering". Public Administration Review. Vol. 60, 2000: 549-559. Web. April 12, 2012.

Denzin, N. K. and Y.S. Lincoln. The Landscape of Qualitative Research: Theories and Issues. Second Edition. Thousand Oaks, CA: Sage Publications Inc. 2003. Print.

Duska, Ronald. "Whistleblowing and Employee Loyalty". Contemporary Issues in Business Ethics, eds J. R. Desjardins and J.J. McCall. Delmont, CA:Wadsworth, 1984. Web. May 10, 2015.

Eur-Lex. "The Precautionary Principle." Summaries of EU Legislation. Nov. 30, 2016. Web. Feb. 20, 2017.

Evans, Anthony J. "Dealing with dissent: whistleblowing, egalitarianism, and the republic of the firm." Innovation: The European Journal of Social Science Research 21,3 (2008): 267-79. Web. Jan. 20, 2015.

Federal Accountability Initiative for Reform (FAIR). "What's Wrong with Canada's Federal Whistleblower Legislation: An analysis of the Public Servants Disclosure Protection Act (PSDPA).” FAIR: April 9, 2012. Print.

Federal Court of Canada. Mactavish, Anne, Honourable Madam Justice. "Charbel ElHelou v. Courts Administration Service et al". Reasons for Judgement and Judgement. Web. Sept. 2012.

Fennessy, Jo-Ann. "Whistleblowing: Responsibility and Accountability. Does responsibility and accountability really exist in Canada?" Thesis - Master of Arts in Public Ethics. Saint Paul University, Ottawa. May 2010. Web. July 2014.

Furmaga, Elaine M. Peter A. Glassman, Francesca E. Cunningham, Chester B. Good. "Reducing the Use of Short-acting Nifedipine by Hypertensives Using a Pharmaceutical Database." Advances in Patient Safety: Vol. 3 (2005) - 277- 89. Web. Oct. 20, 2016.

Gibbs, Lois Marie. "History: Love Canal: the Start of a Movement." Boston University School of Public Health, 2008. Web. January 31, 2015. 
Girard, Rene. The Scapegoat, trans. Yvonne Freccero, Baltimore: The John's Hopkins University Press. 1996. Print.

Glazer, Myron Peretz and Penina Migdal Glazer. The Whistleblowers. Exposing Corruption in Government and Industry. New York: Basic Books Inc., 1989. Print.

Graham, Jill W. Review of: "Blowing the Whistle: The Organizational and Legal Implications for Companies and Employees", Marcia P. Miceli and Janet P. Near. Administrative Science Quarterly. Vol.38, No. 4 (Dec. 1993), 683- 85. Web. Sept. 10, 2016.

Greenwald, Glen, Ewen MacAskill and Laura Poitras. "Edward Snowden: the whistleblower behind the NSA surveillance revelations." The Guardian. June 10, 2013. Web. Jan. 11, 2015.

Havemann, Joel. "The Financial Crisis of 2008: Year In Review 2008". Encyclopedia Britannica Online. Encyclopedia Britannica Inc., 2015. Web. June 22, 2015. Heffernan, Margaret. Willful Blindness. Why We Ignore the Obvious at our Peril. New York: Walker \& Company, 2011. Print.

Heintzman, Ralph. "Renewal of the Federal Public Service. Toward a Charter of Public Service.” Policy Paper, Canada 2020. Ottawa 2014. Web. Jan. 12, 2017.

Hogg, M.A. and D.J. Terry. "Social identity and self-categorization processes in organizational contexts". Academy of Management Review. 25, 1 (2000): 121140. Web. Oct. 19, 2015.

Hoque, Obaidul. "The Neglected State of Whistleblower Laws in Canada". Rochon/Genova LLP. Posted Nov. 13, 2015. Web. Aug. 8, 2016

Hurtubise-Loranger, Elise and Rebecca Katz, comp. "Federal Public Sector Whistleblowing". Canada. Library of Parliament, Legislative and Legislative Affairs Division. 31 October 2008. Revised 26 June 2012. Web. Sept. 10, 2014.

Hutton, David. "Is the public sector integrity commissioner a friend or foe to whistleblowers?" The Hill Times. Feb. 20, 2017. Print.

Jackall, Robert. Moral Mazes: The World of Corporate Managers. Oxford University Press. New York. 1988. Print.

Jost, J. T., \& Young, S. "Antecedents and consequences of system-justifying ideologies." Current Directions in Psychological Science, 2005. 14. 260-265. Web. August 21, 2014 
Jurkiewicz, Carole L. and Robert A. Giacalone. “Organizational Determinants of Ethical Dysfunctionality”. Journal of Business Ethics. 10 September 2014. 1-12. Web.Jan. 15, 2016.

Jurkiewicz, Carole L. and D. Grossman. "Evil at Work". In C.L. Jurkiewicz (Ed.), The foundations of organizational evil. M.E. Sharpe. Armonk, New York. 2012. Web. Jan. 10, 2017.

Kazmierski, Vincent. "Accessing Democracy: The Critical Relationship between Academics and the access to Information Act." Canadian Journal of Law and Society. Vol. 26, Issue 3. Dec. 11, 2011: 613-622.

King, III, Granville. “The Implications of an Organization's Structure on Whistleblowing”. Journal of Business Ethics, 20, 1999: 315-326. Web. Jan. 12, 2015.

Lachman, Vicki D. "Whistleblowing: Role of Organizational Culture in Prevention and Management." Dermatology Nursing. 20, 5. 2010: 394-420. Web.

Larmer, Robert A. "Whistleblowing and employee loyalty." Journal of Business Ethics. Vol. 11, No. 2. Feb. 1992: 125- 8. Web. Jan. 15, 2017.

Latimer, Paul and A J Brown. "Whistleblower Laws: International Best Practice." University of New South Wales Law Journal. Vol. 31, 3. 2008: 766-794. Web. Oct. 15, 2014.

Lazarou, J., B.H. Pomerantz, P.N. Corey. "Incidence of adverse drug reactions in hospitalized patients: a meta-analysis of prospective studies." Journal of the American Medical Association. 279 (15). 1998: 1200-5. Web. Feb. 9, 2016.

Lessig, Lawrence. "Foreword: "Institutional Corruption" Defined." The Journal of Law, Medicine and Ethics. Vol. 41, No. 3. 2013: 553- 55. Web. Oct.20, 2016.

- - -. Republic, Lost. Twelve, Hachette Book Group, New York. 2012. Print.

Lewis, David. "Whistleblowing in a changing legal climate: Is it time to revisit our approach to trust and loyalty at the workplace." Business Ethics: A European Review. Vol. 20, No. 1. Jan. 2011. 71-87. Web. Jan. 13, 2017.

Lewis, Linda. "Hearing examines health of federal whistleblowing, finds alarming changes." Whistleblowing Today. Sept. 16, 2014. Web. April 10, 2015.

Lewis, Michael. The Big Short - Inside the Doomsday Machine. W.W. Norton \& Company Inc. New York. 2011. Print. 
Lexchin, Joel. "Drug makers and drug regulators: Too close for comfort. A study of the Canadian situation." Social Science \& Medicine. Vol. 31, Issue 11, (1990): 1257-1263. Web. Sept. 21, 2015.

- - -. "Medicines and Money: The Corruption of Clinical Information." Crime and Corruption in Organizations. Burke, Ronald J., Edward C. Tomlinson and Cary L. Cooper Eds. Surrey: Gower Publishing Ltd., 2011. Print.

Lexpert-Business of Law Magazine. "Largest Libel Award Against Media in Canadian History.” May 1, 2000. Web. Jan. 20, 2017.

Light, D.W, J. Lexchin and J.J. Darrow. "Institutional Corruption of Pharmaceuticals and the Myth of Safe and effective Drugs." The Journal of Law, Medicine \& Ethics. Special Issue: SYMPOSIUM: Institutional Corruption and the Pharmaceutical Industry. Vo.41, No. 3, (2013): 590-600. Web. Oct. 10, 2016

MacNab, Brent, et al. "Culture and Ethics Management: Whistleblowing and Internal Reporting within a NAFTA Country Context." International Journal of Cross Cultural Management 7,1 (2007) : 5-28. Web. Aug. 20, 2014.

Maclure, Malcolm, Colin Dormuth, Terryn Naumann, James McCormack, Robert Rangno, Carl Whiteside, James M. Wright. "Influences of educational interventions and adverse news about calcium-channel blockers on first-line prescribing of antihypertensive drugs to elderly people in British Columbia." The Lancet. Vol. 352, Issue 9132 (1998). 943-48. Web. Oct. 2016.

Marques, Jose M., Vincent Y. Yzerbyt and Jacques-Philippe Layens. "The 'Black Sheep Effect': Extremity of judgments towards in-group members as a function of group identification". European Journal of Social Psychology, Vol. 18, (1988): 1-16. Web. May 13, 2015.

Miceli, Marcia P. and Janet P. Near. Blowing the Whistle: The Organizational and Legal Implications for Companies and Employees. New York: Lexington Books, 1992. Print.

Miceli, Marcia P, Janet P. Near and Terry M. Dworkin. Whistleblowing in organizations. London: Taylor \& Francis. 2008. Print.

Miceli, Marcia P., Michael Rehg, Janet P. Near and Katherine C. Ryan. "Can Laws Protect Whistleblowers? Results of a Naturally Occurring Field Experiment." Work and Occupations. Vol. 26, No. 1, 1999: 129-151. Web. Sept. 12, 2014.

Miethe, Terance D. and Joyce Rothschild. "Whistleblowing and the Control of Organizational Misconduct". Sociological Inquiry, Vol. 64, No. 3, August 1994: 322-347. Web. Oct. 25, 2014. 
Milgram, Stanley. Obedience to Authority. New York: Harper Perennial Modern Thought Edition. 2009. Web. Sept. 12, 2014.

Modessit, Nancy. "Why Whistleblowers Lose: An Empirical and Qualitative Analysis of State Court Cases." Kansas Law Review. Vol. 62. (2011): 165- 194. Print.

Near, Janet P. and Marcia P. Miceli. "Organizational Dissidence: The Case of WhistleBlowing”. Journal of Business Ethics. 4, (1985): 1-16. Web. Aug. 18, 2014.

- - -. "Whistleblowing: Myth and Reality." Journal of Management. Vol. 22, No. 3, (1996): 507-526. Web. July 10, 2014

- - -. "Wrongdoing, Whistleblowing, and Retaliation in the U.S. Government: What Have Researchers Learned From the Merit Systems Protection |Board (MSPB) Survey Results.” Review of Public Personnel Administration, 28, 3, 2008: 263281. Web. Aug. 17, 2014.

Neilsen, Richard P. "Whistleblowing Methods for Navigating Within and Helping Reform Regulatory Institutions." Journal of Business Ethics, (2013) 112: 385395. Web. Sept. 20, 2015.

Neufeld, Matthew. "Parliament and Some Roots of Whistle Blowing During the Nine Years War." The Historical Journal, 57, 2, 2014: 397-420. Web. July 12, 2014.

Office of the Public Service Integrity Commissioner. "Reprisals." Feb. 26, 2016. Web. April 20, 2016.

Paquette, Gilles and Robert Sheppard. "The Program Review Process: a Deconstruction." Faculty of Administration, University of Ottawa, Working Paper. Vol. 96, Issue 15. 1996. Web. Feb. 1, 2016.

Pharma Intelligence. "Glaxo's Imitrex for Migraine Will Be Available in March After Dec. 28, 1992 approval.” The Pink Sheet. Jan. 4, 1993. Web. Jan. 12, 2017.

Pirmohamed, M. et al. "Adverse Drug Reactions as Cause of Admission to Hospital: Prospective Analysis of 18, 820 Patients." British Medical Journal. Vol. 329, No. 7456, (2004). 15-19.

Professional Institute of the Public Service (PIPS). "Lifting the Silence. The Right to Know, the Right to Say and the Right to Hear." Ottawa: Dialogue With Parliament. 1994. Print.

Public Service Commission. Furi, Megan. "Public Service Impartiality: Taking Stock." July 2008. Web. Jan. 5, 2017 
Punton, Melanie, and Katharina Wells. "Applying Process Tracing in Five Steps." Centre for Development Impact Practice Paper Annex. No. 10 Annex. April 2015. Web. Oct. 1, 2016.

Quintos de Jesus, Melinda. "Whistleblowing: The Media Perspective in the Phillipines." Protecting the Whistleblowers - Asian and European Perspectives." $13^{\text {th }}$ International Anti-Corruption Conference. Athens, Greece. Oct. 31, 2008. 1-14. Web. June 10, 2014

Ramage, Roderick and Sally Ramage. "Book Review. Whistleblowing Law and Practice." John Bowers, Martin Fodder, Jeremy Lewis, Jack Mitchell. OUP (2012). The Criminal Lawyer. Bloomsbury Professional. UK. 2013. Web. Aug. 13, 2014.

Regush, Nicholas. "Migraine Killer.” Mother Jones. Sept./Oct. 1995. Web. Mar. 6, 2013.

Rodwin, M.A. "INTRODUCTION: Institutional Corruption and the Pharmaceutical Policy." The Journal of Law, Medicine \& Ethics. Special Issue: SYMPOSIUM: Institutional Corruption and the Pharmaceutical Industry. Vol. 41, Issue 3, (2013): 544-552. Web. Jan. 13, 2017.

Rongine, N.M. "Toward A Coherent Legal Response to the Public Policy Dilemma Posed by Whistleblowing," American Business Law Journal. Vol. 23 (1985): 281. Web. Nov. 18, 2015.

Rothschild, J. and D. Miethe. Whistleblowers disclosures and managers retaliation. The battle to control information about organizational corruption. Work and Occupations. Vol. 26, No. 1, 1999: 107-128. Web. Sept. 20, 2016.

Sargent, Neil C. "Law, Ideology and Social Change: An Analysis of The Role of Law in The Construction of Corporate Crime." The Journal of Human Justice. Vol. 1, No. 2, Spring, 1990: 97- 116. Web. Nov. 14, 2015.

Saunders, Kelly L. and Joanne Thibault. "The Road to Disclosure Legislation in Canada Protecting Federal Whistleblowers.” Public Integrity 12, 2 (2010): 143-60. Web. May 15, 2015.

Savoie, Donald. Breaking the Bargain: Public Servants, Ministers and Parliament. Toronto: University of Toronto Press, 2003. Print.

- - - Governing from the Centre. The Concentration of Power in Canadian Politics. Toronto: University of Toronto Press. 1999. Print. 
Seddon, John and Brendan O'Donovan. "Why aren't we all working for Learning Organisations?" e-Organisations \&People. 17, 2 (2010): 1-16. Web. Dec. 12, 2014.

Serpico, Frank. "The Police are Still Out of Control". Politico.com Magazine. October 23, 2014. Web. January 31, 2015.

Singh, Jang B. "Ethics Programs in Canada's Largest Corporations." Business and Society Review. 111, 2 (2006) \; 119-136. Web. May 19, 2015.

Sossin, Lorne M. "Speaking Truth to Power? The Search for Bureaucratic Independence". University of Toronto Law Journal. Vol. 55, 2005, 1-60. Web. April 8, 2015.

Stelfox, H.T, G. Chua, K. O'Rourke and A.S Detsky. "Conflict of interest in the debate over calcium-channel antagonists". New England Journal of Medicine. Jan. 8 1998, 338(2): 101-6. Web. Jan. 8, 2016.

Sulzner, George T. "Creating a Strong Disclosure-of-Wrongdoing Regime: The Role of the Public Service Integrity Officer of Canada.” Public Integrity 11, 2, Spring 2009: 171-188. Web. Jan. 10, 2015.

Sumanth, John J., David M. Mayer and Virginia S. Kay. "Why good guys finish last: The role of justification motives, cognition, and emotion in predicting retaliation against whistleblowers." Organizational Psychology Review. Vol. 2, (2011): 65184. Web. Aug. 21, 2015.

Thiessen, Carol D. "Whistleblowing in the Private and Public Sectors: Should Canada Adopt a Modified Form of the American Whistleblowing Legislation?" Thesis Joint Masters of Public Administration. University of Manitoba and University of Winnipeg. Winnipeg, Manitoba. March 1998. Web. June 10, 2015.

Thomas, Paul G. "Problems with Canada's Public Servants Disclosure Protection Act." Optimum Online. The Journal of Public Sector Management. Vol. 41, No. 1, Mar 2011: 1-14. Web. July 18, 2014.

Transparency International. "Whistleblower Protection and the UN Convention Against Corruption”. Berlin. May 2013. Web. Feb. 13, 2027.

Trevino, L.K. "Ethical decision making in organizations: A person-situation interactionist model". Academy of Management Review. 11, 601-617. Web. March 27, 2016.

Trochim, William M. K. Research Methods Knowledge Base. Oct. 20, 2006. Web. Oct. 24, 2016. 
Tweedie, Brendan. "Whistle Stop: The Suppression of Whistleblowers in the Canadian Government". Thesis - Master of Arts in Communication Studies. University of Windsor. Windsor, Ontario. 2010. Web. July 12, 2014.

U.S. Government, Congressional Research Service. Shimabukuro, Jon and L. Paige Whitaker. "Whistleblower Protections Under Federal Law: An Overview". Sept 13, 2012. Web. August 9, 2016

van der Hooft, C. et al. "Adverse Drug Reaction Related Hospitalizaions.” Drug Safety. Vol 29, No. 2 (2006): 161-168.

Vandekerckhove, Wm., M.S. Ronald Commers. "Whistle Blowing and Rational Loyalty." Journal of Business Ethics. Vol. 53, No. 1. (Aug. 2004): 225- 33. Web. Jan. 12, 2017.

Vaughan, Diane. Controlling Unlawful Organizational Behaviour. Chicago: University of Chicago Press, 1983. Print.

- - -. The Challenger Launch Decision: Risky Technology, Culture and Deviance at NASA. Chicago: University of Chicago Press, 1996. Print.

Verzelloni, F. Letter to Dr. Brill-Edwards. Notice of selection. May 22, 1992. BrillEdwards Records. Print.

- - -. Letter to Dr. Brill-Edwards. Formal Offer on Condition of Release. Nov. 16, 1992. Brill-Edwards Records. Print.

- - - Letter to Dr. Brill-Edwards. Withdrawal of Offer as Brill-Edwards Not Available. Jan. 11, 1993. Brill-Edwards Records. Print.

Victor, B and J.B. Cullen. "The organizational bases of ethical work climates". Administrative Science Quarterly. 33, (1988): 101-125. Print.

Von Drehle, David. "FBI's No. 2 Was Deep Throat: Mark Felt Ends 30 Year Mystery of the Post's Watergate Source”. June 1, 2005. Web. January 31, 2015

Wiktorowicz, Mary E. "Shifting priorities at the Health Protection Branch: challenges to the regulatory process." Canadian Public Administration. Volume 43, Issue 1. (March 2000), 1-22. Print.

Wolfe, Simon, Mark Worth, Suelette Dreyfus, and AJ Brown. "Whistleblower Protection Laws in G20 Countries: Priorities for Action. Final Report, Sept. 2014." Blueprint for Free Speech. Web. June 25, 2016. 
Wolfe, Simon, Mark Worth, Sulette Dreyfus. "Protecting Whistleblowers in the UK: A New Blueprint." Blueprint for Free Speech and Thomson Reuters Foundation. Report. Feb. 2016. Web. Nov. 9, 2016.

Wood, Alastair J.J., Michael Stein, and Raymond Woosley. "Making Medicines Safer The Need for an Independent Drug Safety Board". New England Journal of Medicine. Vol. 339 No. 25 (Dec. 17, 1998): 1851-4. Web. Jan. 10, 2015.

Wood, Greg et al. "Implementing the ethos of corporate codes of ethics: Australia, Canada and Sweden." Business Ethics: A European Review. 13, 4 (2004): 389403. Web. Apr. 14, 2015

Xavier University Library. "Qualitative vs Quantitative Research”. Cincinnati, Ohio. Dec. 10, 2012. Web. Dec. 31, 2015

Yin, Robert K. Case Study Research: Design and Methods. Fifth Edition. Thousand Oaks, CA. Sage Publications, Inc. 2014. Print.

Young, Terrence. Death by Prescription - A father takes on his daughter's killer. Toronto, ON: Key Porter Books. 2013. Print.

Zhuang, Jinyun, Stuart Thomas and Diane L. Miller. "Examining Culture's Effect on Whistleblowing and Peer Reporting." Business \& Society 44, 4 (2005): 462-86. Web. Web. Feb. 11, 2015. 